\title{
HEAT RESISTANCE OF BACTERIA
}

IN ALCOHOL-FREE BEER

\begin{abstract}
A Thesis
Submitted to the College of Graduate Studies and Research in Partial Fulfilment of the Requirements for the Degree of Master of Science
\end{abstract}

In the Department of Applied Microbiology and Food Science University of Saskatchewan

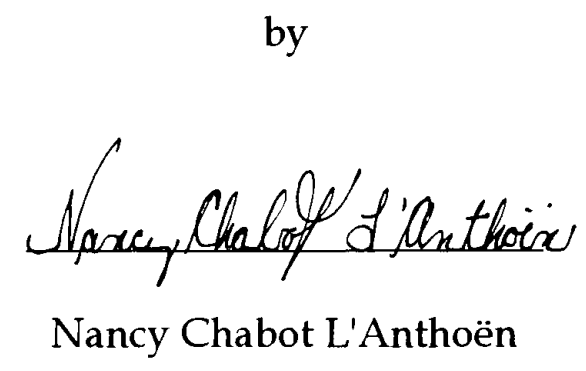

Saskatchewan

Fall, 1995

Copyright Nancy Chabot L'Anthoën, 1995. All rights reserved. 
The author has agreed that the library, University of Saskatchewan, may make this thesis freely available for inspection. Furthermore, the author has agreed that permission for extensive copying of this thesis for scholarly purposes may be granted by the professor who supervised this project recorded herein, or in his absence, by the Head of the Department or the Dean of the College in which the thesis work was done. It is understood that due recognition will be given to the author of this thesis and to the University of Saskatchewan in any use of the thesis. Copying or publication or use of this thesis or parts thereof for financial gain without approval by the University of Saskatchewan and the author's written permission is prohibited.

Request for permission to copy or make any other use of material in this thesis in whole or in part be addressed to:

Head, Department of Applied Microbiology and Food Science University of Saskatchewan

51 Campus Drive

Saskatoon, Saskatchewan

Canada. S7N 5A8 


\begin{abstract}
Two of the most heat resistant beer spoilage organisms found to date, Pediococcus acidilactici and Lactobacillus delbrueckii, and two human pathogens, Escherichia coli 0157:H7 and Salmonella typhimurium (both recently associated with outbreaks of diarrhea and hemolytic uremic syndrome in apple cider), were tested for heat resistance in commercial alcohol-free beer and commercial $5 \%$ alcohol beer. Using the attemperated dilution blank adaption of the multiple point method, known cell concentrations were inoculated into $5 \%$ alcohol beer and alcohol-free beer held at a variety of heating temperatures. Survival curves, $\mathrm{D}$ values, phantom thermal death time curves, and $\mathrm{Z}$ values were determined. Decimal reduction times at $60^{\circ} \mathrm{C}\left(\mathrm{D}_{60}\right)$, a common temperature for beer pasteurization, were obtained by extrapolation. Pathogens demonstrated 3 to 17 times more heat resistance in alcohol-free beer and both lactic acid bacteria showed an increased resistance to heat of 4 to 7 fold in alcohol-free beer compared to $5 \%$ alcohol beer. Results illustrated a significant difference in the pasteurization parameters required to achieve microbiological stability of alcohol-free beers compared to $5 \%$ alcohol beer. Although pathogens tested are not at all heat resistant, and do not survive pasteurization temperatures even over short time intervals, these organisms can grow in
\end{abstract}


alcohol-free beer and industry is cautioned about the safety and sale of unpasteurized low alcohol products when processed by filtration. 


\section{ACKNOWLEDGEMENTS}

I wish to extend my sincere appreciation to Dr. W.M. Ingledew for his supervision, guidance and support during the course of this study, and for numerous reviews of this manuscript. I also want to thank the members of my committee: Dr. K.C. Thomas, Dr. A.R. McCurdy, Dr. N. Low and Dr. L. Yu, for their guidance and supervision.

I extend my sincere thanks to Sandra Hynes, and Anita Dhas for their friendship and helpfull advice. I wish to acknowledge Lorna Mead for her technical assistance, encouragement and friendship.

Special thanks is extended to my family, my mother, my sisters and my brother, for their strong optimism, moral support and encouragement. I acknowledge my godfather whom, through its actions, taught me that enthusiasm, ardour and tenacity of work will always make a winner. And a very special thanks also to Paul-Yves L'Anthoën for his encouragement, and motivation to always move foward.

Provision of a graduate scholarship by the College of Graduate Studies and Research is gratefully acknowledged.

This work is dedicated to my father. 


\section{TABLE OF CONTENTS}

ABSTRACT.

ACKNOWLEDGMENTS.

TABLE OF CONTENTS.

LIST OF TABLES

2. LITERATURE REVIEW.

2.1 Brewing products.................................................................... 4

2.1.1 Regular 5\% AB....................................................... 4

2.1.2 AFB............................................................... 5

2.1.2.1 Manipulated fermentation........................ 6

2.1.2.2 Alcohol separation after fermentation...... 8

2.2 Brewing microbiology

2.2.1 Lactic acid bacteria.................................................... 10

2.2.1.1 Lactobacilli............................................... 10

2.2.1.2 Pediococci.................................................. 11

2.2.2 Zymomonas.......................................................... 12

2.2.3 Acetic acid bacteria............................................... 12

2.2.4 Hafnia protea............................................................... 13

2.2.5 Coliform group........................................................ 14

2.2.5.1 Escherichia coli 0157:H7............................... 15

2.2.6 Obligate anaerobes................................................. 16

2.2.7 Salmonella typhimurium.............................................. 18

2.2.8 Wild yeasts............................................................. 19

2.3 Pasteurization in the brewing industry................................ 19

2.4 Heat resistance of microorganisms in brewing..................... 21

2.4.1 Heat resistance in regular 5\% AB............................. 21

2.4.2 Heat resistance of microbes in AFB.......................... 23

2.4.2.1 Molzahn et al. (1983).................................. 23

2.4.2.2 Kilgour and Smith (1985)............................ 24

2.4.2.3 Adams et al. (1988)...................................... 25

2.5 Factors affecting the heat resistance of microbes.................... 25

2.5.1 Carbohydrate content.............................................. 27

2.5.2 Alcohol concentration............................................ 27

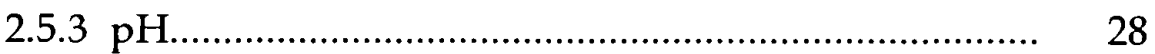


2.5.4 Proteins and lipids................................................... 29

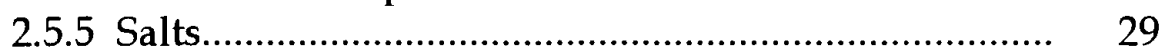

2.5.6 Carbon dioxide........................................................ 29

2.6 Determination of heat resistance............................................. 30

2.6.1 Growth-no-growth method...................................... 30

2.6.2 "End point" method.................................................. 30

2.6.3 "Multiple point" method............................................. 31

2.6.4 "Reichart" method..................................................... 32

2.7 Heat resistance terminology................................................ 33

2.7.1 Thermal death time................................................ 33

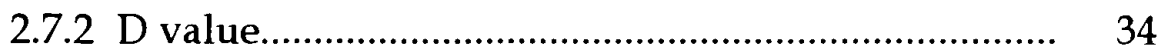

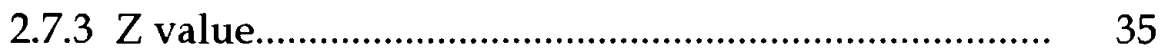

3. MATERIALS AND METHODS.................................................... 36

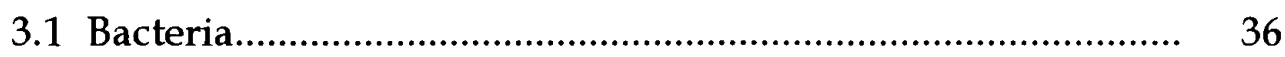

3.1.1 Bacterial cultures...................................................... 36

3.1.2 Cultures maintenance and purity............................. 37

3.2 Media.

3.2.1 Choice of heating media.............................................. 37

3.2.1.1 Analysis of commercial AFB and AB......... 37

3.2.1.1.1 HPLC analysis.............................. 39

3.2.1.1.2 Free alpha-amino nitrogen (FAN) 39 assays....................................... 39

3.2.1.1.3 Ethanol assays............................... 40

3.2.1.1.4 Specific gravity.............................. 41

3.2.1.1.5 pH............................................... 42

3.2.2 Heating media.......................................................... 42

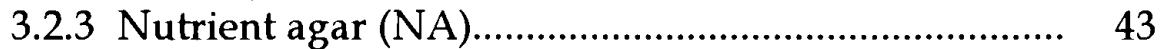

3.2.4 Nutrient broth (NB)................................................. 43

3.2.5 NB+10\% AB...................................................... 44

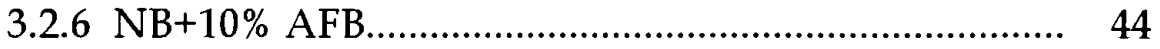

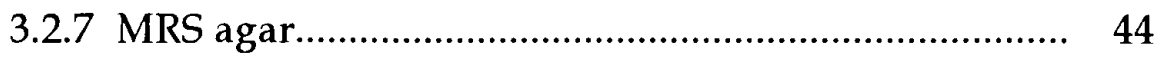

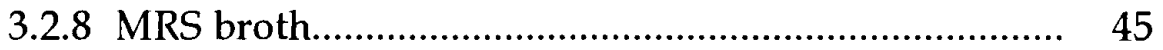

3.2.9 MRS broth $+10 \%$ AB.............................................. 45

3.2.10 MRS broth+10\% AFB.......................................... 45

3.3 Heat-killing experiments...................................................... 46

3.3.1 Culturing and conditioning...................................... 46

3.3.2 Growth curve and cell viability .................................. 46

3.3.3 Preparation of cell inoculum..................................... 47

3.3.4 Heating techniques and conditions............................ 48

3.3.5 Recovery of heat-stressed organisms......................... 50

3.3.5.1 Dilutions and plating techniques.................. 50

3.3.5.2 Incubation and counting............................... 51

3.3.6 Calculation and plots.................................................. 51 
3.4 Tests of growth of pathogens in AFB...................................... 52

4. RESULTS AND DISCUSSION....................................................... 53

4.1 Chemical analyses of six commercial AFB............................ 53

4.2 Composition of heating media.............................................. 57

4.3 Survival curves and kinetic parameters of 4 microbes

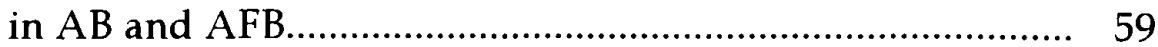

4.3.1 Lactobacillus delbrueckii (Miller Brewing Co.).............. 59

4.3.2 Pediococcus acidilactici NCIB \#6990.............................. 66

4.3.3 Escherichia coli ATCC \#43889..................................... 72

4.3.4 Salmonella typhimurium ATCC \#14028........................ 77

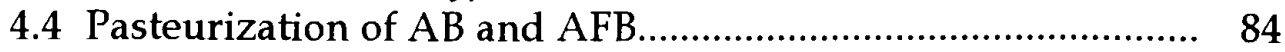

4.5 Microbial stability of commercial AFB.................................. 87

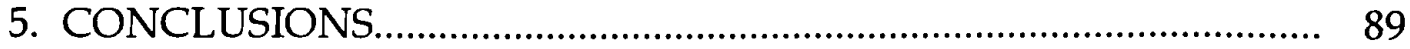

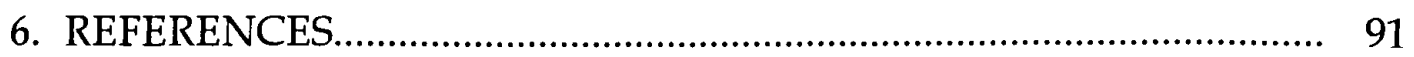

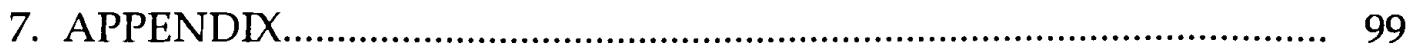




\section{LIST OF TABLES}

$\underline{\text { Tables }}$

Page

3.1 Heat killing temperatures in $\mathrm{AB}$ and $\mathrm{AFB}$ for the four bacteria..... 49

4.1 Fermentable sugars, "dextrins", glycerol, and ethanol of six commercial AFB by HPLC......................................................... 54

4.2 Determination of ethanol in AFB by alcohol dehydrogenase......... 55

4.3 Determination of free alpha-amino nitrogen (FAN), density

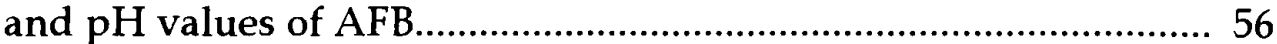

4.4 Characteristics of the chosen AFB and its $5 \%$ AB counterpart....... 58

4.5 Survival curve data for L. delbrueckii heated in AB and AFB......... 63

4.6 Phantom TDT data for L. delbrueckii heated in AB and AFB........ 65

4.7 Survival curve data for P. acidilactici in AB and AFB................ 69

4.8 Phantom TDT data for P. acidilactici heated in AB and AFB........ 70

4.9 Survival curve data for $E$. coli 0157:H7 heated in $\mathrm{AB}$ and AFB..... 76

4.10 Phantom TDT data for E. coli 0157:H7 heated in AB and AFB..... 79

4.11 Survival curve data for S. typhimurium heated in AB and AFB.... 82

4.12 Phantom TDT data for S. typhimurium heated in AB and AFB..... 83

7.1 Representative survival curve data of L. delbrueckii in $\mathrm{AB}$ at $51^{\circ} \mathrm{C}$

7.2 Representative survival curve data of L.delbrueckii in $\mathrm{AB}$ at $53^{\circ} \mathrm{C}$ 
7.3 Representative survival curve data of L.delbrueckii in $\mathrm{AB}$ at $55^{\circ} \mathrm{C}$.

7.4 Representative survival curve data of L.delbrueckii in $\mathrm{AB}$ at $57^{\circ} \mathrm{C}$.

7.5 Representative survival curve data of L.delbrueckii in $\mathrm{AFB}$ at $51^{\circ} \mathrm{C}$.

7.6 Representative survival curve data of L.delbrueckii in $\mathrm{AFB}$ at $53^{\circ} \mathrm{C}$.

7.7 Representative survival curve data of L.delbrueckii in $\mathrm{AFB}$ at $55^{\circ} \mathrm{C}$

7.8 Representative survival curve data of L.delbrueckii in $\mathrm{AFB}$ at $57^{\circ} \mathrm{C}$.

7.9 Representative survival curve data of $P$. acidilactici in $\mathrm{AB}$ at $47^{\circ} \mathrm{C}$

7.10 Representative survival curve data of $P$. acidilactici in $\mathrm{AB}$ at $49^{\circ} \mathrm{C}$.

7.11 Representative survival curve data of $P$. acidilactici in $\mathrm{AB}$ at $51^{\circ} \mathrm{C}$

7.12 Representative survival curve data of $P$. acidilactici in $\mathrm{AB}$ at $53^{\circ} \mathrm{C}$.

7.13 Representative survival curve data of $P$. acidilactici in $\mathrm{AFB}$ at $49^{\circ} \mathrm{C}$

7.14 Representative survival curve data of $P$. acidilactici in $\mathrm{AFB}$ at $51^{\circ} \mathrm{C}$.

7.15 Representative survival curve data of $P$. acidilactici in $\mathrm{AFB}$ at $53^{\circ} \mathrm{C}$.

7.16 Representative survival curve data of $P$. acidilactici in $\mathrm{AFB}$ at $55^{\circ} \mathrm{C}$.

7.17 Representative survival curve data of E. coli 0157:H7 in $\mathrm{AB}$ at $45^{\circ} \mathrm{C}$. 
7.18 Representative survival curve data of E. coli 0157:H7 in $A B$ at $47^{\circ} \mathrm{C}$

7.19 Representative survival curve data of E. coli 0157:H7 in $\mathrm{AB}$ at $49^{\circ} \mathrm{C}$

7.20 Representative survival curve data of E. coli 0157:H7 in $\mathrm{AB}$ at $51^{\circ} \mathrm{C}$......

7.21 Representative survival curve data of E. coli $0157: \mathrm{H} 7$ in $\mathrm{AFB}$ at $49^{\circ} \mathrm{C}$...

7.22 Representative survival curve data of E. coli 0157:H7 in $\mathrm{AFB}$ at $51^{\circ} \mathrm{C}$.

7.23 Representative survival curve data of E. coli 0157:H7 in $\mathrm{AFB}$ at $53^{\circ} \mathrm{C}$.

7.24 Representative survival curve data of E. coli $0157: \mathrm{H} 7$ in $\mathrm{AFB}$ at $55^{\circ} \mathrm{C}$.

7.25 Representative survival curve data of $S$. typhimurium in $\mathrm{AB}$ at $43^{\circ} \mathrm{C}$.

7.26 Representative survival curve data of S. typhimurium in $\mathrm{AB}$ at $45^{\circ} \mathrm{C}$

7.27 Representative survival curve data of S. typhimurium in $\mathrm{AB}$ at $47^{\circ} \mathrm{C}$

7.28 Representative survival curve data of S. typhimurium in $A B$ at $49^{\circ} \mathrm{C}$

7.29 Representative survival curve data of $S$. typhimurium in $\mathrm{AFB}$ at $47^{\circ} \mathrm{C}$

7.30 Representative survival curve data of S. typhimurium in $\mathrm{AFB}$ at $49^{\circ} \mathrm{C}$.

7.31 Representative survival curve data of $S$. typhimurium in $\mathrm{AFB}$ at $51^{\circ} \mathrm{C}$.

7.32 Representative survival curve data of S. typhimurium in $\mathrm{AFB}$ at $53^{\circ} \mathrm{C}$. 


\section{LIST OF FIGURES}

$\underline{\text { Figures }}$

Page

4.1 Survival curves of $L$. delbrueckii heated in AB............................. 60

4.2 Survival curves of $L$. delbrueckii heated in AFB........................... 61

4.3 Phantom TDT curves for L. delbrueckii in AB and AFB................. 64

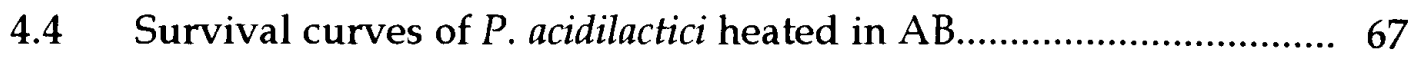

4.5 Survival curves of $P$. acidilactici heated in AFB........................... 68

4.6 Phantom TDT curves for P. acidilactici in AB and AFB................. 71

4.7 Phantom TDT curves for $L$. delbrueckii and P. acidilactici

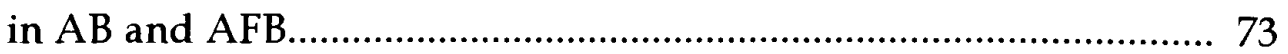

4.8 Survival curves of $E$. coli 0157:H7 heated in AB............................ 74

4.9 Survival curves of $E$. coli 0157:H7 heated in AFB.......................... 75

4.10 Phantom TDT curves for E. coli 0157:H7 in AB and AFB.............. 78

4.11 Survival curves of $S$. typhimurium heated in AB......................... 80

4.12 Survival curves of $S$. typhimurium heated in AFB........................ 81

4.13 Phantom TDT curves for S. typhimurium in AB and AFB............. 85

7.1 Growth curves of L. delbrueckii in MRS $+10 \% \mathrm{AB}$ and MRS+10\% AFB at $27^{\circ} \mathrm{C}$ in $\mathrm{CO}_{2}$ incubator...................................... 100

7.2 Viable counts of $L$. delbrueckii in MRS+10\% AB............................ 101

7.3 Viable counts of $L$. delbrueckii in MRS+10\% AFB.......................... 102 
7.4 Growth curves of $P$. acidilactici in MRS $+10 \% \mathrm{AB}$ and $\mathrm{MRS}+10 \% \mathrm{AFB}$ at $27^{\circ} \mathrm{C}$ in $\mathrm{CO}_{2}$ incubator.

7.5 Viable counts of $P$. acidilactici in MRS $+10 \%$ AB ............................ 104

7.6 Viable counts of $P$. acidilactici in MRS+10\% AFB.......................... 105

7.7 Growth curves of E. coli $0157: \mathrm{H7}$ in $\mathrm{NB}+10 \% \mathrm{AB}$ and $\mathrm{NB}+10 \% \mathrm{AFB}$ at $30^{\circ} \mathrm{C}$ 106

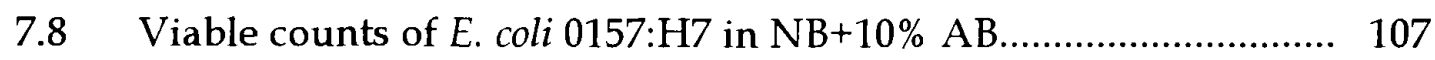

7.9 Viable counts of $E$. coli $0157: \mathrm{H} 7$ in $\mathrm{NB}+10 \%$ AFB........................ 108

7.10 Growth curves of $S$. typhimurium in $\mathrm{NB}+10 \% \mathrm{AB}$ and $\mathrm{NB}+10 \% \mathrm{AFB}$ at $30^{\circ} \mathrm{C}$

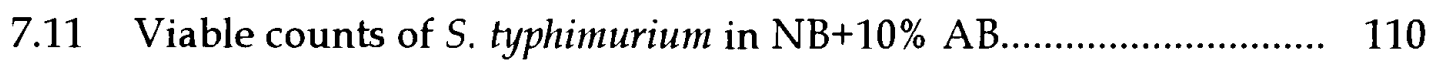

7.12 Viable counts of $S$. typhimurium in NB+10\% AFB........................... 111

7.13 Growth curves of Aeromonas hydrophila in NB, AFB, and $\mathrm{AB}$ at $30^{\circ} \mathrm{C}$..

7.14 Growth curves of Bacillus cereus NB, AFB, and $\mathrm{AB}$ at $30^{\circ} \mathrm{C} \ldots \ldots \ldots \ldots . . .113$

7.15 Growth curves of Enterococcus faecium in NB, AFB, and $\mathrm{AB}$ at $30^{\circ} \mathrm{C}$..

7.16 Growth curves of E. coli 0157:H7 in NB, AFB, and AB at 30 ${ }^{\circ} \mathrm{C} \ldots . . .115$

7.17 Growth curves of Klebsiella pneumoniae in NB, AFB, and $\mathrm{AB}$ at $30^{\circ} \mathrm{C}$.

7.18 Growth curves of Listeria monocytogenes in NB, AFB, and $\mathrm{AB}$ at $30^{\circ} \mathrm{C}$.

7.19 Growth curves of Pseudomonas aeroginosa in NB, AFB, and $\mathrm{AB}$ at $30^{\circ} \mathrm{C}$.

7.20 Growth curves of Salmonella typhimurium in NB, AFB, and $\mathrm{AB}$ at $30^{\circ} \mathrm{C}$. 
7.21 Growth curves of Shigella flexneri in NB, AFB, and $\mathrm{AB}$ at $30^{\circ} \mathrm{C}$......

7.22 Growth curves of Staphylococcus aureus in NB, AFB, and $\mathrm{AB}$ at $30^{\circ} \mathrm{C}$.

7.23 Growth curves of Yersinia enterocolitica in NB, AFB, and $\mathrm{AB}$ at $30^{\circ} \mathrm{C}$.. 


\section{LIST OF ABREVIATIONS}
$\mathrm{AB}$
$5 \% \mathrm{v} / \mathrm{v}$ alcohol beer
AFB
Alcohol-free beer
D
Decimal reduction time
$\mathrm{D}_{60}$
Decimal reduction time at $60^{\circ} \mathrm{C}$
FAN
Free alpha-amino nitrogen
HPLC
High performance liquid chromatography
MRS
deMan, Rogosa, and Sharpe's medium
MRS $+10 \%$ AB deMan, Rogosa, and Sharpe medium combined with $10 \%$ $\mathrm{AB}$
MRS+10\% AFB deMan, Rogosa, and Sharpe medium combined with 10\% AFB
NA
nutrient agar
NB
nutrient broth
$\mathrm{NB}+10 \% \mathrm{AB} \quad$ nutrient broth combined with $10 \% \mathrm{AB}$
$\mathrm{NB}+10 \% \mathrm{AFB} \quad$ nutrient broth combined with $10 \% \mathrm{AFB}$
TDT thermal death time 


\section{INTRODUCTION}

Alcohol-free beer has been defined by Moll (1991) as a beer containing $0.5 \%$ alcohol or less by volume. Although in this work, the term will be used to describe beer of $<0.5 \% \mathrm{v} / \mathrm{v}$, the reader should understand that beers with even lower alcohol contents are under production. Unlike the production of regular $5 \%$ alcohol beer, a large variety of processes are available to produce alcoholfree beers. Alcohol-free products, whose chemical compositions differ markedly from one another according to their production processes, have associated with them several inherent microbiological concerns. Early reports on heat resistance of microbes in alcohol-free products (Fricker, 1984; Kilgour and Smith, 1985; Adams et al., 1989) as well as studies of factors affecting thermal death (Hansen and Riemann, 1963; O'Connor-Cox et al., 1991) have suggested that a variation in heat resistance would occur for some organisms when the alcohol concentration is reduced. In most canned and bottled beers, the microbial stability depends on final in-pack pasteurization. It is therefore essential for industry to know the effectiveness of a pasteurization regime when applied to products with lower concentrations of alcohol. In addition to the reduction in alcohol concentration, the presence of a broad range of nutrients in 
greater amounts, combined with a higher $\mathrm{pH}$ and variable hop content suggest that a broader range of organisms would be able to grow and spoil alcohol-free beers. Compared to the rest of the food industry, the brewing industry has never been concerned with pathogens; they do not grow at the low $\mathrm{pH}(<4.2)$ or high alcohol concentration $(5 \% \mathrm{v} / \mathrm{v})$ of the regular product (Ingledew and Hysert, 1994). In alcohol-free beer, not only must the increased probability of spoilage be considered but also the new possibility of growth of pathogens.

The objective of this study was to assess the increased heat resistance of bacteria in commercial alcohol-free beer compared with commercial 5\% alcohol beer using the attemperated dilution blank adaptation of the multiple point method (Menegazzi and Ingledew, 1980; Tsang, 1982) and to test the possibility of growth of pathogens in alcohol-free beer. In order to set pasteurization parameters, the brewing industry should use the most thermoresistant contaminants that can be found in brewing products (O'Connor-Cox et al., 1991). For this reason, Pediococcus acidilactici and Lactobacillus delbrueckii, the most heat resistant beer spoilage organisms (Tsang, 1981; M. Barney, Miller Brewing Co., personal communication), were used for the comparative studies. Escherichia coli 0157:H7 and Salmonella typhimurium, both of which are exceptionally acid tolerant (Miller and Kaspar, 1994) and have been identified in outbreaks with apple cider (Anonymous, 1975; Besser, 1992), were tested for growth in alcoholfree beer and then for heat resistance in both beer products. 
This project has provided information for the brewing industry useful for the establishment of pasteurization parameters for the biological stability of alcohol-free beer. Although the tested pathogens did not survive pasteurization temperatures, these organisms were found to grow in alcohol-free beer. Industry is therefore cautioned about filtration and marketing of low alcohol products which have not been heat processed. 


\section{LITERATURE REVIEW}

The chemical constituents in wort and brewing products provide selectivity and dictate which organism may infect, survive and grow in these products. The composition of wort is usually $11-16 \%$ total solids of which 90 $92 \%$ is carbohydrate, $5-6 \%$ is nitrogenous material, and $2 \%$ is ash. Wort is an excellent medium, with a $\mathrm{pH}$ near 5.0 and a wide range of carbohydrates, assimilable nitrogen and other growth factors; it can support the growth of a multitude of organisms (Ingledew, 1975). Brewing products, however, are fermented. Beer is much more selective due to reduced concentrations of nutrients and the increased levels of fermentation end products; the low $\mathrm{pH}$ tends to be antimicrobial. Hops added in the process may also have antimicrobial properties (Simpson, 1993).

\subsection{Brewing products}

\subsubsection{Regular 5\% alcohol beer (AB)}

The traditional brewing process by which wort is made and subsequently fermented and aged, does not differ much from one brewery to the other. Beer production is divided into eight essential operations, including milling of the malt and unmalted grains, mashing, mash filtration, boiling of the 
wort, wort processing, fermentation, maturation or conditioning, and filtration. The resulting commercial beers have basically the same potential to be contaminated by spoilage microbes. As a result of wort fermentation, fermentable carbohydrates have been dissimilated through the glycolytic pathway leaving only traces of maltose and maltotriose in beer. Residual carbohydrates are usually limited to "dextrins" larger in size than maltotriose. Usable nitrogenous materials and growth factors are mostly removed and the $\mathrm{pH}$ is reduced (3.8-4.2). In addition, ethanol, organic acids, fusel alcohols, esters, glycerol and dissolved carbon dioxide are produced (Rainbow, 1971). At any stage of the process, beer can contain a number of bacteria and wild yeasts which can cause undesirable flavour and/or appearance. Because of the low $\mathrm{pH}$, high concentration of alcohol, and perhaps the antimicrobial property of hops resins in beer, only a limited range of bacteria and wild yeasts are able to cause spoilage. All microbes present in $5 \% \mathrm{AB}$ have been found to be spoilage organisms - none are pathogenic.

\subsubsection{Alcohol-free beer (AFB)}

Theoretically, an AFB should not contain any alcohol; this would be achieved by distillation. However, future international regulation is directed towards a maximum alcohol concentration of $0.5 \%(\mathrm{v} / \mathrm{v})$ in products to be labeled "alcohol-free beer" (Moll, 1991). For the purpose of this work, this terminology of "alcohol-free beer" is used. 
There is a considerable interest for brewers to develop high quality alcohol-free products since a greater demand for such products is expected in the future. A multitude of recent publications on $\mathrm{AFB}$ production processes illustrates the increasing popularity of these products. The quality of AFB has been significantly improved since 1980 as a result of better control of processing. Several new processes have been developed and kept as industrial secrets. However, the taste and aroma of AFB (particularly malty, worty, estery, fruity or diacetyl off-flavours) are still far from the flavour profile of regular alcohol beer.

In fact, unlike the production of $5 \% \mathrm{AB}$, there are many possible ways to produce AFB (Moll, 1991). The processes can be divided into two general methodologies; the manipulated fermentation, and the normal fermentation followed by alcohol separation.

\subsubsection{Manipulated fermentation}

The development of a technology which would enable the production of an AFB using existing plant procedures would an advantage. Alcohol removal systems need considerable capital investment and such beer requires extra processing in the brewery. Limited or interrupted fermentation on the other hand, have the advantage that existing brewing equipment can be utilised, although the degree of control required in the fermentation process is more demanding. Different methods exist to manipulate fermentation to obtain a 
beer with a very low alcohol content. Among the alternatives is the selection of a low alcohol producing yeast strain (maltose/maltotriose negative strains), or the use of other organisms (Haehn, 1938; Mändl, 1977; Brenner, 1980; Steiner, 1987). One major disadvantage with this alternative is that particular care must be exercised to avoid any cross-contamination when breweries work with a number of yeast strains. The use of immobilized yeasts and reduction of the time of wort contact with yeast can result in the production of a beer with reduced ethanol concentration. Adjustment of the initial carbohydrate content or separation of fermentable sugars using membranes prior to fermentation are two other alternatives (De Clerck and Konovaloff, 1946; Wellhoner, 1965; Brenner, 1980; Jäger, 1983). Attenborough (1988) also described a process using spent grains to obtain a wort with a low extract content and a final beer containing $1 \%$ alcohol by volume. One of the most popular methods is the interrupted fermentation whereby the time of fermentation is reduced (Muller, 1990; Chandrasekhar, 1993; Stein, 1993). The major problem associated with AFB produced by interrupted fermentation is a worty or malty flavour as well as an imbalance in the flavour profile of the beer produced. AFB produced by manipulated fermentation processes still contains appreciable amounts of nutrients, and has a high $\mathrm{pH}(4.2-5.2)$. These beers are very susceptible to microbial contamination. 


\subsubsection{Alcohol separation after fermentåtion}

This second group of AFB brewing products is made by a process based on a variety of different physical principles. In most cases, the wort is prepared and fermented, and alcohol content is adjusted only after completion of fermentation. The ethanol of the beer can be removed by distillation. This is an old method and it has many disadvantages, in particular changes that occur in hop substances on second boiling (Moll, 1991). This process was improved by Brenner (1980) who obtained a $2.5 \%$ alcohol beer of improved quality with a vacuum evaporation method. The vacuum evaporation process (Brenner, 1980; Berger, 1982; Olivier-Daumen, 1982; Attenborough, 1985; Olivier-Daumen, 1986; Krüger et al., 1986; Attenborough 1988; Regan, 1990) and the vacuum distillation process (Attenborough, 1988; Regan, 1990) provide two important alternatives to remove ethanol from beer. Separation of ethanol is also possible via membrane technology using dialysis (Niefind and Schmitz, 1981) and reverse osmosis (Kieninger et al., 1975; Etuk and Murray, 1990). As well, absorption or solvent extraction (supercritical $\mathrm{CO}_{2}$ ) can be used to remove alcohol from beer (Stein, 1993). Dealcoholized beer from any alcohol separation process should be very similar in its chemical composition to $5 \% \mathrm{AB}$ (except for alcohol content).

\subsection{Brewing microbiology}

As AFB is a relatively new product, literature concerning brewing contaminants does not yet include information regarding its micobiological 
spoilage. $A F B$, which is normally a richer medium than a regular $5 \% A B$, is susceptible to growth of the usual and well known beer contaminants. In addition, this less selective medium (higher $\mathrm{pH}$, broader range of nutrients, $<0.5 \% \mathrm{v} / \mathrm{v}$ alcohol) may be infected by a wider range of organisms. The possibility of growth of pathogens must also be considered.

The six distinct bacterial groups capable of spoilage of regular $\mathrm{AB}$ include the lactic acid group, Zymomonas spp., the acetic acid bacteria, Hafnia protea (now considered to be a coliform), the coliform group, and a group composed of obligate anaerobes Pectinatus and Megasphaera (Chelak and Ingledew, 1987). A few other genera (like Salmonella) have at times been found in brewing by products.

Yeast also cause beer spoilage. Since a wild yeast may be defined as any yeast that is not deliberately employed and controlled in the process, lager yeasts in an ale fermentation may be considered as a wild yeast. Other genera of yeasts are often found in pitching yeast, and are the major reason why new culture yeasts are routinely introduced into most breweries. Numerous excellent reviews on beer spoilage yeasts and bacteria have been published (Wiles, 1954; Rainbow, 1971; Ingledew, 1979; Gilliland, 1980; O'Connor-Cox et al., 1991). 


\subsubsection{Lactic acid bacteria}

This group contains two genera of importance to brewers; Lactobacillus and Pediococcus. In brewing, these organisms most frequently originate from plant sources such as malt and malt dust. Although some relatively heat resistant species may survive mashing, they are killed during kettle boiling. If allowed to contaminate beer after initiation of fermentation, they will grow. They will be harvested with the yeast and will become a constant source of contamination to the brewer on repitching of the infected yeast.

\subsubsection{Lactobacilli}

These are Gram-positive, microaerophilic, non-motile, medium to long rods. They are hop insensitive and tolerate up to $5 \%$ alcohol. Brewing lactobacilli are saccharolytic and heterofermentative organisms. They metabolize sugars to form lactic acid, ethanol, carbon dioxide, acetate and glycerol. Minor amounts of 2,3- butanediol and diacetyl are also produced. The latter cause off-flavors, while lactic acid gives an astringent and sour aftertaste to the product. The organisms grow well between $\mathrm{pH} 4.1$ to 4.5 and have an optimal growth temperature near $30^{\circ} \mathrm{C}$. The cells occur mostly in pairs and in short chains in liquid media. Thermophilic strains have been isolated (Kleyn and Hough, 1971; Gilliland, 1980; Tsang, 1981) and more recently, a strain of Lactobacillus delbrueckii was found to be among the most heat resistant beer spoilage organisms. The $\mathrm{D}_{60}$ value for this organism (isolated from a 
spoiled, underpasteurized beer) was approximately $2 \mathrm{~min}$ in normal lager beer (M. Barney, Miller Brewing Co., personal communication), although a different strain from the same species was not as resistant (Tsang and Ingledew, 1982).

\subsubsection{Pediococci}

Pediococci are Gram-positive, microaerophilic to anaerobic nonmotile cocci. Pediococci will grow to form tetrads and pairs in liquid media. They grow well at $\mathrm{pH} 3.5$ to 5.5 (the exact $\mathrm{pH}$ range of fermentation) with an optimal growth temperature between $21-25^{\circ} \mathrm{C}$. They are widespread on materials of vegetable origin. Unlike the lactobacilli, the pediococci are homofermentative, converting sugar to a single primary end product, lactic acid. They also produce diacetyl in higher concentrations than do lactobacilli. This secondary metabolic by product has a very low threshold level in beer and results in an odour and flavour resembling honey or butterscotch. As few as 20,000 pediococci per $\mathrm{ml}$ in fermenting beer can produce a diacetyl concentration of $0.36 \mathrm{ppm}$ which is three times the taste and aroma threshold levels (Kissel and Dakin, 1956). A strain of Pediococcus acidilactici was the most thermally-resistant organism in beer described by Tsang and Ingledew (1982). Their studies showed a $D_{60}$ value for this organism of $0.867 \mathrm{~min}$. 


\subsubsection{Zymomonas}

The genus Zymomonas is composed of motile Gram-negative rods that are strictly anaerobic and have a narrow range of sugar fermentation ability. They utilize only the substrates glucose, fructose and sucrose. These bacteria can tolerate up to $6 \%$ ethanol and grow well between $\mathrm{pH} 3.5$ to 7.5 with an optimal temperature of $30^{\circ} \mathrm{C}$. They will grow equally well in hopped or unhopped beer. Like yeast, their main metabolic end products are ethanol and carbon dioxide. They also produce minor secondary end products such as hydrogen sulphide (rotten-egg smell) and acetaldehyde (rotten-apple smell). These off odours in beer are often accompanied by turbidity. Infection by these organisms is rare and when it occurs, the source of contamination is often improperly cleaned equipment such as filling tubes, brushes, or keg washing machines. The usual beer isolates include Z. anaerobia and Z. mobilis (Dadds and Martin, 1973; Richards and Corbey, 1974).

\subsubsection{Acetic acid bacteria}

Acetic acid bacteria are Gram-negative short rods. They are normally obligate aerobes but some may grow with much less oxygen present. They are insensitive to hops and tolerate very low $\mathrm{pH}$. They are strongly oxidizing organisms, capable of converting ethanol to acetic acid and in some cases, completely to carbon dioxide and water. This group contains two genera of importance in beer spoilage; Acetomonas and Acetobacter species. Acetomonas, 
which was previously called Gluconobacter, will convert ethanol to acetic acid and are commonly used for vinegar manufacture. They use proline (an abundant unutilized nitrogen source in beer) and are capable of using ethanol as the sole carbon source. Like Pediococcus, these organisms produce a capsular material which can lead to ropiness in beer. Acetobacter species are more oxidative than Acetomonas. In the presence of oxygen, they further oxidize acetic acid to carbon dioxide and water. The result is a lowered $\mathrm{pH}$, a marked decrease in ethanol, and a vinegar taste and odour. They also form pellicles in beer. Acetic acid bacteria, although considered to be aerobes, can survive and even grow under more microaerophilic conditions. An example is their growth in partially filled beer kegs. As a result, the acetic acid bacteria are particularly problematic in draught beer spoilage. Studies on the heat resistance of acetic acid bacteria in beer have shown that a proper maximum temperature of pasteurization $\left(60^{\circ} \mathrm{C}\right)$ should eliminate the presence of any acetic acid bacteria in finished beer (Epstein and Dee Snell, 1940; Laufer and Brenner, 1940; Lund, 1946; Del Vecchio et al., 1951). These organisms are of more concern in unpasteurized products from which oxygen is not completely excluded.

\subsubsection{Hafnia protea}

Formerly known as Flavobacterium proteus or Obesumbacterium proteus, this organism is a short, fat, Gram-negative, facultatively anaerobic rod that has now been reclassified as a coliform bacterium. It is hop insensitive and 
metabolizes sugars in similar fashion to the coliform group forming ethanol and lactate as major end products. It is notorious for producing a parsnip-like odour indicating the presence of dimethyl sulphide, and secondary products such as fusel alcohols, acetoin and volatile fatty acids. The organism will grow well at $\mathrm{pH} 4.3$ (optimal $\mathrm{pH}$ is 6 ) in degassed beer or wort. It will not grow at a $\mathrm{pH}$ less than 3.9 , so it may not cause spoilage of regular beer (3.8-4.2 final $\mathrm{pH})$. It grows more rapidly at higher fermentation temperature and therefore is much more problematic in ale fermentations. The literature does not include studies on thermal resistance of Hafnia protea. Since it has been reclassified as a coliform organism it is likely that its heat resistance is similar. If present in wort, this organism should not survive fermentation and therefore, resistance to pasteurization is not a concern.

\subsubsection{Coliform group}

The coliform group contains genera such as Enterobacter, Klebsiella, Escherichia, Citrobacter, and Serratia - all aerobic or facultatively anaerobic, Gramnegative rods. Coliforms will not grow in regular $5 \% \mathrm{AB}$ since almost all genera require a $\mathrm{pH}$ in excess of 4.3. They can grow in wort and have been implicated in the production of various off-flavours and off-odours. Infected wort usually has a celery-like, sweet fruity flavour, and medicinal and phenolic off-flavors have also been reported. The end products of a mixed acid fermentation by these organisms are ethanol, carbon dioxide, acetate, acetoin, 
and 2,3-butanediol. Small amount of dimethyl sulphide are also produced. One species of particular interest is Enterobacter agglomerans, an organism that is able to increase the $\mathrm{pH}$ of the wort as well as cause extreme off-flavours and offodours due to dimethyl sulphide production (van Vuuren, 1987). Since the coliforms do not grow in regular $5 \% \mathrm{AB}$, there is no information regarding studies on their sensitivity to the pasteurization process.

As far as $\mathrm{AB}$ is concerned, no coliform other than Enterobacter agglomerans and Hafnia protea should survive the brewing process. However, foodassociated outbreaks of diarrhea and hemolytic uremic syndrome caused by Escherichia coli 0157:H7 (Besser et al., 1992) and Salmonella typhimurium (Anonymous, 1975) have occurred in apple cider. These outbreaks are of particular concern because apple cider (like beer) typically has a $\mathrm{pH}$ of 4.0 (due to the presence of malic and lactic acids), and although unfermented, may contain a low level of alcohol.

\subsubsection{Escherichia coli 0157:H7}

This organism is a Gram-negative, facultative anaerobic, rod-shaped coliform. Cells are small and spherical, never elongated, and occur singly or in pairs in liquid media. The optimum temperature of growth is $37^{\circ} \mathrm{C}$. Simple fermentable sugars like glucose are converted to lactic, acetic, formic acid and other end products common to mixed acid fermentation. This particular bacterium is characterized by its inability to ferment sorbitol and a slower (or 
no) growth at temperatures $>44.5^{\circ} \mathrm{C}$ (Doyle, 1991). This bacterium does not survive the traditional brewing process because of a combination of the low $\mathrm{pH}$ and alcohol produced during fermentation.

E. coli $0157: \mathrm{H} 7$ was identified as the causative agent in an outbreak of diarrhea and hemolytic uremic syndrome associated with apple cider (Besser et al., 1993). The outbreak in apple cider indicates that resistance to acidic $\mathrm{pH}$ is an additional characteristic that distinguishes the 0157:H7 serotype from other strains of E. coli. E. coli $0157: \mathrm{H} 7$ can grow at $\mathrm{pH}$ values ranging from 4.0 to 9.0 . In addition, survival of this pathogen has been demonstrated in frozen ground beef and sausage (in which it was resistant to fermentation by-products), and after two months storage of dry products at $4^{\circ} \mathrm{C}$ (Glass et al., 1992). Miller and Kaspar (1994) demonstrated that E. coli 0157:H7 strains were able to withstand and survive $\mathrm{pH} 2$ (in apple cider) with only a marginal decrease in colony forming units (cfu). The survival was greater at $4^{\circ} \mathrm{C}$ when the $\mathrm{pH}$ extreme.

\subsubsection{Obligate anaerobes}

Pectinatus cerevisiiphilus, a rod shaped organism very similar to Zymomonas in its capacity to produce large amounts of hydrogen sulphide, was first described by Lee et al. (1980). This microbe ferments several sugars but does not produce ethanol. Instead it produces large amount of propionic acid. Pectinatus is a strict anaerobe and fails to grow on solid media in a $\mathrm{CO}_{2}$ atmosphere. However, the use of a strongly reduced medium (containing 
ascorbic acid and sodium thiosulphate) sterilized in a Lee tube, with subsequent incubation in a Gas Pak jar will provide the strict anaerobic requirement of this bacterium. These bacteria can tolerate up to $4.5 \%$ ethanol and can grow at $\mathrm{pH}$ values as low as 3.7 , with an optimum of $>4.5$. Lee et al. (1980) reported that Pectinatus is rather sensitive to heat since exposure of the organism for one minute at $58^{\circ} \mathrm{C}$ is sufficient to kill it.

Another Gram-negative strict anaerobe, Megaspaera, has been isolated from spoiled beer (Weiss et al., 1976). Megaspaera cerevisiae is a motile, slightly elongated coccus that forms significant amounts of butanol, butyric acid, valeric acid and isovaleric acid. It occurs in pairs and occasionally in short chains. This bacterium grows well on lactate and pyruvate but less well on glucose and maltose, the typical fermentation sugars. However, fructose is well metabolized by this organism (Back et al., 1981). This strictly anaerobic bacterium will grow in hopped beer and will tolerate alcohol to $0.5 \% \mathrm{w} / \mathrm{v}$. Pectinatus and Megasphaera have been recently reviewed (Chelak and Ingledew, 1987). Infection of beer by such contaminants is rare but has been noted in kegs. They are generally found in aging tanks and in bottling lines. Recent advances in filling technology, which efficiently reduces the oxygen concentration in the finished beer, as well as recent interest in the production of low alcohol beer, lead to more favourable conditions of growth for these organisms. Their ability to use alternate carbon sources such as lactate and unused fermentable sugars 
(especially fructose) increases their possibility of growth in a mixed infection of $5 \%$ alcohol beer or alcohol-free beer.

Recently a number of new Gram-negative obligate anaerobes have been described. A new species of the genus Pectinatus, P. frisingensis, Zymophilus raffinosivorans and Zymophilus paucivorans, and Selenomonas lacticifex from the recently described genus Selenomonas (Schleifer et al., 1990) have been described. Because of increasing concern in the brewing industry as well as, an improvement in techniques required to isolate strict anaerobes, it is expected that other anaerobes will be isolated and described in the future.

\subsubsection{Salmonella typhimurium}

This bacterium is not found in $A B$ but can be found in by products such as spent grains or spent yeast. S. typhimurium is a small, Gram-negative, nonsporing rod, and facultatively anaerobic bacterium. Many species of this genus are pathogenic for humans, animals, and birds. For optimal growth, Salmonella requires $\mathrm{pH}$ values between $6.6-8.2$ and a temperature of $\sim 37^{\circ} \mathrm{C}$. However, several studies have demonstrated the acid resistance of S. typhimurium (Foster and Hall, 1991; Foster, 1992; Gorden and Small, 1993; Leyer and Johnson, 1993). Growth of S. typhimurium at $6^{\circ} \mathrm{C}$ has also been reported (Matches and Liston, 1968). S. typhimurium is the serotype most frequently encountered in foodborne outbreaks of salmonellosis. Outbreaks of typical gastrointestinal 
symptoms through the consumption of contaminated apple cider with $S$. typhimurium have been reported (Anonymous, 1975).

\subsubsection{Wild yeasts}

A wild yeast is defined as any yeast not deliberately used or under full control (Wiles, 1954). For instance, an ale yeast is considered to be wild in a lager fermentation and vice versa. In multiplant breweries where products are also often made under license, many proprietory yeasts Saccharomyces are used. Each can be considered "wild" to the fermentation process mediated by another. Among the wide range of wild yeast isolated in breweries and causing beer spoilage, Saccharomyces species are the most widely found but Brenner and Hsu (1971) found that Candida and Hansenula yeasts were also found as pitching yeast contaminants. Of lesser importance, Pichia spp. may also cause brewing spoilage problems. Members of the genera Kloeckera, Brettanomyces, Torulopsis, Rhodotorula, Debaromyces and Hanseniaspora are less frequently found; among these six, only Kloeckera and Brettanomyces are important contaminants (Campbell, 1987).

\subsection{Pasteurization in the brewing industry}

Compared to other food industries, breweries have had a rather straightforward and limited spectrum of microorganisms to deal with (Ault, 1965; Brenner and Hsu, 1971; Kleyn and Hough, 1971; Ingledew, 1979; Gilliland, 
1980). Moreover, because in $5 \%$ alcohol products none of the pathogens survive, microbial spoilage and loss of profit and market share are considered the only important microbiological problems.

Pasteurization is a process in which elevated temperature is used over a prescribed period of time to destroy undesirable organisms in a product. It is widely practiced in brewing with the primary objective to secure the biological stability of the product, prolonging the shelf-life of beer. The process should not adversely affect product quality. Heat processing was successfully applied to beer by Louis Pasteur in 1870. Pasteur found that temperatures from 50 to $55^{\circ} \mathrm{C}$ were sufficient to preserve beer, but he did not specify the length of time. The term pasteurization originated with Austrian vintners who followed Pasteur's teachings. The application of this research to brewery processing in the latter part of the nineteenth century led to a commercial "rule-of thumb" that an adequate pasteurization process was achieved when a temperature of $60^{\circ} \mathrm{C}$ was maintained for 15 minutes.

Pasteurization is commonly measured in the brewing industry in terms of pasteurization units (PU), where one PU is defined as uniform exposure of the product to $60^{\circ} \mathrm{C}$ for 1 minute. Laboratory tests indicate that values from $1-5$ PU are effective in achieving commercial sterility in 5\% alcohol beer (Ault and Newton, 1971; Tsang and Ingledew, 1982). However, many brewers use 8 to 30 PU (Ault and Newton, 1971; Coleman, 1976), perhaps to ensure a built-in safety factor in case of possible resistant contaminants. Initial pasteurization 
parameters were based on studies with mixed cultures and not with the most heat-resistant microbes known to infect beer. Success based on early methods was somewhat fortuitous. There is no information published about the number of PU used for AFB pasteurization in the industry.

\subsection{Heat resistance of microorganisms in brewing}

Many experiments on thermal death of brewery contaminants have been carried out to investigate the death kinetics of various bacteria and yeasts in regular 5\% AB. Tsang (1981), Tsang and Ingledew (1982), and Patino et al. (1985) reinvestigated pasteurization in brewing and they summarized in detail prior heat killing experiments in traditional beer. Studies on heat resistance of microorganisms in alcohol-free beer are far less numerous. For this reason the following section will review very briefly experiments on regular beer emphasizing heat killing studies in AFB.

\subsubsection{Heat resistance in regular $5 \% \mathrm{AB}$}

Up to $1940-45$, the literature of thermal death of brewery contaminants was very inconsistent. Differences and contradictions in the results of heat resistance studies (Shimwell, 1935; 1936; 1937; 1947; Laufer, 1937; Epstein and Dee Snell, 1940; Laufer and Brenner, 1940) were probably due to the way the organisms were handled, the type of growth medium used, the source of 
isolation, the concentration of inoculum, the heating menstruum used and the type and the age of organisms.

In 1946, the thermal death time of microorganisms was studied again by Lund. Lund carried out two experiments using beer as the heating menstruum. Experiments were conducted to determine the thermal death time of eleven brewing microorganisms (including lactic acid and acetic acid bacteria, and yeasts), and to verify the results obtained. Starting in 1951, Del Vecchio et al. (1951), Dayharsh and Del Vecchio (1952) and Baselt et al. (1954) did significant work in the area of beer pasteurization. They adopted and defined the pasteurization unit and studied the thermal death time of numerous beer spoilage organisms. They were the first to measure the efficiency of pasteurization, express the results in pasteurization units and to use a thermal death time curve to predict pasteurization units required for biological stability. They recognized the importance of a time-temperature relationship. Scruggs and Baselt (1955), Runkel (1975) and Dallyn and Falloon (1976) also performed heat resistance studies of beer contaminants to determine optimal pasteurization units. Tsang and Ingledew (1982) and Patino et al. (1985), recently provided detailed kinetic studies on wild yeast and heat resistant brewing bacteria using a regular $5 \% \mathrm{AB}$ as a heating menstruum. Tsang and Ingledew (1982) demonstrated that the $Z$ value (the number of degrees in temperature to bring about a ten-fold reduction in $\mathrm{D}$ value) does not adequately 
describe heat resistance and recommended that the decimal reduction time of the most heat resistant bacterium of significance to brewing should be used.

\subsubsection{Heat resistance of microbes in AFB}

Generic studies on the effects of environment were detailed by Hansen and Rieman (1963). Chemicals in the suspending medium may protect cells on heating or enhance their death. Increased heat lethality in the presence of ethanol has been noted by Splittstoesser et al. (1975) who studied the influence of wine composition on heat resistance of potential spoilage organisms and noted that the presence of ethanol increased heat lethality of contaminating organisms. The more recent information summarized below will help to put much of this work into perspective as it relates to brewing.

\subsubsection{Molzahn et al. (1983)}

Molzahn and his co-workers studied the factors influencing flash pasteurization of beer. The heat resistance of Saccharomyces uvarum, Saccharomyces diastaticus and Lactobacillus brevis were tested using the pasteurization method described by Tsang and Ingledew (1982), except that degassed commercial lager beer, alcohol-free lager or saline served as pasteurization menstrua. The primary objectives of Molzahn's group were to gain a better understanding of the lethal rate and decimal reduction time approaches, and to identify possible causes of sporadic failure of the flash 
pasteurizer. The results of this study allowed the authors to conclude that ethanol augmented thermal killing and also eliminated recovery of sub-lethally damaged microorganisms. For L. brevis, a 1 minute $\mathrm{D}$ value (the time in minute at a specific temperature required to destroy $90 \%$ of the organisms in a population) in $\mathrm{AFB}$ was obtained at $49.4^{\circ} \mathrm{C}$; in $4 \% \mathrm{v} / \mathrm{v}$ lager beer, a $1 \mathrm{~min} \mathrm{D}$ value was obtained at $46.1^{\circ} \mathrm{C}$.

\subsubsection{Kilgour and Smith (1985)}

Kilgour and Smith compared the multiple point method and the Reichart method in measuring $\mathrm{D}$ and $\mathrm{Z}$ values for two thermotolerant beer spoilage yeasts in both alcoholic and non-alcohol beers. Commercial AFB $(<0.05 \% \mathrm{v} / \mathrm{v}$

alcohol) and an equivalent $A B(3.7 \% \mathrm{v} / \mathrm{v})$ were used for the comparative study. The $\mathrm{pH}$ values of the beers were not reported. By the Reichart method, $\mathrm{D}_{60}$ values for Saccharomyces diastaticus vegetative cells were 0.06 in $A B$ and 0.51 in AFB. The second Saccharomyces strain (isolated from pasteurized AFB), demonstrated $D_{60}$ values of 0.03 in $A B$ and 0.11 in $A F B$ when tested by the Reichart method, and 0.24 and 0.53 , respectively, when tested by the multiple point method. Their work confirmed that alcohol content had a powerful effect in enhancing thermal killing in beer. 


\subsubsection{Adams et al. (1988)}

Adams et al. (1988) studied the effect of ethanol concentration of beer on the heat resistance of a spoilage Lactobacillus in beer. They determined D values of the organism at 55,60 and $65^{\circ} \mathrm{C}$ in beers of different alcohol concentration. Commercially available lager beers were used including an alcohol-free $(<0.05 \%$ $\mathrm{v} / \mathrm{v} ; \mathrm{pH} 4.2)$, a low alcohol lager $(0.9 \% \mathrm{v} / \mathrm{v} ; \mathrm{pH} 4.0)$, a conventional lager $(3.3 \%$ $\mathrm{v} / \mathrm{v} ; \mathrm{pH} 4.2)$ and a strong lager $(4.4 \% \mathrm{v} / \mathrm{v} ; \mathrm{pH} 4.1)$. They used the attemperated dilution blank adaptation of the multiple point method. This method was described by Menegazzi and Ingledew (1980), and has been used by Tsang (1981) and Tsang and Ingledew (1982) for thermal death studies in 5\% AB. D values calculated from survivor curves of Lactobacillus decreased with increasing temperature and, at each temperature, decreased with increasing ethanol concentration. The $D_{60}$ value in alcohol-adjusted beer at $0.5 \%$ was 2.08 min, and in $3.0 \%$ ethanol concentration beer it was $1.29 \mathrm{~min} . \mathrm{Z}$ values in commercial beers of differing ethanol content $(<0.05 \%, 0.9 \%, 3.3 \%, 4.4 \%)$ were, respectively, $12.13,9.17,9.96$ and 10.60 .

\subsection{Factors affecting the heat resistance of microbes}

The thermal resistance of bacteria is influenced by a number of factors.

To realize a relevant comparative study, it is of importance to control and standardize all experimental variables. As the objective of this work was to compare the heat resistance of bacteria in media of different chemical 
composition, variables such as the composition of the culture media in which the organisms are grown before heating, the composition of recovery media, the time and temperature of incubation before and after heating, the age and physiological state of the cells had to be standardized. For example, bacteria have been shown to exhibit changes in heat resistance as the culture passes from one growth phase to the next; early stationary phase cells were found to be the most resistant (Dallyn and Falloon, 1976; Molzahn et al., 1983; McNeil and Garrick, 1984). For this reason these authors sugested that bacterial cells used for heat killing experiments should always be from the early stationary phase of growth.

Alcohol-free beer and the corresponding 5\% alcohol product, used for the comparative study, are very different in their chemical composition. The differences are even more important if $A F B$ is produced through an interrupted-fermentation process. In this specific case, in addition to a much lower concentration of ethanol, the alcohol-free product contains more carbohydrates (fermentable sugars as well as unfermentable dextrins), more nutrients and has a higher $\mathrm{pH}$ than the fully brewed product. The following is a summarization of how these composition factors affect the heat resistance of microbes in both products. 


\subsubsection{Carbohydrates content}

Bacteria heated in a menstruum in which the water activity has been decreased by the addition of carbohydrates would exhibit an increased heat resistance (Hansen and Rieman, 1963). It has been found that high concentrations of soluble carbohydrate(s) generally result in increased heat resistance of yeasts and bacteria (Schmidt, 1954; Baumgartner and Herson, 1956; Hansen and Rieman, 1963), although the protective effect of sucrose solutions on heated $E$. coli was nullified when the $\mathrm{pH}$ was lowered to 4.0. Torreggiana and Toledo (1986) demonstrated that a substance altering the water activity can confer some protection to cells, or influence the rate of repair of cell damage. In regular $5 \% \mathrm{AB}$, very few fermentable sugars (glucose, fructose, sucrose, maltose and maltotriose) are left in the fully fermented beer. However, in an interrupted fermentation process, a greater concentration of these sugars is left in the $\mathrm{AFB}$ and solute protection may occur during pasteurization and may facilitate cellular repair after heat injury.

\subsubsection{Alcohol concentration}

Ethanol enhances the thermal death of microorganisms (Molzahn et al., 1983; Kilgour and Smith, 1985; Adams et al., 1989). Thus, (all other factors being equal), pasteurization is more effective in $5 \% \mathrm{AB}$ because of the presence of ethanol. Studies on heat sensitivity of organisms (Molzahn et al., 1983; Garrick and McNeil, 1984) confirmed that $\mathrm{pH}$, carbonation and alcohol content of beer 
do alter the organism during pasteurization. Due to the increased popularity of AFB, the influence of ethanol on beer pasteurization efficiency has been studied more intensely. It is crucial to prevent over-pasteurization defects in this type of beer where off-flavors might be more noticeable. Considering ethanol effects alone, $\mathrm{AFB}$ requires a more severe heat treatment than normal beers with a higher alcohol content. Since adverse flavor changes and energy costs, due to over pasteurization, must be considered, Adams et al. (1989) proposed an alternative which involved the application of higher hopping rates in AFB.

\subsection{3 $\mathrm{pH}$}

Heat denaturation of protein and therefore heat resistance of bacteria are affected by acidic or alkaline reactions. The heat resistance of a particular organism has an optimum within a narrow $\mathrm{pH}$ range outside which the resistance falls rapidly. Only weak acids or alkalies are generally required to lower the thermoresistance of microorganisms. Regular alcohol beer $\mathrm{pH}$ is low (3.8-4.2). Such a low $\mathrm{pH}$ will assist pasteurization efficiency during heating to $60^{\circ} \mathrm{C}$. However, the pasteurization of $\mathrm{AFB}$, because of a higher $\mathrm{pH}(4.2-5.2)$, may required more pasteurization units to achieve the same degree of efficiency. 


\subsubsection{Proteins and lipids}

Proteins and lipids exert a protective effect on microorganisms during heating. Protection by lipids is suspected to act through a physical isolation of cells from water due to fat layers surrounding the cells (Hansen and Rieman, 1963). The mechanism of protein protection is still unknown but enzyme stability may be increased. Fully brewed and finished beers contain very little protein and even less lipid. AFB may contain more of these two components but their very low concentrations are not likely to exert significant protective effects.

\subsubsection{Salts}

Various chloride salts are known to affect the thermotolerance and repair characteristics of bacteria (Beuchat, 1978). Regular AB and AFB contain some chloride salts. Their effects on contaminants in alcohol or non-alcohol beers are unknown. Other salts have not been well studied, but salts used to adjust ion content of brewing water should be studied in detail.

\subsubsection{Carbon dioxide}

Carbon dioxide is present in both $5 \% \mathrm{AB}$ and $\mathrm{AFB}$. This component should affect equally the heat resistance of the contaminants in both products when pasteurized. Unfortunately, beers used for studies such as described in this thesis are often decarbonnated so that volume measurements can be made 
with precision, and death kinetic data are statistically better. Carbon dioxide dissolved in beer is known to have an effect on the $\mathrm{pH}$ of the product.

\subsection{Determination of heat resistance}

In the literature, four different methods are commonly reported to determine thermal resistance of microorganisms.

\subsubsection{Growth-no-growth method (Frazier and Westhoff, 1978)}

A constant initial number of a particular organism is inoculated into a series of tubes or vials containing the same sterile medium. Each tube is heat treated at the same temperature. At 5 minutes intervals, tubes are removed, incubated at the organism's optimal temperature for growth, and subsequently checked for turbidity. By choosing appropriate intervals between 5 and 10 minutes and repeating the experiments, (under identical conditions), the thermal death time value for the organism at $60^{\circ} \mathrm{C}$ can be determined.

\subsection{2 "End point" method (Ingram, 1969)}

In this method, the heat treatment time required to destroy all of a known number of organisms in a tube or vial is determined. This involves the preparation of a series of replicate tubes each containing a different but known number of cells. Each series is treated individually for a successively longer period of time, and the contents are cultured to see if any organisms remain 
viable. The shortest treatment time which leaves no survivors is noted. This method is similar to the growth-no-growth method except in this approach, survival is attained in only one of several tubes heated at each temperature. In order to obtain more accuracy, at least five different population levels must be used to create one survival curve.

\subsection{3 "Multiple point" method (Ingram, 1969)}

In this method, a known concentration of cells is heat treated continuously and samples are withdrawn at specific time intervals. The number of survivors at each time interval is determined by viable plate counts. The process is repeated at various temperatures. The traditional multiple point method generates a series of individual heat survival curves of the selected organism at various temperatures. The $\mathrm{D}$ values at each temperature are determined from the slope of the curves. The $\mathrm{Z}$ values are then obtained by plotting D values vs. temperature, creating a phantom thermal death curve for each organism (Tsang and Ingledew, 1982). The attemperated dilution blank adaptation of this method is the best to study the heat resistance of vegetative cells although it is not suitable at temperatures near or above $100^{\circ} \mathrm{C}$. If the heating medium is pretempered, the addition of a small volume (large number) of microbes in a large volume of suspending fluid results in instantaneous heating of microbes to the temperature under test. This eliminates the death occuring in the "come-up" times associated with heated samples which are not 
pretempered. The attemperated dilution blank adaptation of the multiple point method is described by Menegazzi and Ingledew (1980), Tsang (1981), Tsang and Ingledew (1982), and Magnus et al.(1986).

\subsection{4 "Reichart" method (Reichart, 1979)}

The newest experimental method described in 1979, involves an apparatus where the temperature of the suspension is continually increased during which time samples are withdrawn and cooled at predetermined intervals. Decimal reduction times or death rate coefficients are calculated between adjacent points of the curve and their logarithms are plotted against temperature to produce a phantom thermal death time curve, or Arrhenius plot. This method has been compared to the multiple point method under brewing conditions (Kilgour and Smith, 1985). It was shown that a sufficient number of D values could be obtained by the Reichart method to construct a phantom thermal death time (TDT) curve. However, scattering of data was problematic since each D value was created from only two survival points. When Kilgour and Smith compared the two methods for a given organism, Reichart's method was found to give lower values for both $\mathrm{D}$ and $\mathrm{Z}$; no consistency in the degree of discrepancy was observed. The authors concluded that until the reasons for the differences between the two methods were determined, they could not recommend the use of Reichart's method even though it was rapid and simple. 


\subsection{Heat resistance terminology}

The effectiveness of pasteurization is determined by the physical and chemical properties of the product, as well as by the type, number, and heat resistance of the microorganism(s) present. In order to measure the heat resistance and make comparison of this resistance between microorganisms or to compare the heat resistance of a single organism in different media, it is necessary to find some regularity of behaviour which can be expressed in numerical terms. Such regularity of behaviour is expressed in terms of parameters such as the $D$ and $Z$ values.

\subsubsection{Thermal death time (TDT)}

Heat resistance of an organism is determined from its (TDT) or phantom TDT curves. These curves must be produced under clearly defined conditions as many physiological properties of both the organism and the substrate or menstruum will alter them. In this work, phantom TDT curves were plotted from data obtained from survival curves. A survival curve plots the number of viable organisms (semi-log) versus the time of exposure at each particular temperature. Multiple samples are taken from the same flask over the time course of experiment. The negative value of the reciprocal of the slope of the survival curve ( $D$ value) characterizes the heat resistance of the organism in question (Tsang, 1981; Tsang and Ingledew, 1982; Röcken, 1985) but values are 
comparable only if the conditions imposed in each experiment are identical (O'Connor-Cox et al., 1991).

A thermal death time (TDT) is the time in minutes required to kill all organisms in a suspension (in a sealed vial) at a given temperature under defined conditions. This value depends on the number and type of organisms present. Thus thermal death times reported in the literature can be rather doubtful values, as the number of organisms used in experiments varies considerably (Tsang, 1981). The heating time applied prior to achieving the desired temperature also results in significant death. For this reason, the $\mathrm{D}$ value is more accurate, especially when done by the attemperated dilution blank adaptation.

\subsubsection{D value (decimal reduction time)}

The decimal reduction time ( $D$ value) of a specific organism is defined as the time in minutes at a specific temperature required to destroy $90 \%$ of the organisms in a population (decrease the surviving population by one log cycle). The $\mathrm{D}$ value enables one to compare the heat resistance of different organisms in the same heating medium at the same temperature, or heat resistance of a selected organism in the same medium at different temperatures, or even the same organism at the same temperature in different heating media. The $\mathrm{D}$ value may be determined in several ways but the most accurate method is to

obtain it directly from a survival curve. When a straight line response is 
obtained, the $\mathrm{D}$ value at the particular temperature used can be read off easily from the graph or estimated by a calculator. In the cases where the survival curve has an initial shoulder or when it is concave upward, the D value can be obtained from the straight portion of the graph. The goodness of fit of the curve can be determined by linear regression, and the $\mathrm{D}$ value calculated from the negative of the reciprocal slope by regression or mathematically (Stumbo, 1973).

To characterize cell death during processing, the $\mathrm{D}$ value alone is not sufficient since it does not indicate how variations from the stated temperature affect killing (each D value is determined at one temperature).

\subsection{3 $\mathrm{Z}$ value}

An indication of how $D$ changes with temperature is provided by $Z$, a value which indicates the number of degrees the temperature must be increased in order to decrease the D value by a factor of 10 (Potter, 1978). The usual way to obtain the $\mathrm{Z}$ value is by plotting $\mathrm{D}$ values semilogarithmically against temperature, and the best fit line drawn throught the points allows the slope of the line to be determined. This is called a phantom thermal death time (phantom TDT) curve, and the reciprocal of the slope is the $Z$ value. However, it should be understood that it is $\mathrm{D}$ and not $Z$, which is an absolute measure of the heat resistance. $\mathrm{Z}$ is a temperature coefficient expressing the rate at which $\mathrm{D}$ varies with temperature. 


\section{MATERIALS AND METHODS}

\subsection{Bacteria}

\subsubsection{Bacterial cultures}

The following bacteria were used in this research project for the heat

resistance study:

Salmonella typhimurium

Escherichia coli 0157:H7

ATCC 14028

Pediococcus acidilactici

ATCC 43889

Lactobacillus delbrueckii

NCIB 6990

Miller Brewing Co.

The following bacteria were used for growth tests in AFB:

Salmonella typhimurium

Escherichia coli 0157:H7

Staphylococcus aureus

Shigella flexneri

Listeria monocytogenes

Yersinia enterocolitica

Klebsiella pneumoniae

Bacillus cereus

Enterococcus faecium

Pseudomonas aeruginosa

Aeromonas hydrophila
ATCC 14028

ATCC 43889

ATCC 13565

Department of Microbiology,

University of Saskatchewan

ATCC 43256

ATCC 35669

ATCC 13883

ATCC MBCL 27

ATCC 19434

ATCC 27853

ATCC 7965 


\subsubsection{Culture maintenance and purity}

Stock cultures of the bacterial strains were frozen at $-70^{\circ} \mathrm{C}$, in double strength skim milk (Difco Laboratories, Detroit, Michigan, USA) with 50\% $(w / v)$ glycerol. Working cultures were obtained by streaking stock cultures on slants of nutrient agar (Difco Laboratories, Detroit, Michigan, USA) for pathogens and opportunistic pathogens (listed above), and on slants of MRS agar (Oxoid, Unipath Ltd., Basingstoke, Hampshire, UK) for $P$. acidilactici and $L$. delbrueckii. The working cultures of S. typhimurium, E. coli 0157:H7 and bacteria used for the growth testing were incubated 2 days at $30^{\circ} \mathrm{C}$, except that $P$. acidilactici and L. delbrueckii slants were incubated 4 and 7 days respectively at $27{ }^{\circ} \mathrm{C}$ in an anaerobic incubator (model 103, National Appliance Co., Portland, Oregon, USA) evacuated 2 cycles and filled with beverage grade $\mathrm{CO}_{2}$. All working cultures were stored at $4{ }^{\circ} \mathrm{C}$. Culture purity was confirmed periodically by Gram stain, and by cell and colony morphology.

\subsection{Media}

\subsubsection{Choice of heating media}

\subsubsection{Analysis of commercial AFB and commercial AB}

The commercial AFB examined for potential use as heating media were identified with the following information on the can:

Falcon Light: $\quad$ Fully brewed. Imported by Jay Sea Management Ltd. North Vancouver, B.C., Canada, V7L 4K6 
Ingredients: water, malt, corn and hops $60 \mathrm{cal} / 250 \mathrm{KJ} / 355 \mathrm{ml}$

$0.5 \%$ alc. $/ \mathrm{vol}$

Labatt 0.5:

Fully brewed. Labatt Brewing Company Limited, London, Vancouver, Edmonton, Saskatoon, Winnipeg, Toronto, Montreal, St-John's, Halifax. Canada-Union made. $85 \mathrm{cal} / 360 \mathrm{KJ} / 355 \mathrm{ml}$ $0.5 \%$ alc. $/$ vol

Molson Exel: $\quad$ Fully brewed. Molson Breweries. Vancouver, Calgary, Edmonton, Regina, Winnipeg, Toronto, Barrie, Montreal, StJohn's. Canada-Union made. Brasserie Molson-O'Keefe. $0.5 \%$ alc. $/$ vol

O'Doul's: $\quad$ Anheuser-Busch, Inc. St. Louis, MO., USA.

Ingredients: water, barley malt, corn, hops, yeast.

$0.5 \%$ alc. $/$ vol

Sharp's: $\quad$ Fully brewed. Miller Brewing Company, Milwaukee, WI, USA.

$85 \mathrm{cal} / 356 \mathrm{KJ} / 355 \mathrm{ml}$

$0.7 \mathrm{~g}$ protein, $0.0 \mathrm{~g}$ fat, $17.8 \mathrm{~g}$ carbohydrates

$<0.5 \%$ alc. $/$ vol

Tourtel: $\quad$ Importé par Evian Source de France Inc., Montréal, Toronto. Canada. Brassé/Brewed by Kronenbourg S.A., Strasbourg, France.

$90 \mathrm{cal} / 380 \mathrm{KJ} / 330 \mathrm{ml}$

$0.5 \%$ alc. $/$ vol

It was decided to use the corresponding $5 \%$ alcohol beer from the company which brewed the chosen AFB (see Results and Discussion). 


\subsection{HPLC analysis}

Frementable sugars, glycerol, and ethanol in six $\mathrm{AFB}$ and the selected $\mathrm{AB}$ were measured in triplicate by high performance liquid chromatography (HPLC). "Dextrins", larger than maltotriose, were estimated using the response factor obtained by injection of known quantities of maltotetraose. Attemperated $\mathrm{AFB}$ and $\mathrm{AB}$ were degassed and membrane filtered $(0.45 \mu \mathrm{m}$, Gelman Scientific Co Ltd.) to obtain clear supernatant samples. Each sample $(0.1 \mathrm{ml})$ was diluted 10 fold with $0.85 \mathrm{ml}$ deionized distilled water and $0.05 \mathrm{ml}$ of methanol as internal standard. Then $5 \mu \mathrm{l}$ were injected into a FAM-PAK ${ }^{\mathrm{TM}}$ column (Waters Chromatographic Division, Milford, MA) maintained at $65^{\circ} \mathrm{C}$. The components were eluted from the column with HPLC-grade water (Milli-Q double distilled and deionized (ddd), Millipore Corporation, Bedford, MA) containing $1.5 \mathrm{mM}$ orthophosphoric acid. The separated components were detected with a differential refractometer (Model 410, Waters Chromatographic Division, Milford, MA) and quantified using the Maxima 810 computer program (Waters Scientific). The elution rate was $1 \mathrm{ml} / \mathrm{min}$ (Thomas et al., 1993).

\subsection{Free alpha-amino nitrogen (FAN) assays}

The ninhydrin method can be used to determine the quantity of free alpha-amino nitrogen (FAN) remaining in each beer after fermentation. The method measures amino acids and end group amino nitrogen in peptides and proteins. 
It is essential to use specially washed glassware and to wear gloves throughout the experiment as contaminating amino acids may affect the results. Samples, in duplicate, were appropriately diluted 1:51 and the standard diluted 1:201. A volume of $2.0 \mathrm{ml}$ of each diluted sample was added to the tubes. Then, $1.0 \mathrm{ml}$ of ninhydrin color reagent $\left(100 \mathrm{~g} \mathrm{Na}_{2} \mathrm{HPO}_{4} \bullet 12 \mathrm{H}_{2} \mathrm{O}, 60 \mathrm{~g} \mathrm{KH}_{2} \mathrm{PO}_{4}\right.$, $5.0 \mathrm{~g}$ ninhydrin, and $3.0 \mathrm{~g}$ fructose made up to 1 liter with autoclaved ddd water) was added and the tubes were vortexed gently. The tubes were placed in a boiling waterbath for exactly 16 minutes. A marble on the top of each tube to reduce solution evaporation. The tubes were cooled 20 minutes in a waterbath at $20^{\circ} \mathrm{C}$. Then, $5 \mathrm{ml}$ of color diluent $\left(2.0 \mathrm{~g} \mathrm{KIO}_{3}\right.$ dissolved in $600 \mathrm{ml}$ ddd water and $400 \mathrm{ml} 95 \%$ ethanol) was added and mixed to stabilize the reaction. A parafilm square was place on the top of the tubes and contents were mixed by inversion. Absorbance, read at $570 \mathrm{~nm}$ by spectrophotometer (Milton Roy Spectronic 1201, Fisher Scientific Co., Edmonton AB), was measured within 30 minutes. The quantity of FAN in $\mathrm{mg}$ per $\mathrm{L}$, was calculated according to the equation below (Anonymous, 1992).

\subsection{Ethanol assays}

Ethanol concentrations in the six $A F B$ and the two $A B$ were determined by the alcohol dehydrogenase enzymatic method. In this method, ethanol is oxidized to acetaldehyde with simultaneous reduction of nicotinamide adenine dinucleotide (NAD) to NADH, by the enzyme alcohol dehydrogenase (ADH). 
The consequent increase in absorbance at $340 \mathrm{~nm}$ is directly proportional to alcohol concentration in the sample (Anonymous, 1992).

The attemperated and degassed beers were appropriately diluted with distilled deionized water (1:51 dilution). Each beer was analysed in duplicate. A volume of $50 \mu \mathrm{l}$ of diluted sample and $25 \mu \mathrm{l}$ of $1 \%$ standard ethanol solution (made from 95\% ethanol) were added to labelled screw capped tubes. In each tube, $3 \mathrm{ml}$ of NAD - glycine pyrophosphate solution (made by dissolving 1.194 $\mathrm{mg}$ NAD in each $3.0 \mathrm{ml}$ of glycine pyrophosphate buffer at $\mathrm{pH} 9.2$ ) was added and vortexed gently. Then $50 \mu \mathrm{l}$ of ADH $(56 \mathrm{mg}$ ADH reconstituted in $5 \mathrm{ml}$ ice cold distilled water, $340 \mathrm{U} / \mathrm{mg}$ solid) was added to each tube and vortexed gently. The absorbance at $340 \mathrm{~nm}$ after exactly 15 minutes incubation at room temperature was measured by spectrophotometer (Milton Roy Spectronic 1201). From the known absorbance of the solution and standards, the concentration of ethanol in $\mathrm{w} / \mathrm{v}$ and $\mathrm{v} / \mathrm{v}$ was calculated (Sigma Chemical Corporation, Bulletin No 331 UV; St. Louis, MO).

\subsection{Specific gravity}

The digital density meter simplifies the accurate determination of density of liquids by electronic measurement of sample. The density is calculated automatically by a built-in arithmetic processor. The digital density meter is used for determining the specific gravity of beer and has been shown to be comparable to the use of a pycnometer (Anonymous, 1978). 
The beers to be analysed were filtered and decarbonated. The digital density meter (DMA 45, Anton-Paar, Graz, Austria) was first calibrated at $20^{\circ} \mathrm{C}$ with water and air. Each sample was injected into the sample tube with a hypodermic syringe, filling the tube completely without any entrapped gas. The measurement was obtained at thermal equilibrum in the thermostated sample tube.

\subsubsection{5 pH}

Each beers was attemperated to room temperature and degassed thoroughly. The $\mathrm{pH}$ was measured using a $\mathrm{pH}$ meter $\left(\mathrm{pH}\right.$ meter 10 , Accumet ${ }^{\mathrm{R}}$, Fisher Scientific) which was first standardized and calibrated with $\mathrm{pH} 7.0$ and $\mathrm{pH} 4.0$ buffers according to the protocol (Anonymous, 1992) The method for $\mathrm{pH}$ measurement of beer is detailed in the same protocol.

\subsubsection{Heating media}

Commercial alcohol-free Tourtel (imported by Evian Source de France Inc., Montreal-Toronto, Canada, brewed by Kronenbourg S.A., Strasbourg, France) and commercial 5\% alcohol Kronenbourg lager beer (Kronenbourg S.A., Strasbourg, France) were chosen and used as heating media for all the comparative studies.

Kronenbourg and Tourtel beers were degassed and sterilized by membrane filtration (type GSWP, $0.22 \mu \mathrm{m}$ pore size, Millipore Corporation, 
Bedford, MA, USA). After filtration, $99 \mathrm{ml}$ aliquots were aseptically dispensed into sterile $250 \mathrm{ml}$ Wheaton dilution blank media bottles using sterile $100 \mathrm{ml}$ graduated cylinders.

The same beers used for heat kill experiments were also used for the tests of growth with a range of potential pathogens. Volumes of $50 \mathrm{ml}$ of sterile $\mathrm{AB}$ and $\mathrm{AFB}$ were aseptically transferred into $250 \mathrm{ml}$ sterile side-arm flasks. To verify sterility, uninoculated controls were kept at room temperature throughout the growth experiments.

\subsubsection{Nutrient agar (NA)}

This medium was used to enumerate S. typhimurium and E. coli 0157:H7 under aerobic conditions at $30^{\circ} \mathrm{C}$. Nutrient agar was prepared with deionized, distilled water according to the manufacturer's directions (Difco Laboratories, Detroit, MI). It was autoclaved for 15 minutes at $15 \mathrm{psi}\left(121^{\circ} \mathrm{C}\right)$, cooled to $45^{\circ} \mathrm{C}$ and dispensed into sterile plastic Petri dishes, and stored at $4^{\circ} \mathrm{C}$.

\subsubsection{Nutrient broth (NB)}

This medium was used for primary growth and conditioning of $S$. typhimurium and E. coli 0157:H7 in heat killing experiments. It was prepared with deionized, distilled water and according to the manufacturer's instructions. Volumes of $50 \mathrm{ml}$ of nutrient broth (Difco Laboratories) were 
dispensed into $250 \mathrm{ml}$ side-arm flasks and autoclaved 15 minutes at 15 psi $\left(121^{\circ} \mathrm{C}\right)$

\subsubsection{Nutrient broth $+10 \% \mathrm{AB}(\mathrm{NB}+10 \% \mathrm{AB})$}

The reason for incorporating $10 \%$ beer in growth media was to condition S. typhimurium and E. coli 0157:H7 to beer which would be used in subsequent heat shock experiments (Tsang and Ingledew, 1982). The medium was prepared by aseptically removing $5 \mathrm{ml}$ from the autoclaved $50 \mathrm{ml} \mathrm{NB}$ in the side-arm flask and replacing it with filtered beer.

\subsubsection{Nutrient broth $+10 \%$ AFB (NB $+10 \%$ AFB)}

The incorporation of $10 \% \mathrm{AFB}$ in the growth media was also to condition the two pathogens to AFB used for the heat killing studies. In this case, filtered AFB replaced the $5 \mathrm{ml}$ of sterile NB aseptically removed from the side-arm flask.

\subsubsection{MRS agar}

This medium was used to enumerate $P$. acidilactici and $L$. delbrueckii under anaerobic conditions at $27^{\circ} \mathrm{C}$. MRS agar (Oxoid, Unipath Ltd., Basingstoke, Hampshire, UK) was prepared using deionized, distilled water according to the manufacturer's directions. The medium was autoclaved for 15 minutes at 15 psi $\left(121^{\circ} \mathrm{C}\right)$, cooled to $45^{\circ} \mathrm{C}$ and poured into sterile plastic Petri dishes. 


\subsubsection{MRS broth}

This medium was used for primary growth of both of the heat resistant lactic acid bacteria. MRS broth (Oxoid) was reconstituted with deionized, distilled water and prepared as recommended by the manufacturer. MRS broth was dispensed in $50 \mathrm{ml}$ quantities in $250 \mathrm{ml}$ screw-capped side-arm flasks and autoclaved 15 minutes at 15 psi $\left(121^{\circ} \mathrm{C}\right)$.

\subsubsection{MRS broth $+10 \%$ AB (MRS $+10 \% \mathrm{AB})$}

The $10 \% \mathrm{AB}$ incorporated in the media was to condition P. acidilactici and L. delbrueckii to the beer used for the heat killing experiments. Although these two bacteria are common beer spoilage organisms, it was found that the bacteria which had not been grown in beer previously would die off when introduced to beer (Burton and Ingledew, unpublished data). The mode of preparation was as described for $\mathrm{NB}+10 \% \mathrm{AB}$ and $\mathrm{NB}+10 \% \mathrm{AFB}$.

\subsubsection{MRS broth $+10 \%$ AFB}

This media, used to condition P. acidilactici and L. delbrueckii to AFB was prepared as for MRS $+10 \% \mathrm{AB}$. 


\subsection{Heat-killing experiments}

\subsubsection{Culturing and conditioning}

Working cultures of S. typhimurium or E. coli 0157:H7 were loopinoculated into $50 \mathrm{ml}$ of $\mathrm{NB}$ in a $250 \mathrm{ml}$ side-arm flask and incubated in an incubator shaker (G24 Environmental Shaker, New Brunswick Scientific Co., Edison, N.J., USA) at $30^{\circ} \mathrm{C}$ for 24 hours. The lactic acid bacteria were inoculated into a $250 \mathrm{ml}$ side-arm Erlenmeyer flask containing $50 \mathrm{ml}$ of MRS broth and incubated for 96 hours (L. delbrueckii) or 24 hours ( $P$. acidilactici) at $27^{\circ} \mathrm{C}$ in a $\mathrm{CO}_{2}$ incubator evacuated through 2 cycles and refilled with beverage grade $\mathrm{CO}_{2}$.

After primary growth, $1 \mathrm{ml}$ of S. typhimurium or E. coli $0157: \mathrm{H} 7$ were subcultured into a $250 \mathrm{ml}$ side-arm flask containing $50 \mathrm{ml}$ of $\mathrm{NB}+10 \% \mathrm{AB}$ or $\mathrm{NB}+10 \% \mathrm{AFB}$. The inoculated side-arm flasks were incubated under the same conditions described for primary growth. The reason for the conditioning step was to adapt the organisms to the beer and alcohol-free beer which would be used as heating menstrua in subsequent heat-killing experiments (Tsang and Ingledew, 1982).

\subsubsection{Growth curve and cell viability}

It was necessary to reproducibly grow and then determine the time at which the cells were in early stationary phase. Cells for heat killing experiments were harvested from the early stationary phase of growth because 
it is known that heat sensitivity varies with physiological age, and stationary phase cells are the most heat-resistant (Hansen and Rieman, 1963).

Growth was monitered by measuring turbidity using a Klett-Summerson photoelectric colorimeter with \# 66 red filter (Model 800-3, Klett Mfg. Co. Ltd., New York, N.Y., USA). Appropriate flasks containing uninoculated media were used as blanks in measuring bacterial growth. At various times, $1.0 \mathrm{ml}$ of culture was removed, appropriately diluted in $0.1 \%$ peptone water and membrane filtered in triplicate. Cells number was enumerated after 1 day of incubation at $30^{\circ} \mathrm{C}$ for S. typhimurium or E. coli 0157:H7; P. acidilactici and L. delbrueckii were enumerated after 2 days and 5 days incubation respectively at $27^{\circ} \mathrm{C}$ in a $\mathrm{CO}_{2}$ incubator. Subsequently, the optical density (Klett units) was plotted against time (hours) to determine when the cell populations reached early stationary phase. The optical density (Klett units) plotted against number of cells $(\mathrm{CFU} / \mathrm{ml})$ showed the concentration of cells at the early stationary phase (harvesting time) or any stage of the growth curve.

\subsubsection{Preparation of cell inoculum}

The early stationary phase cells used as inoculum for the heat killing experiments were prepared according to the section 3.3.1. Cells grown in specific media at specific conditions reached early stationary phase at specific time as shown by the growth curve studies (Appendix Figures 7.1, 7.4, 7.7 and 
7.10). These times were reproducible when cells were pregrown and handled as specified above.

$\begin{array}{lll}\text { S. typhimurium } & \mathrm{NB}+10 \% \mathrm{AB} & 10 \text { hours (275 Klett units) } \\ & \mathrm{NB}+10 \% \mathrm{AFB} & 6 \text { hours (156 Klett units) } \\ \text { E. coli } 0157: \mathrm{H} 7 & \mathrm{NB}+10 \% \mathrm{AB} & 9 \text { hours }(232 \text { Klett units) } \\ & \mathrm{NB}+10 \% \mathrm{AFB} & 6 \text { hours (156 Klett units) } \\ \text { P. acidilactici } & \text { MRS }+10 \% \mathrm{AB} & 10 \text { hours (335 Klett units) } \\ & \text { MRS }+10 \% \mathrm{AFB} & 10 \text { hours (325 Klett units) } \\ & & \\ \text { L. delbrueckii } & \text { MRS }+10 \% \mathrm{AB} & 50 \text { hours (270 klett units) } \\ & \text { MRS }+10 \% \mathrm{AFB} & 50 \text { hours (260 klett units) }\end{array}$

\subsubsection{Heating techniques and conditions}

Heating conditions for each of the organisms in the two heating media are summarized in Table 3.1. These temperature ranges were established by trial and error because the temperature sensitivity of the strains varied in the two selected menstrua (Table 3.1).

The thermosensitivity of the four organisms in $5 \% \mathrm{AB}$ and in $\mathrm{AFB}$ was compared by the attemperated dilution blank bottle method (Menegazzi and Ingledew, 1980; Tsang and Ingledew, 1982). Inoculated $99 \mathrm{ml}$ degassed sterile $\mathrm{AB}$ or $\mathrm{AFB}$ menstrua in $250 \mathrm{ml}$ screw-cap dilution bottles were tempered at specific temperatures for one hour in a circulating water bath (Haake Buchler Instruments, Inc., Saddle Brook, New Jersey, USA) with the water level maintained $1 \mathrm{~cm}$ below the screw-cap of the bottle. The temperature of the heating media was monitered by a thermocouple in an second dilution blank 
Table 3.1. Heat killing temperatures ${ }^{1}$ in $A B$ and $A F B$ for the four bacteria

\begin{tabular}{lccccc}
\hline \multicolumn{1}{c}{ Organism } & Media & \multicolumn{5}{c}{ Temperatures } \\
& & \multicolumn{5}{c}{$\left({ }^{\circ} \mathrm{C}\right)$} \\
\hline \hline S. typhimurium & $\mathrm{AB}$ & 47 & 49 & 51 & 53 \\
& $\mathrm{AFB}$ & 49 & 51 & 53 & 55 \\
\hline E. coli 0157:H7 & $\mathrm{AB}$ & 47 & 49 & 51 & 53 \\
& $\mathrm{AFB}$ & 49 & 51 & 53 & 55 \\
\hline P. acidilactici & $\mathrm{AB}$ & 47 & 49 & 51 & 53 \\
& $\mathrm{AFB}$ & 49 & 51 & 53 & 55 \\
\hline L. delbrueckii & $\mathrm{AB}$ & 51 & 53 & 55 & 57 \\
& $\mathrm{AFB}$ & 51 & 53 & 55 & 57 \\
\hline
\end{tabular}

1 These values were selected after numerous preliminary experiments in order to achieve a large number of points on each survival curve permitting analysis of data. 
heating media was monitered by a thermocouple in an second dilution blank bottle containing the same fluid and volume. The thermocouple was connected to a digital display (Model 850Z, Cole Parmer Instrument Co., Chicago, Ill., USA). When the temperature of the system reached the desired value, $1.0 \mathrm{ml}$ (or appropriate volume to reach the specific cell number - Appendix Figures 7.2-7.3, 7.5-7.6, 7.8-7.9, 7.11-7.12) was inoculated. The same volume of culture was appropriately diluted at room temperature and membrane filtered to determine the exact number of cells inoculated into the heating medium. At fixed intervals, in the experimental dilution blank containing the menstruum, aliquots of $1 \mathrm{ml}$ or $11 \mathrm{ml}$ were withdrawn and transferred into a sterile $250 \mathrm{ml}$ dilution blank bottle containing $99 \mathrm{ml}$ of $0.1 \%$ peptone water held at $20-24^{\circ} \mathrm{C}$.

\subsubsection{Recovery of heat-stressed organisms}

\subsubsection{Dilutions and plating techniques}

A series of sequential dilutions of $10^{-1}$ and $10^{-2}$ were carried out using sterile $11 \mathrm{ml}$ or $1 \mathrm{ml}$ pipettes and sterile screw-capped $250 \mathrm{ml}$ dilution blank bottles containing $99 \mathrm{ml}$ of $0.1 \%$ peptone water. The membrane filtration techniques for viable counting as described by Tsang and Ingledew (1982) were used throughout the experiment. Aliquots of $10 \mathrm{ml}$ or appropriate volumes of the original sample or the above dilutions of the heat treated organisms were filtered through sterile $0.45 \mu \mathrm{m}$ (pore size) cellulose ester membrane (Millipore 
S-pak gridded, Millipore Corp., MA, USA). When filtration was not possible in a short period of time, the first dilution was kept on ice.

\subsubsection{Incubation and counting}

The plates of heat-shocked lactic acid bacteria were incubated anaerobically on MRS agar plates at $27^{\circ} \mathrm{C}$ for 48 hours ( $P$. acidilactici) to 120 hours (L. delbrueckii). The other heat treated microbes were incubated aerobically on NA at $30^{\circ} \mathrm{C}$ for 24 hours. Enumeration was facilitated by using a Quebec Colony Counter (Model 3327 American Optical Corp, Buffalo, N.Y., USA). Plates containing between 20-250 colonies were selected for counting.

\subsubsection{Calculation and plots}

Survival curves were obtained by plotting the means of triplicate viable counts vs. time on semilogarithmic paper. The best fitted line was drawn using linear regression as calculated on a Texas Instrument TI-60 calculator. D values at each temperature were calculated from the slopes of survivor curves, and phantom thermal death time curves (D values on semilog scale vs. temperature) were constructed using linear regression. $\mathrm{D}_{60}$ values were obtained by extrapolation (using the a TI-60 calculator). 


\subsection{Tests of growth of pathogens in AFB}

The eleven pathogens or opportunistic pathogens were loop-inoculated into $50 \mathrm{ml}$ of sterile $\mathrm{AFB}$ and $\mathrm{AB}$ in $250 \mathrm{ml}$ side-arm flasks. Inoculation of the eleven organisms took place in a biohood (Nuaire ${ }^{\mathrm{TM}}$ Biological Safety Cabinet, class II, type A/B3, 2100 Ferbrook Lane, Plymouth, MN 55447) to avoid health hazards. Side-arm flasks were placed in an incubator shaker (G24 Environmental Incubator Shaker, New Brunswick Scientific Co. Inc., Edison, N.J., USA) at $30^{\circ} \mathrm{C}$. The growth was monitored over 2 days by Klett measurements. Growth curves of optical density (Klett units) vs time (hours) were prepared to illustrate the results of the growth experiments. 


\section{RESULTS AND DISCUSSION}

\subsection{Chemical analyses of the six AFB}

Because there are many possible ways to produce AFB, each different brand of commercial AFB may have a markedly different chemical composition. Tables 4.1-4.3 show some of these differences between 6 commercial AFB analyzed for fermentable sugars, glycerol, "dextrins", free amino nitrogen and ethanol content, and their $\mathrm{pH}$ and specific gravity.

HPLC analysis showed that the Tourtel AFB had an overall content of tri-, di-, and monosaccharides higher than the 5 other AFB (Table 4.1). Falcon light and O'Doul's products showed the highest amounts of "dextrins" (glucose polymers larger than maltotriose and not metabolized during fermentation), but they were lower in maltotriose, maltose, and fructose. Five of the six commercial products had an ethanol concentration less than $0.5 \% \mathrm{v} / \mathrm{v}(0.337-$ 0.482\%) (Table 4.2). According to future international regulations, the terminology "alcohol-free beer" can be used for these five low alcohol products. However, an ethanol content of $0.534 \%(\mathrm{v} / \mathrm{v})$ was measured in Miller Sharp's. The FAN levels were the highest in Labatt 0.5, Miller Sharp's, and Tourtel products (Table 4.3). Free alpha-amino acid nitrogen may not protect bacteria 


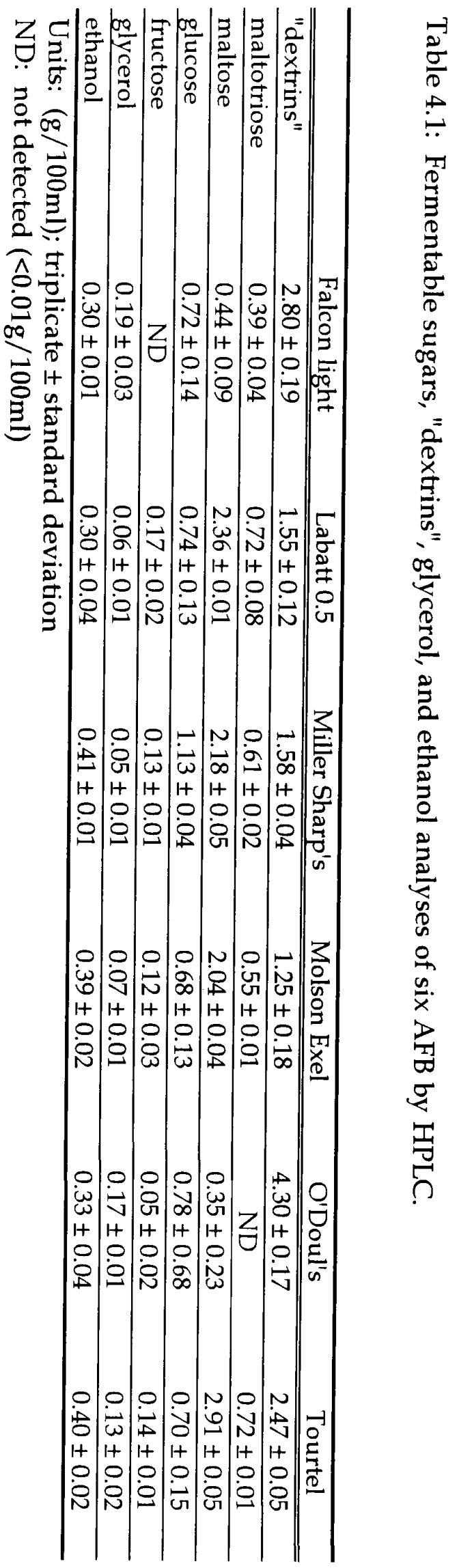




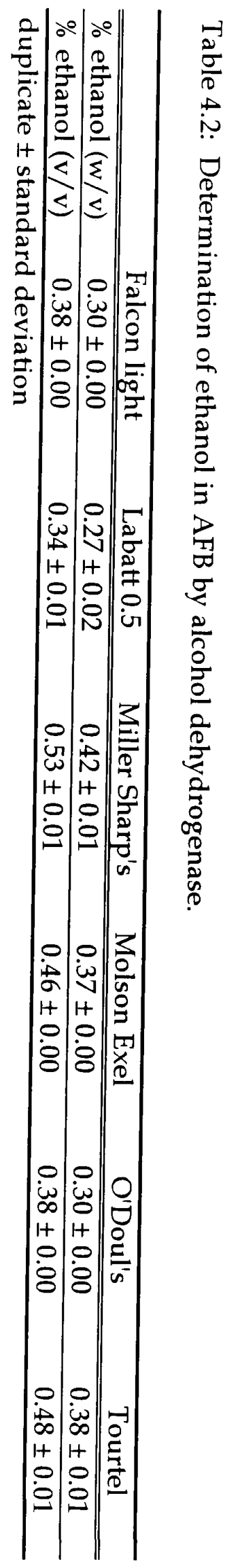




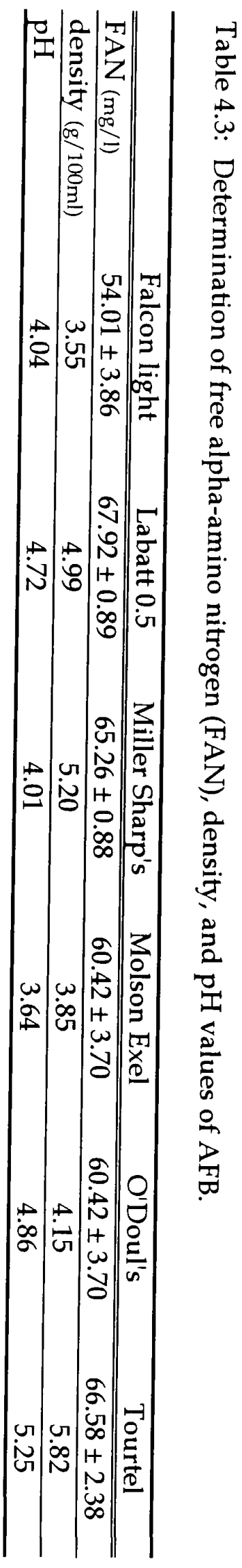


during pasteurization, but it may help injured cells to recover after heat treatment. FAN is also an assimilable source of nitrogen for growth of contaminating microbes.

The $\mathrm{pH}$ of the heating menstruum is an important factor affecting the thermal resistance of microorganisms. The Tourtel product had the highest $\mathrm{pH}$ (5.25) of the AFB samples analyzed. The combination of relatively high $\mathrm{pH}$, high FAN level and overall high carbohydrate content was selected as ideal for this study. Tourtel, therefore, represents a more protective and nutrient rich AFB. It is a suitable medium which should support growth for microbes and also a protective heating medium for heat resistant spoilage organisms. The selection of Tourtel resulted in automatic inclusion of Kronenbourg 5\% v/v alcohol beer for comparative study. The composition analysis information on the label of the cane was: Kronenbourg 1664, 5\% alc./vol.

\subsection{Composition of the heating menstrua}

The chemical compositions of the commercial $<0.5 \% \mathrm{AFB}$ and its $5 \% \mathrm{AB}$ counterpart are listed in Table 4.4. Some of the striking differences in composition which are known to effect heat resistance are evident. Notably the $\mathrm{pH}$ and the ethanol concentrations of $\mathrm{AB}$ and $\mathrm{AFB}$ are markedly different. According to the factors affecting heat resistance of microorganisms, described in section 2.6, the kinetic parameters of the four organisms tested (Lactobacillus delbrueckii, Pediococcus acidilactici, Escherichia coli 0157:H7 and Salmonella 


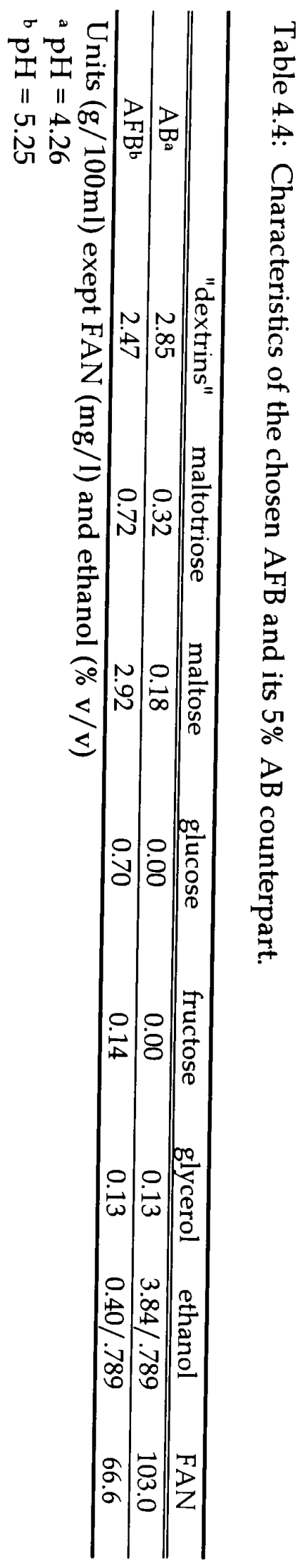


typhimurium), should be expected to show significant differences when heat treated in both menstrua.

\subsection{Survival curves and kinetic parameters of 4 microbes in AB and AFB}

\subsubsection{Lactobacillus delbrueckii (Miller Brewing Co.)}

Inspection of the survival curves of L. delbrueckii, in Figures 4.1 (AB) and 4.2 (AFB), indicated an initial shoulder or lag followed by straight line kinetics. Straight line kinetics illustrate the logarithmic death of vegetative cells due to moist heat ( $\mathrm{O}^{\prime} \mathrm{C}$ onnor-Cox et al., 1991). The controls at $25^{\circ} \mathrm{C}$ show that this microbe was well conditioned to the beer and did not die when inoculated into the heating medium under non-heat stressing conditions. The shoulder or lag phenomena can be accounted for on the basis of the multihit or multitarget model of viability loss (Hansen and Rieman, 1963; Ingram, 1969). This model is based on the assumption that many of the microbial cells are in chains, pairs or clumps (depending on strains) during heat treatment. Reduction in viable count is noted only when the viability of the last organism in each chain, pair or clump is destroyed. Cell cultures used in this work were monitored microscopically. Very little clumping was noted by microscope but in $L$. delbrueckii a number of chains were observed. The subsequent straight line kinetics represent death of single cells. To obtain a meaningful estimate of the rate of death of this organism, the straight line portion of the survival curves was used to calculate kinetic parameters (Appendix Tables 7.1 to 7.8). All 


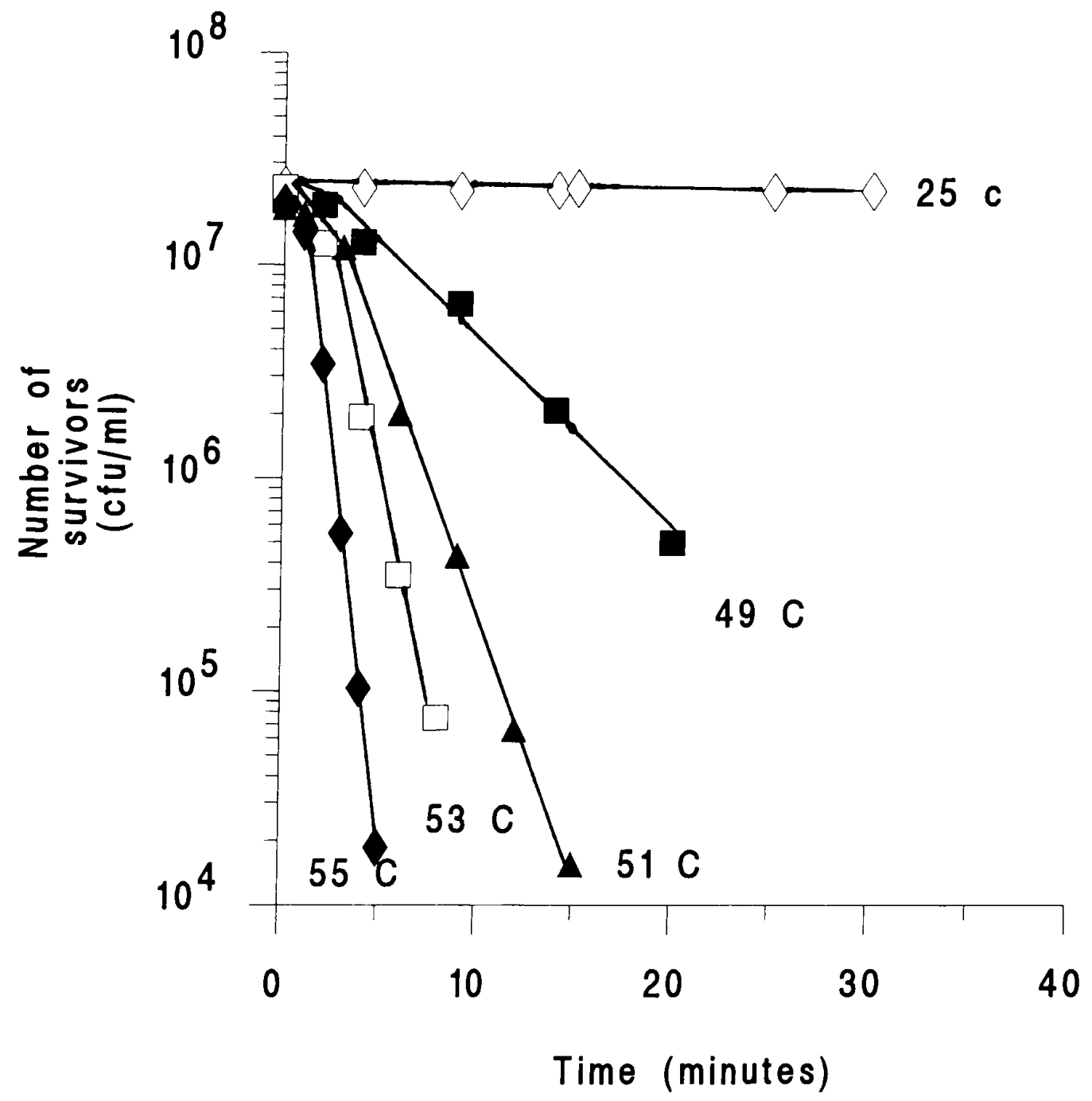

Fig 4.1: $\quad$ Survival curves of $L$. delbrueckii heated in AB. 


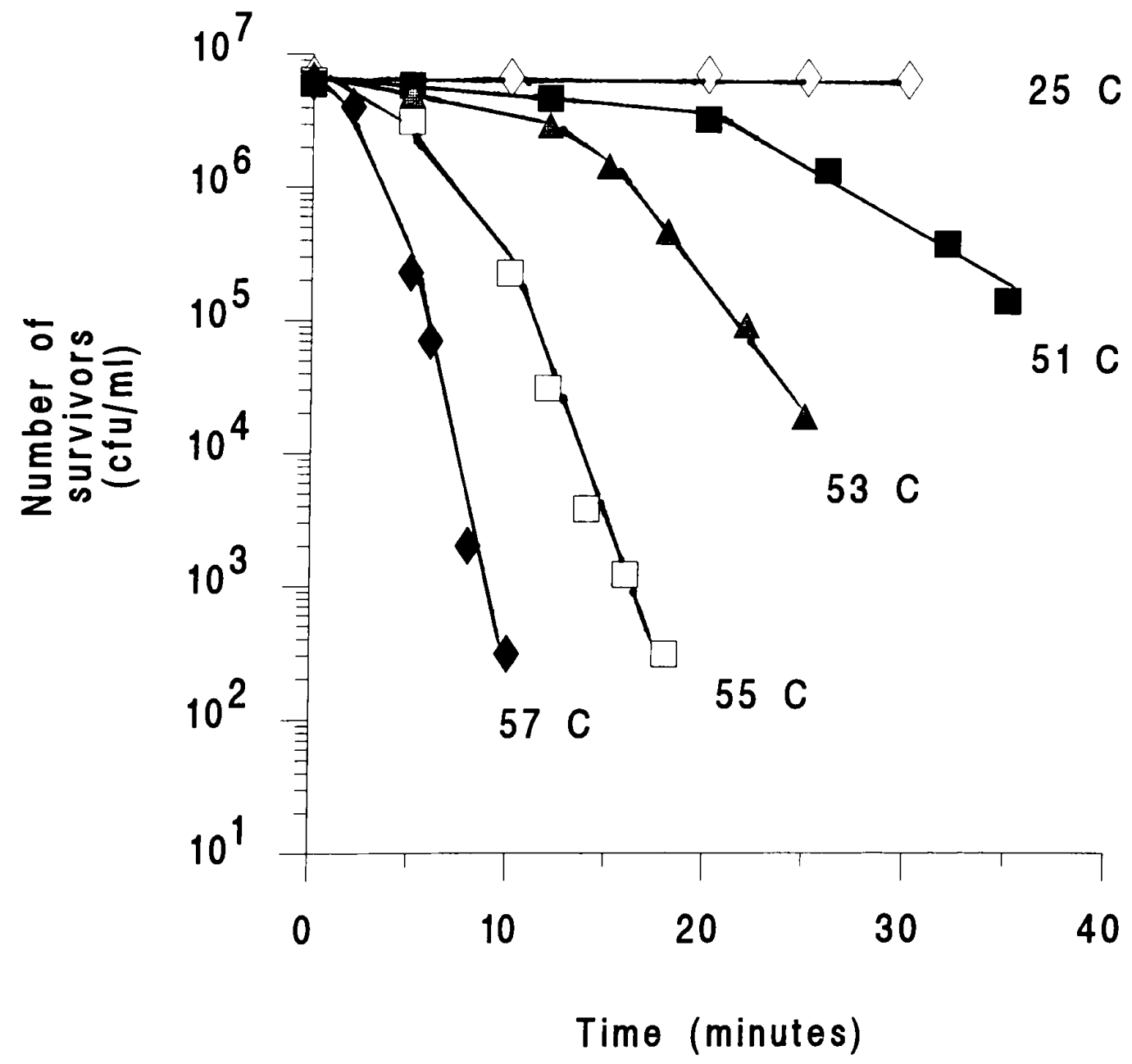

Fig 4.2: Survival curves of L. delbrueckii heated in AFB. 
survival curves showed good correlation between survivors $(\mathrm{cfu} / \mathrm{ml})$ and time (minutes). Correlation coefficients measure the degree of closeness of a linear relationship between the variables of the two axes. All correlation coefficients for the survival curves (Table 4.5 ) were within the range -0.9887 to -0.9991 . The close relationship between survivors and time is visually obvious in the figures.

Table 4.5 also shows the D values obtained and used to construct the phantom TDT curves (Figures 4.3). The phantom TDT curves for L. delbrueckii in $\mathrm{AB}$ and $\mathrm{AFB}$ have negative correlation coefficients of 0.9931-0.9845 (Table 4.6), and are linear with correlation coefficients between $D$ values and temperatures. Phantom TDT curves show how the D value changes with temperature. Thus, the accuracy of the phantom TDT curve is determined by D values obtained from the four survival curves. Since each $D$ value at a specific temperature contributes to the slope of the phantom TDT curve, any D value inaccurately determined will lead to deviations from the slope.

$D_{60}$ values (decimal reduction times at $60^{\circ} \mathrm{C}$ ), shown in Table 4.6 , as obtained in $\mathrm{AB}$ and $\mathrm{AFB}$, were 0.64 and 4.00 minutes. Lactobacillus delbrueckii demonstrates more than 6 times more heat resistance in AFB compared to AB. The same organism, tested in $\mathrm{AB}$ by M. Barney (Miller Brewing Co., personal communication) was reported to have a $D_{60}$ of approximately 2 minutes. The difference between the $D_{60}$ value determined by Barney and the $D_{60}$ value of this study may be due to how the organism was handled prior to the heat killing experiment, the type of growth medium used, the heating menstruum 
Table 4.5: $\quad$ Survival data for $L$. delbrueckii heated in $\mathrm{AB}$ and AFB.

\begin{tabular}{lcccc}
\hline & $\begin{array}{c}\text { Temperature } \\
\left({ }^{\circ} \mathrm{C}\right)\end{array}$ & $\begin{array}{c}\text { Slope of } \\
\text { survival curve } \\
(\mathrm{cfu} / \mathrm{min})\end{array}$ & $\begin{array}{c}\text { D value } \\
(\text { minutes })\end{array}$ & $\begin{array}{c}\mathrm{r} \\
\text { (correlation } \\
\text { coefficient of } \\
\text { survival curve) }\end{array}$ \\
\hline \hline $\mathrm{AB}$ & 51.14 & -0.0892 & 11.21 & -0.9887 \\
& 53.00 & -0.1692 & 5.91 & -0.9925 \\
& 54.95 & -0.3576 & 2.80 & -0.9924 \\
\hline $\mathrm{AFB}$ & 56.90 & -0.5365 & 1.86 & -0.9918 \\
& 51.14 & -0.0667 & 15.00 & -0.9929 \\
& 53.11 & -0.0917 & 10.91 & -0.9981 \\
& 55.00 & -0.1319 & 7.58 & -0.9890 \\
& 56.94 & -0.1508 & 6.63 & -0.9991 \\
\hline
\end{tabular}




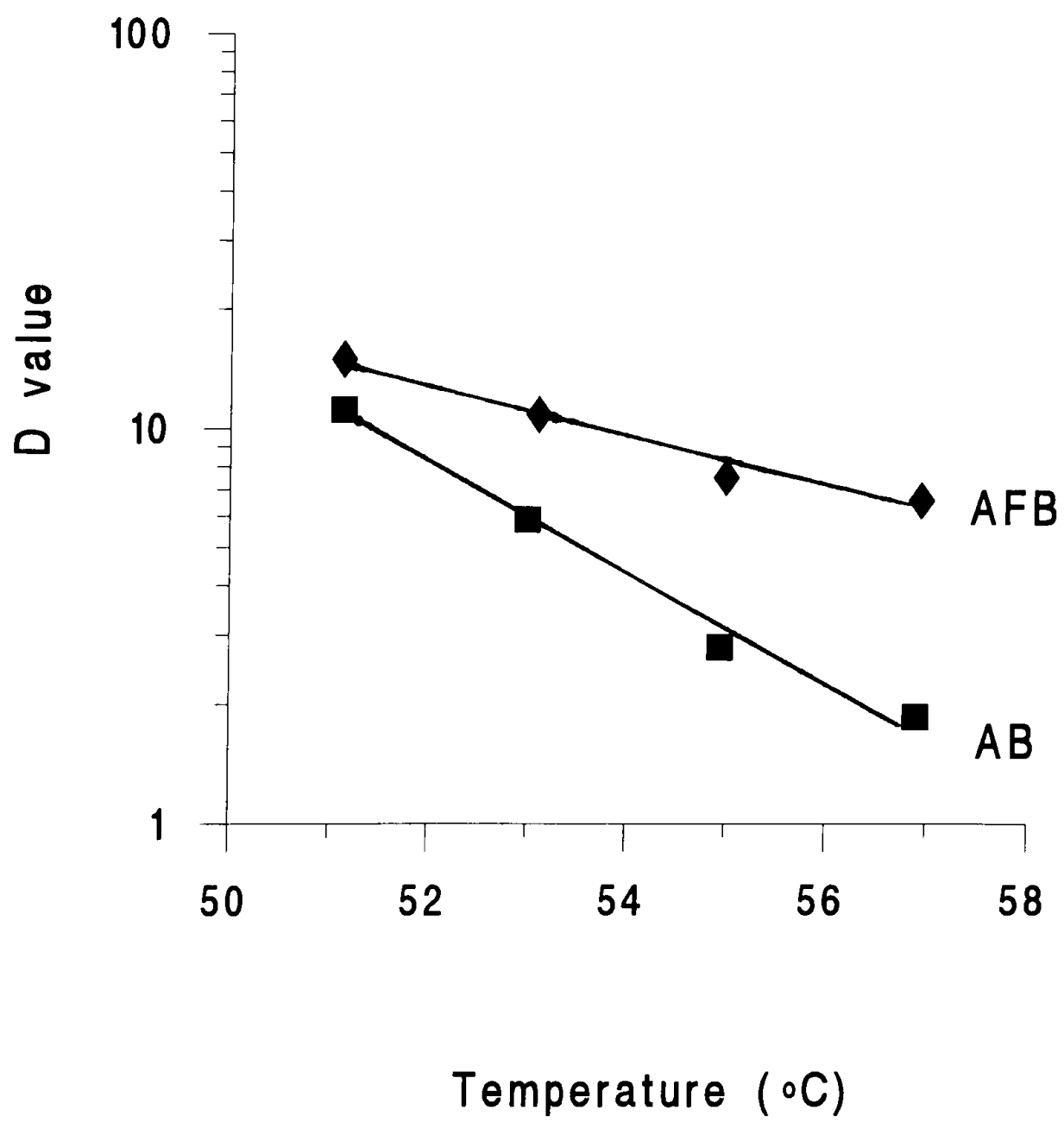

Fig 4.3: $\quad$ Phantom TDT curves for L. delbrueckii in AB and AFB. 
Table 4.6: $\quad$ Phantom TDT data for L. delbrueckii heated in AB and AFB.

\begin{tabular}{|c|c|c|c|c|c|c|c|}
\hline & $\log D$ & $\begin{array}{c}\text { Temp. } \\
\left({ }^{\circ} \mathrm{C}\right)\end{array}$ & $\begin{array}{c}\text { Slope of } \\
\text { phantom } \\
\text { TDT } \\
\text { curve }\end{array}$ & $\mathrm{Z}$ value & $\begin{array}{c}\mathbf{r} \\
\text { (correlation } \\
\text { coefficient } \\
\text { of phantom } \\
\text { TDT curve) } \\
\end{array}$ & $\begin{array}{l}\log \mathrm{D} \\
\text { at } 60^{\circ} \mathrm{C}\end{array}$ & $\begin{array}{c}\mathrm{D}_{60} \\
\text { (minutes) }\end{array}$ \\
\hline $\mathrm{AB}$ & $\begin{array}{l}1.0496 \\
0.7717 \\
0.4465 \\
0.2704 \\
\end{array}$ & $\begin{array}{l}51.14 \\
53.00 \\
54.95 \\
56.90 \\
\end{array}$ & -0.1384 & 7.23 & -0.9931 & -0.1961 & 0.64 \\
\hline$\overline{A F B}$ & $\begin{array}{l}1.1759 \\
1.0378 \\
0.8798 \\
0.8220 \\
\end{array}$ & $\begin{array}{l}51.14 \\
53.11 \\
55.00 \\
56.94 \\
\end{array}$ & -0.0632 & 15.82 & -0.9845 & 0.6026 & 4.01 \\
\hline
\end{tabular}


and the physiological age of the organism. Details on the experiments run at Miller have not been reported.

\subsubsection{Pediococcus acidilactici NCIB \#6990}

The survival curves of $P$. acidilactici $\mathrm{NCIB} \# 6990$ in AFB and AB are shown in Figures 4.4 and 4.5. Semilog plots of the number of survivors vs. time gave straight lines with negative correlation coefficients of 0.9918 to 0.9999 (Table 4.7). Control experiments at $25^{\circ} \mathrm{C}$, performed for the 4 organisms tested, ensured that resuspension of the organisms into $A B$ and $A F B$ did not result in perceptible death under non-heat stressing conditions. Like L. delbrueckii, cultured cells of $P$. acidilactici were microscopically checked; a number a tetrads were observed. Therefore, of each cell in a tetrad has to be killed before the loss of one colony forming unit would be noted. This explained the initial "shoulder" or lag phase noted in the survival curves with Pediococcus.

Pediococcus acidilactici NCIB \#6990 was reported by Tsang (1981) and Tsang and Ingledew (1982) to be the most heat resistant organism studied to that date in a $5 \%$ alcohol beer menstruum, with a $D_{60}$ value of 0.867 minute. In this study, similar and significant heat resistance was again found. Table 4.8 shows extrapolated $D_{60}$ values, obtained from the two phantom TDT curves (Figures 4.6) in $\mathrm{AB}$ and $\mathrm{AFB}$. They were respectively 1.33 and 7.66 minutes. $P$. acidilactici is the most heat resistant microbe in $\mathrm{AB}$ as well as in $\mathrm{AFB}$. The time required to kill this microbe is significant in relation to the desired use of 


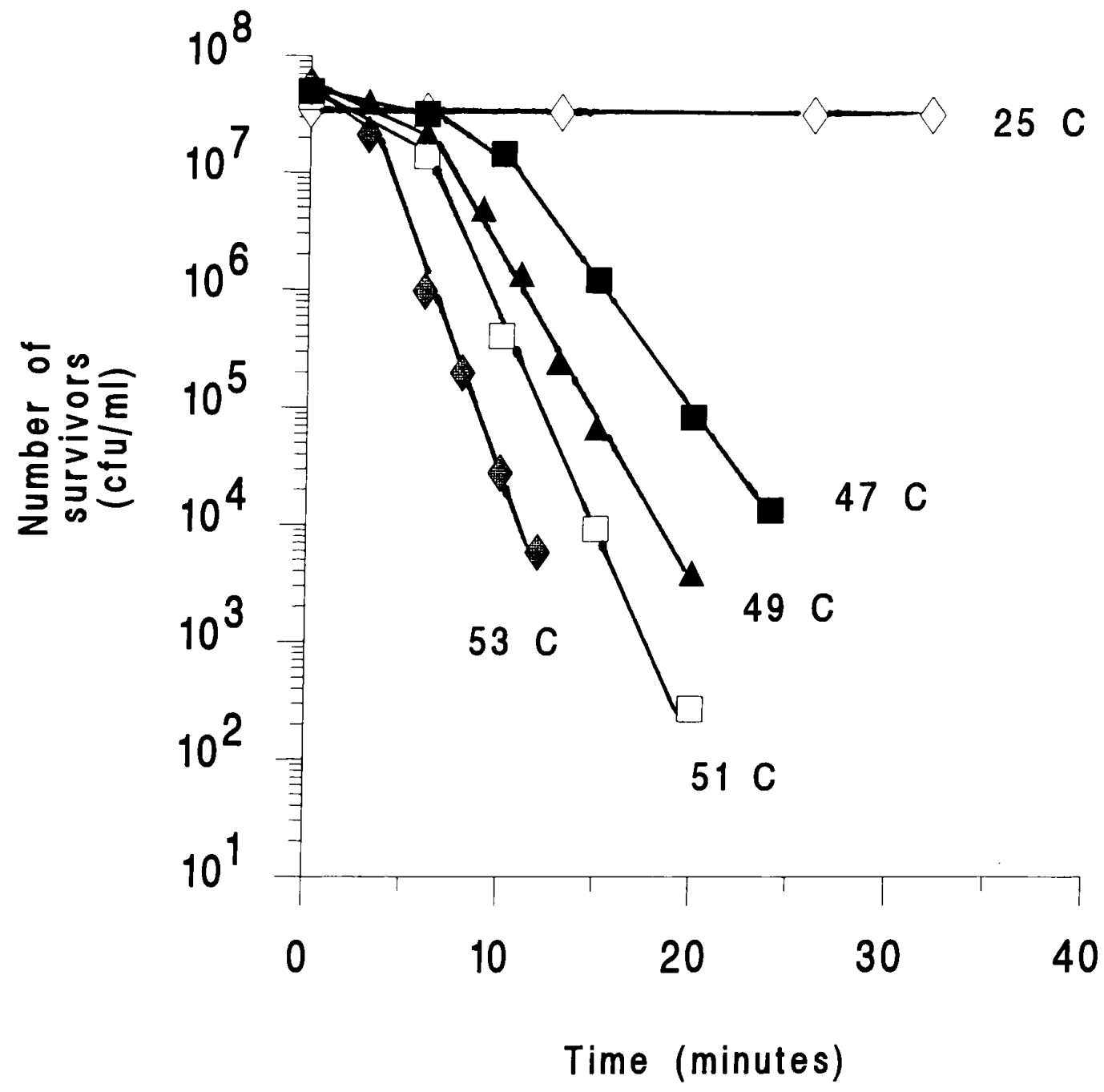

Fig 4.4: $\quad$ Survival curves of P. acidilactici NCIB \#6990 heated in AB. 


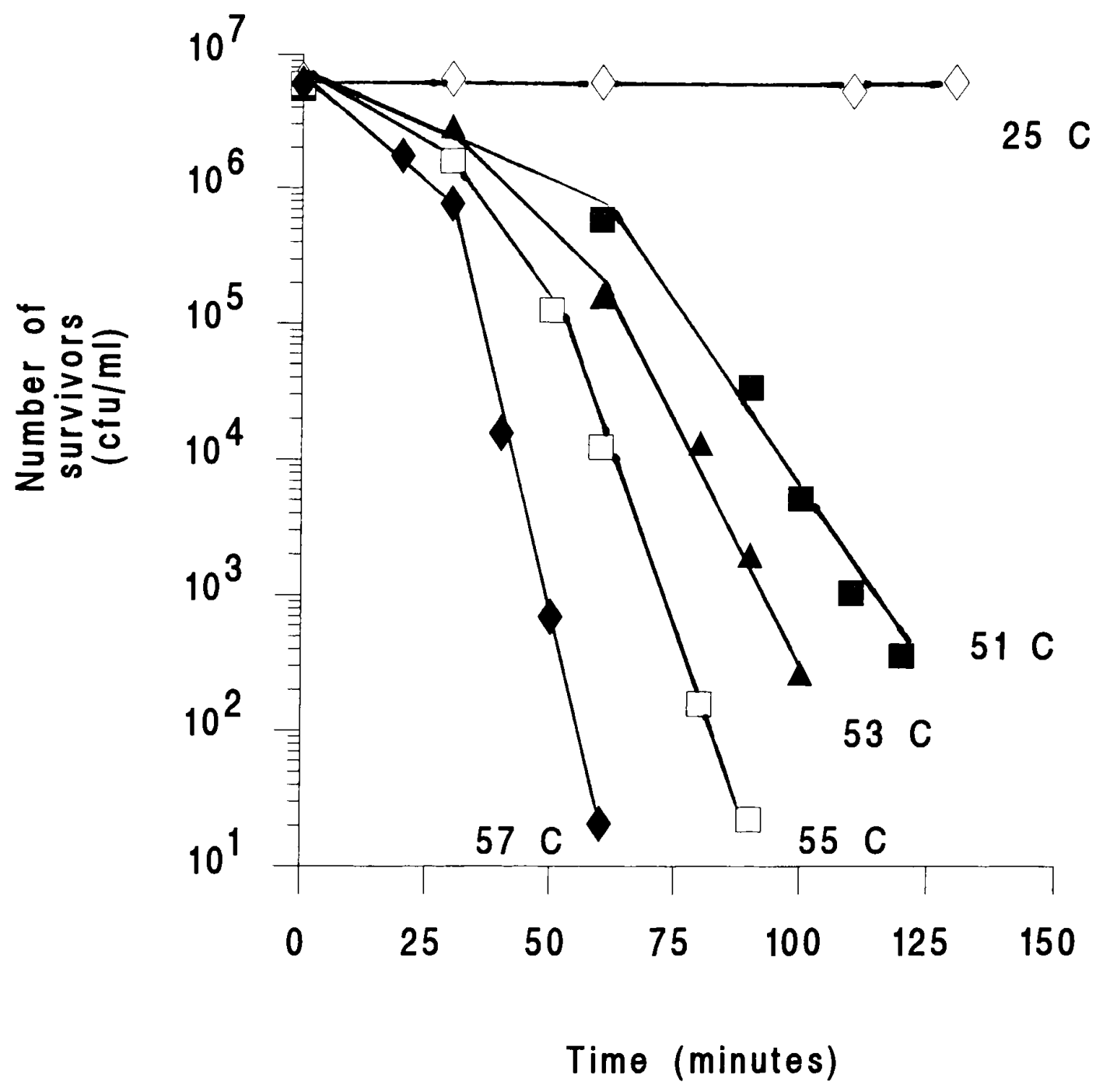

Fig 4.5: $\quad$ Survival curves of $P$. acidilactici NCIB \#6990 heated in AFB. 
Table 4.7:

Survival data for P. acidilactici in $\mathrm{AB}$ and AFB.

\begin{tabular}{lcccc}
\hline & $\begin{array}{c}\text { Temperature } \\
\left({ }^{\circ} \mathrm{C}\right)\end{array}$ & $\begin{array}{c}\text { Slope of } \\
\text { survival curve } \\
(\mathrm{cfu} / \text { minute) }\end{array}$ & $\begin{array}{c}\text { D value } \\
\text { (minutes) }\end{array}$ & $\begin{array}{c}\mathrm{r} \\
\text { (correlation } \\
\text { coefficient of } \\
\text { survival curve) }\end{array}$ \\
\hline \hline $\mathrm{AB}$ & 47.01 & -0.2190 & 4.57 & -0.9995 \\
& 49.22 & -0.2842 & 3.52 & -0.9968 \\
& 51.09 & -0.3350 & 2.99 & -0.9999 \\
\hline $\mathrm{AFB}$ & 53.26 & -0.3941 & 2.54 & -0.9990 \\
\hline & 49.19 & -0.0785 & 12.73 & -0.9988 \\
& 51.01 & -0.0875 & 11.43 & -0.9999 \\
& 53.03 & -0.0916 & 10.91 & -0.9946 \\
& 54.98 & -0.1046 & 9.56 & -0.9918 \\
\hline
\end{tabular}


Table 4.8: $\quad$ Phantom TDT data for P. acidilactici heated in AB and AFB.

\begin{tabular}{|c|c|c|c|c|c|c|c|}
\hline & $\log D$ & $\begin{array}{c}\text { Temp. } \\
\left({ }^{\circ} \mathrm{C}\right)\end{array}$ & $\begin{array}{c}\text { Slope of } \\
\text { phantom } \\
\text { TDT } \\
\text { curve }\end{array}$ & $Z$ value & $\begin{array}{c}\mathbf{r} \\
\text { (correlation } \\
\text { coefficient } \\
\text { of phantom } \\
\text { TDT curve) } \\
\end{array}$ & $\begin{array}{l}\log \mathrm{D} \\
\text { at } 60^{\circ} \mathrm{C}\end{array}$ & $\overline{D_{60}}$ \\
\hline$\overline{\mathrm{AB}}$ & $\begin{array}{l}0.6596 \\
0.5464 \\
0.4750 \\
0.4044 \\
\end{array}$ & $\begin{array}{l}47.01 \\
49.22 \\
51.09 \\
53.26 \\
\end{array}$ & -0.0406 & 24.61 & -0.9939 & 0.1229 & 1.33 \\
\hline$\overline{A F B}$ & $\begin{array}{l}1.1049 \\
1.0580 \\
1.0380 \\
0.9804\end{array}$ & $\begin{array}{l}49.19 \\
51.01 \\
53.03 \\
54.98\end{array}$ & -0.0203 & 49.26 & -0.9835 & 0.8843 & 7.66 \\
\hline
\end{tabular}




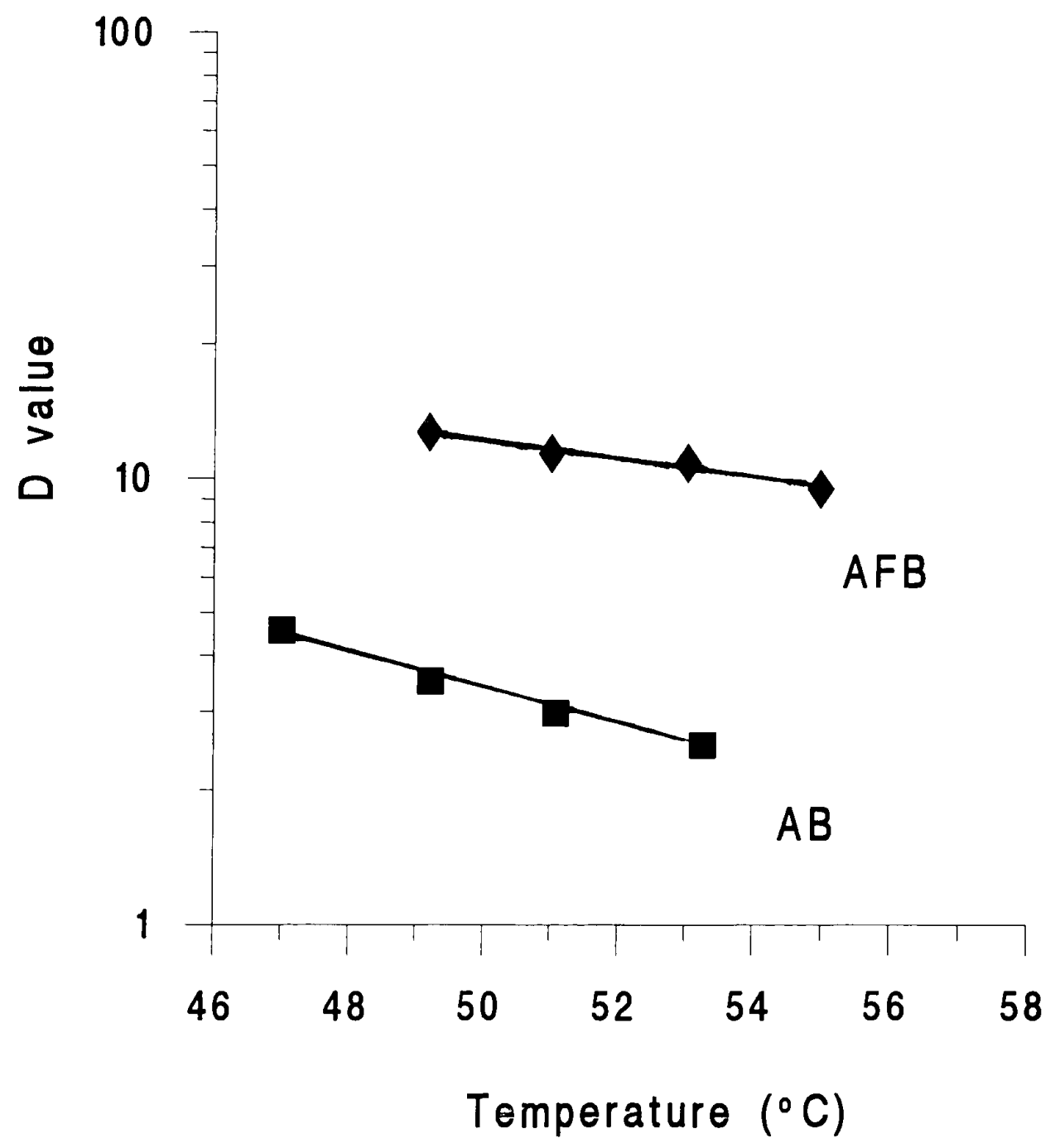

Fig 4.6: $\quad$ Phantom TDT curves for F. acidilactici NCIB \#6990 in AB and AFB. 
pasteurization to provide freedom of spoilage to brewers. Moreover, this organism shows a 7 fold increase in the time required to affect one logarithmic reduction in cell number in $A F B$ compared to regular $A B$. The large $Z$ values of $P$. acidilactici indicate a "closer to horizontal" slope. This results in the line crossing other phantom TDT curves (Figure 4.7) and leads to this organism in AFB being less resistant than Lactobacillus at temperature under $53^{\circ} \mathrm{C}$ but more resistant than Lactobacillus at temperature over $53^{\circ} \mathrm{C}$. Tsang and Ingledew (1982) have addressed this problem with hypothetical examples.

\subsubsection{Escherichia coli 0157:H7 ATCC \#43889}

The Figures 4.8 and 4.9 show the survival curves of $E$. coli 0157:H7 ATCC \#43889 when heated in $\mathrm{AB}$ and $\mathrm{AFB}$ at temperature of $45^{\circ} \mathrm{C}$ to $51^{\circ} \mathrm{C}$ and $49^{\circ} \mathrm{C}$ to $55^{\circ} \mathrm{C}$ respectively. Table 4.9 shows excellent correlation coefficients for all survival curves and for the $D$ values obtained at each temperature in each medium. Very small shoulders are present in survival curves when cells of $E$. coli were heated in AFB. In fact a number of pairs of $E$. coli cells were observed microscopically in $\mathrm{NB}+10 \% \mathrm{AFB}$ and $\mathrm{NB}+10 \% \mathrm{AB}$ prior the heat kill experiments. However survival curves in $\mathrm{AB}$ do not graphically portray such

shoulders. The two ranges of temperatures for the heat kill experiments give an indication of the sensitivity of this pathogen when heated in presence of ethanol, and its increased resistance when processed in a product of higher $\mathrm{pH}$ and very low ethanol concentration. As heating temperature increased, cell 


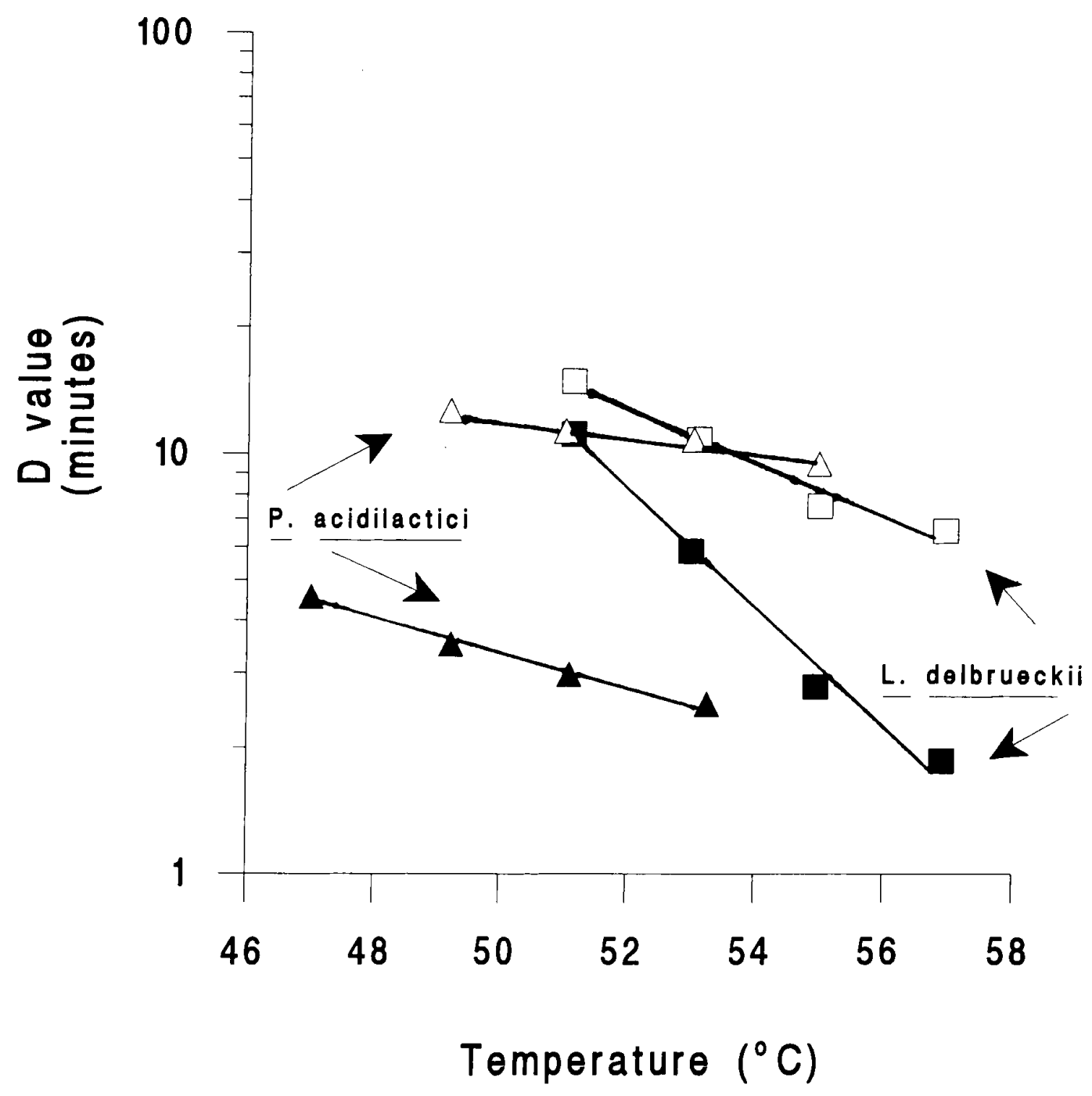

Fig 4.7: $\quad$ Phantom TDT curves for L. delbrueckii and P. acidilactici in AB (closed symbols) and AFB (opened symbols). 


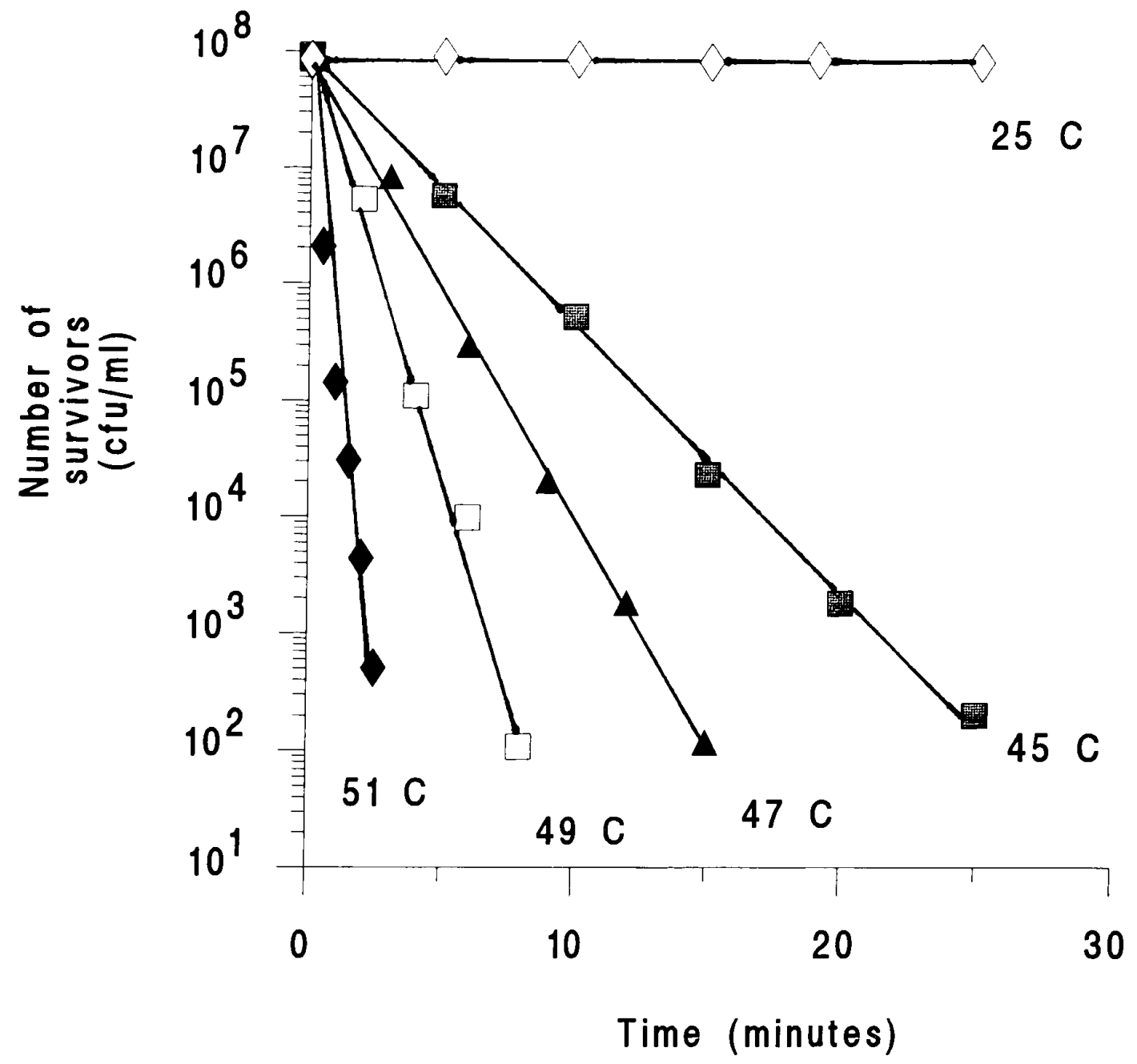

Fig 4.8: $\quad$ Survival curves of E. coli 0157:H7 ATCC \#43889 heated in AB. 


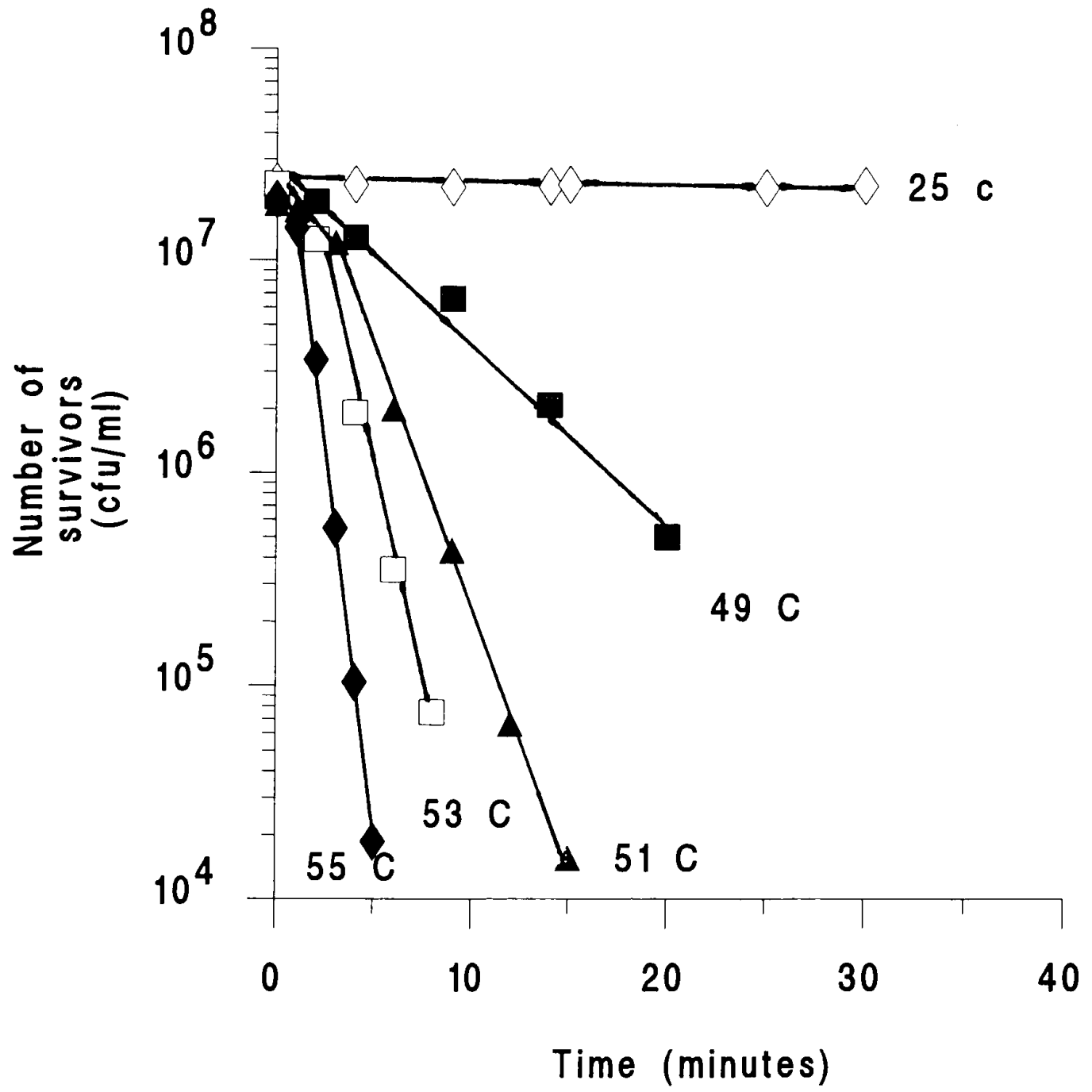

Fig 4.9: $\quad$ Survival curves of E. coli 0157:H7 ATCC \#43889 heated in AFB. 
Table 4.9: $\quad$ Survival data for E. coli 0157:H7 heated in AB and AFB.

\begin{tabular}{lcccc}
\hline & $\begin{array}{c}\text { Temperature } \\
\left({ }^{\circ} \mathrm{C}\right)\end{array}$ & $\begin{array}{c}\text { Slope of } \\
\text { survival curve } \\
\text { (cfu/minute) }\end{array}$ & $\begin{array}{c}\text { D value } \\
\text { (minutes) }\end{array}$ & $\begin{array}{c}\mathbf{r} \\
\text { (correlation } \\
\text { coefficient of } \\
\text { survival curve) }\end{array}$ \\
\hline \hline $\mathrm{AB}$ & 45.03 & -0.2438 & 4.10 & -0.9936 \\
& 47.02 & -0.5146 & 1.94 & -0.9944 \\
& 49.07 & -1.2433 & 0.80 & -0.9977 \\
$\mathrm{AFB}$ & 50.75 & -1.8182 & 0.55 & -0.9714 \\
\hline 49.16 & -0.1120 & 8.93 & -0.9981 \\
& 51.11 & -0.2279 & 4.39 & -0.9963 \\
& 52.98 & -0.3700 & 2.70 & -0.9991 \\
& 54.99 & -0.7270 & 1.38 & -0.9994 \\
\hline
\end{tabular}


injury and death occurred more quickly and there was a more immediate reduction in cell viability. At higher temperatures, the shoulders of survival curves, almost disappeared (Fig. 4.9). The absence of perceptible shoulders in curves from $A B$ may be attributed to the faster death of the cells occurring in a media of low $\mathrm{pH}$ and high alcohol content.

In Figure 4.10, in can be seen that $E$. coli 0157:H7 is much more resistant in $A F B$ than in $A B$. This is verified by examining the $D_{60}$ values extrapolated from data in Table 4.10. The $\mathrm{D}_{60}$ values obtained by extrapolation (by calculator) were 0.02 and 0.28 minute for E. coli $0157: \mathrm{H} 7$ in $\mathrm{AB}$ and $\mathrm{AFB}$. Although the organism demonstrates 17 times more heat resistance in AFB than in $A B$, it does not represent a risk when $A F B$ is pasteurized. It is very important to note that at the temperature of significance to brewers (i.e. $60^{\circ} \mathrm{C}$ ) (the pasteurization temperature), this organism is particularly heat sensitive.

\subsubsection{Salmonella typhimurium ATCC \#14028}

Survival curves for S. typhimurium ATCC \#14028 in AB and AFB are shown in Figures 4.11 and 4.12. These curves show typical first order kinetics with classical straight line responses. A straight line response indicates the uniformity of rate of death and the homogeneity of the organism in response to heat (Stumbo, 1976). All survival curves, as calculated by the linear regression method, showed correlation coefficients within the range of 0.9884-0.9991 (Table 4.11). Table 4.12 shows $D_{60}$ values of 0.01 and 0.03 (in minutes), for Salmonella in 


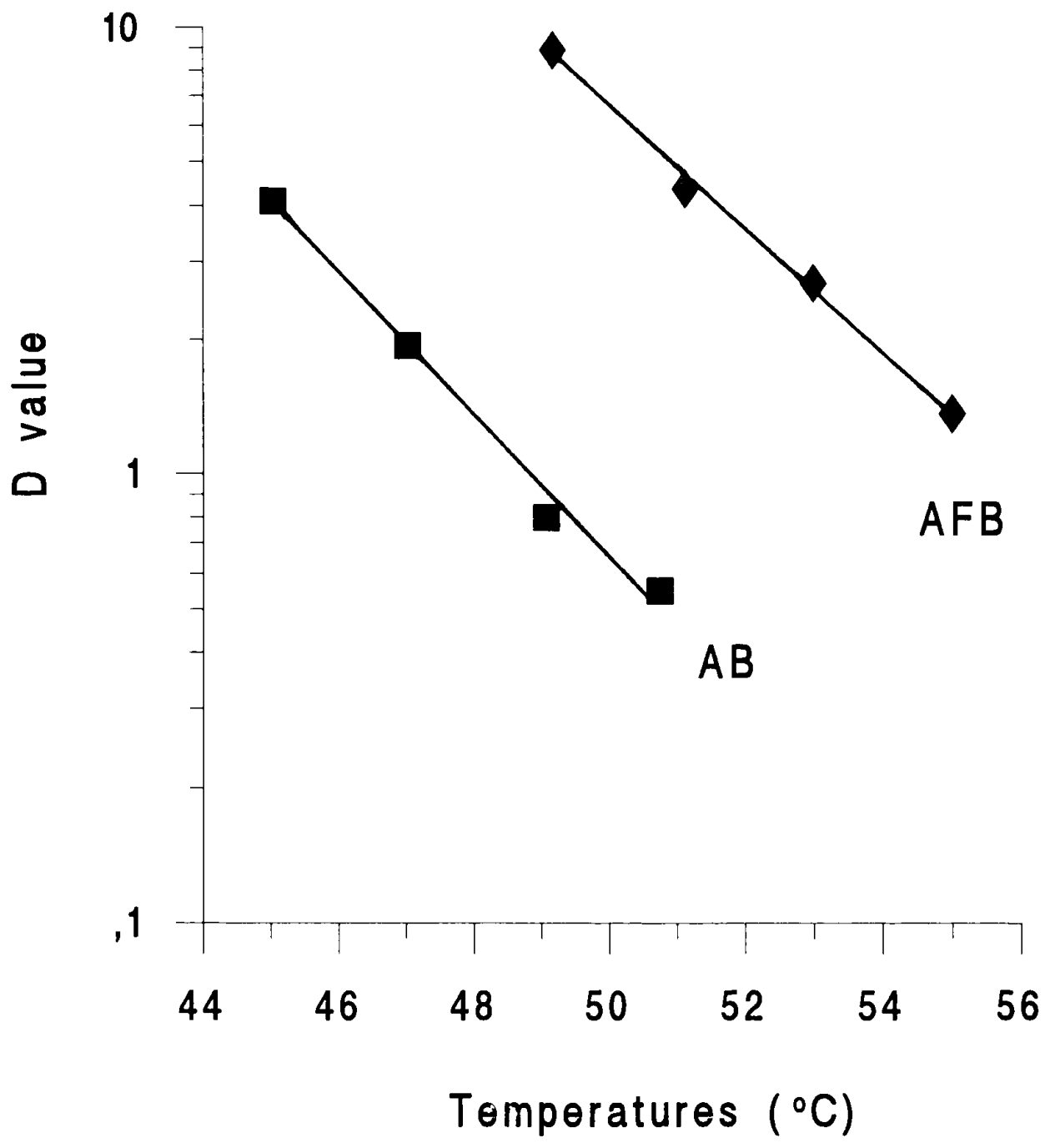

Fig 4.10: Phantom TDT curves for E. coli 0157:H7 ATCC \#43889 in AB and AFB. 
Table 4.10: Phantom TDT data for E. coli 0157:H7 heated in AB and AFB.

\begin{tabular}{|c|c|c|c|c|c|c|c|}
\hline & $\log D$ & $\begin{array}{c}\text { Temp. } \\
\left({ }^{\circ} \mathrm{C}\right)\end{array}$ & $\begin{array}{c}\text { Slope of } \\
\text { phantom } \\
\text { TDT } \\
\text { curve }\end{array}$ & $Z$ value & $\begin{array}{c}\mathbf{r} \\
\text { (correlation } \\
\text { coefficient } \\
\text { of phantom } \\
\text { TDT curve) } \\
\end{array}$ & $\begin{array}{l}\log D \\
\text { at } 60^{\circ} \mathrm{C}\end{array}$ & $\mathrm{D}_{60}$ \\
\hline$\overline{A B}$ & $\begin{array}{r}0.6129 \\
0.2885 \\
-0.0946 \\
-0.2596 \\
\end{array}$ & $\begin{array}{l}45.03 \\
47.02 \\
49.07 \\
50.75 \\
\end{array}$ & -0.1569 & 6.37 & -0.9943 & -1.7512 & 0.02 \\
\hline AFB & $\begin{array}{l}0.9508 \\
0.6422 \\
0.4318 \\
0.1385\end{array}$ & $\begin{array}{l}49.16 \\
51.11 \\
52.98 \\
54.99\end{array}$ & -0.1368 & 7.31 & -0.9982 & -0.5455 & 0.28 \\
\hline
\end{tabular}




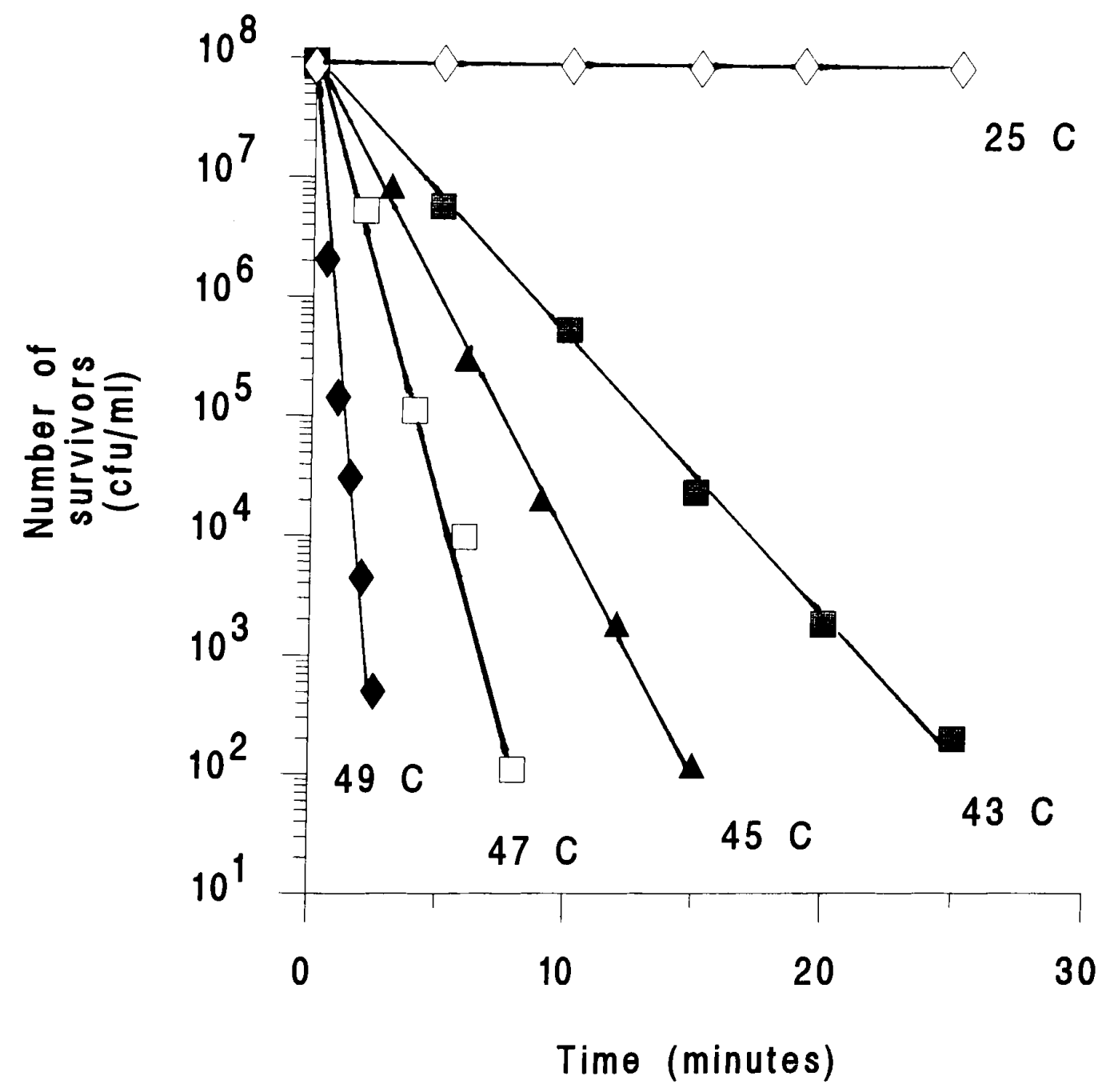

Fig 4.11: Survival curves of S. typhimurium ATCC \#14028 heated in AB. 


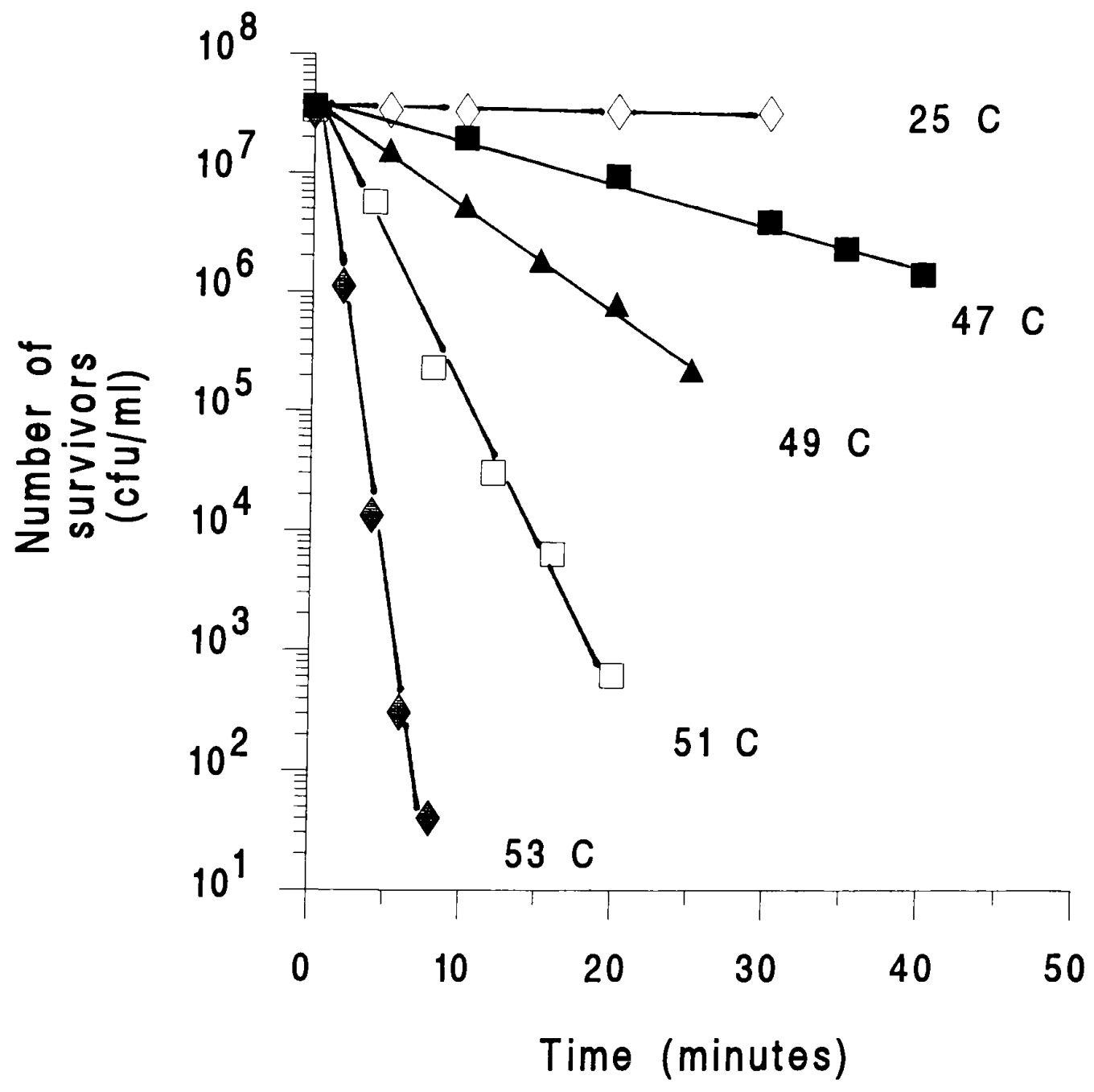

Fig 4.12: $\quad$ Survival curves of S. typhimurium ATCC \#14028 heated in AFB. 
Table 4.11: $\quad$ Survival data for S. typhimurium heated in AB and AFB.

\begin{tabular}{ccccc}
\hline & $\begin{array}{c}\text { Temperature } \\
\left({ }^{\circ} \mathrm{C}\right)\end{array}$ & $\begin{array}{c}\text { Slope of } \\
\text { survival curve } \\
\text { (cfu/minute) }\end{array}$ & $\begin{array}{c}\text { D value } \\
\text { (minutes) }\end{array}$ & $\begin{array}{c}\mathbf{r} \\
\text { (correlation } \\
\text { coefficiet of } \\
\text { survival curve) }\end{array}$ \\
\hline \hline $\mathrm{AB}$ & 43.17 & -0.2292 & 4.36 & -0.9991 \\
& 45.00 & -0.3942 & 2.54 & -0.9990 \\
& 47.1 & -0.7299 & 1.37 & -0.9962 \\
$\mathrm{AFB}$ & 49.16 & -1.9851 & 0.50 & -0.9892 \\
\hline 47.14 & -0.0346 & 28.90 & -0.9958 \\
& 49.22 & -0.0873 & 11.45 & -0.9988 \\
& 51.18 & -0.2743 & 3.65 & -0.9884 \\
& 53.08 & -0.7710 & 1.30 & -0.9938 \\
\hline
\end{tabular}


Table 4.12: Phantom TDT data for S. typhimurium heated in AB and AFB.

\begin{tabular}{|c|c|c|c|c|c|c|c|}
\hline & $\log D$ & $\begin{array}{c}\text { Temp. } \\
\left({ }^{\circ} \mathrm{C}\right)\end{array}$ & $\begin{array}{c}\text { Slope of } \\
\text { phantom } \\
\text { TDT } \\
\text { curve }\end{array}$ & $Z$ value & $\begin{array}{c}\mathbf{r} \\
\text { (correlation } \\
\text { coefficient } \\
\text { of phantom } \\
\text { TDT curve) }\end{array}$ & $\begin{array}{l}\log D \\
\text { at } 60^{\circ} \mathrm{C}\end{array}$ & $\begin{array}{c}\mathrm{D}_{60} \\
\text { (minutes) }\end{array}$ \\
\hline$\overline{\mathrm{AB}}$ & $\begin{array}{c}0.6398 \\
0.4043 \\
0.1367 \\
-0.2978 \\
\end{array}$ & $\begin{array}{l}43.17 \\
45.00 \\
47.17 \\
49.16 \\
\end{array}$ & -0.1530 & 6.53 & -0.9897 & -1.9024 & $\overline{0.01}$ \\
\hline$\overline{\mathrm{AFB}}$ & $\begin{array}{l}1.4609 \\
1.0588 \\
0.5618 \\
0.1129\end{array}$ & $\begin{array}{l}47.14 \\
49.22 \\
51.18 \\
53.08\end{array}$ & -0.2293 & 4.36 & -0.9985 & -1.4593 & 0.03 \\
\hline
\end{tabular}


$\mathrm{AB}$ and $\mathrm{AFB}$ respectively. Figure 4.13 shows the phantom TDT curves used to extrapolate the decimal reduction times at $60^{\circ} \mathrm{C}$. This organism demonstrated similar heat resistance as seen with $E$. coli $0157: \mathrm{H} 7$ in $\mathrm{AB}$. Its heat resistance in AFB showed a three fold increase in the time required to reduce the population by one log. Like E. coli $0157: \mathrm{H} 7$, S. typhimurium is very sensitive to heat and does not survive pasteurization temperatures used in brewing even over very short time intervals.

\subsection{Pasteurization of $\mathrm{AB}$ and $\mathrm{AFB}$}

In order to see if laboratory results could be used to predict industrial pasteurization, heat killing experiments and simulated pasteurization were conducted by Tsang (1981). The two sets of results appeared to be similar and the author concluded that laboratory values could be used to predict industrially oriented pasteurization.

To set pasteurization parameters for $\mathrm{AB}$ and $\mathrm{AFB}$, the brewing industry should use the most thermoresistant contaminants that can be found in brewing products. P. acidilactici NCIB \#6990 was found to be the most resistant organism in $A B$ (Tsang, 1981), and it was also the most heat resistant organism observed in this study in both $\mathrm{AB}$ and $\mathrm{AFB}$. P. acidilactici should receive great attention since it took 1 minute and 19 seconds and 7 minutes and 40 seconds, respectively, at $60^{\circ} \mathrm{C}$ to kill $1 \log$ of cells in $\mathrm{AB}$ and $\mathrm{AFB}$. The time-temperature relationship of pasteurization should be adjusted to effectively destroy such 


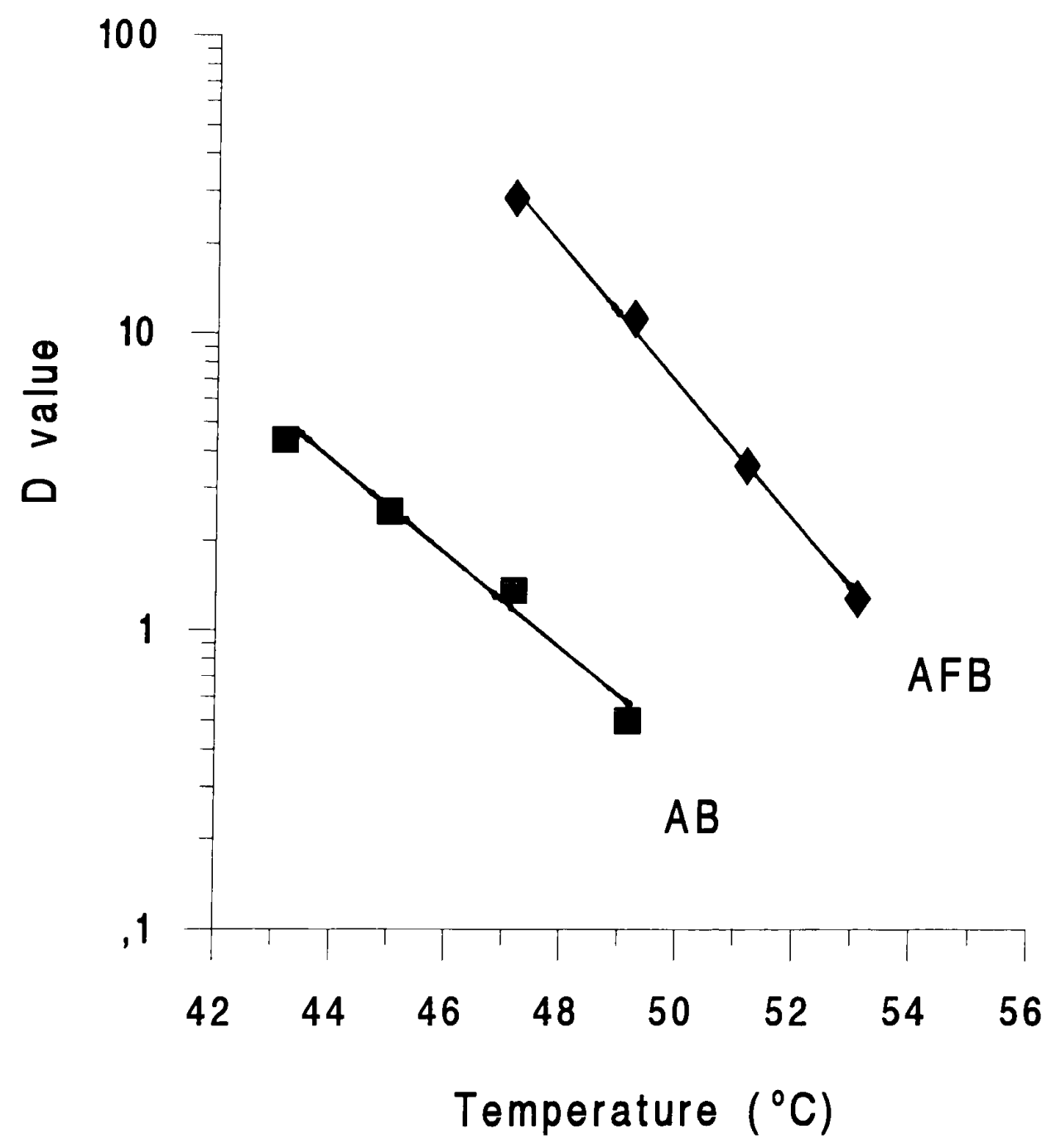

Fig 4.13: Phantom TDT curves for S. typhimurium ATCC \#14028 in AB and AFB. 
heat resistant organisms. Calculations based on the most resistant microbe(s) usually encountered in a plant or chain of breweries, led to the recommendation of the use of a term called the inactivation factor as an alternative approach in pasteurization of beer (Tsang, 1981; Tsang and Ingledew, 1982). This inactivation factor (IF) describes the degree of reduction in the number of viable organisms (Russell, 1971).

$$
\mathrm{IF}=10^{\text {(treatment dose } / \mathrm{D} \text { value })}
$$

From the example given by Tsang (1981), if the organism tested is $P$. acidilactici $\mathrm{NCIB} \# 6990$, with $\mathrm{D}_{60}$ values of 1.33 and 7.66 minutes in $\mathrm{AB}$ and $\mathrm{AFB}$ (as found in this study), and the total treatment dose for both products is 15 minutes (including fractional D values at each temperature of the heating, cooling and holding time), then the IF would respectively be $10^{11}$ and $10^{2}$. Unsing the formula below, if the average number of organisms per bottle is 1000 or less, this treatment should result in protection of $>10^{8}$ bottles of $A B$ before one bottle of $A B$ might be found unpasteurized.

Degree of sterility $=\mathrm{IF} /$ (average number of organisms per bottle)

However, with the assumptions above but with $\mathrm{AFB}$, the same treatment would result in protection of $>10^{-1}$ bottle of AFB. In other words 10 bottles of AFB might be found unpasteurized for each bottle of AFB adequately protected. This type of consideration illustrates clearly how the pasteurization parameters required for biological stability have changed for normal $5 \%$ alcohol beer 
compared to its alcohol-free $(0.5 \%)$ counterpart. The consequences of the differences in chemical composition of the commercial 5\% AB and its AFB counterpart in relation to their impact on pasteurization are evident.

\subsection{Microbial stability of commercial AFB}

Preliminary tests were conducted to see if pathogens were able to grow in the AFB chosen for the heat killing studies (Appendix Figures 7.13-7.23). These figures demonstrate that several pathogens or opportunistic pathogens may, if present in the wort, survive and even grow during the "brewing process" of AFB. If inadequate pasteurization (or filtration) of beer occured, they would also grow in the packaged product. Incomplete inhibition of growth from the constituents and metabolic products of yeast made during the brewing process was evident. Escherichia coli 0157:H7 ATCC \#43889, one of the eleven organisms tested, was identified in apple cider as the causative agent in an outbreak of diarrhea and hemolytic uremic syndrome (Besser et al., 1992) and is characterized by its exceptional tolerance to acidic $\mathrm{pH}$ values (Zhao et al., 1993; Miller and Kaspar, 1994). Consumption of apple cider contaminated with Salmonella typhimurium ATCC \#14028 resulted of an outbreak of salmonellosis (Anonymous, 1975). These two pathogens grew well in AFB. Others like Shigella flexneri, Pseudomonas aeruginosa, Klebsiella pneumoniae, and Yersinia enterocolitica showed, to different degrees, an ability to multiply in AFB. 
This is the first report on the growth of pathogens or opportunistic pathogens in AFB. Further studies are needed to assess the microbial stability of commercial AFB regarding pathogens and other microbial contaminants. Growth tests would need to be performed under different conditions, notably using other brands of $\mathrm{AFB}$, in the presence of dissolved $\mathrm{CO}_{2}$, and at different temperatures of incubation, and to evaluate, for example, the storage of AFB at cold temperatures. Contaminants isolated from spoiled and underpasteurized AFB need to be identified and studied for their heat resistance and growth characteristics.

Of particular concern is that the growth of the above potentially pathogenic bacteria occurs in $0.5 \%$ alcohol beer. Brewers also produce beer with less than $0.1 \%$ alcohol. Such products have not been examined in this work for their ability to support the growth of microbes not normally seen in brewery products, and no detailed and comprehensive heat killing experiments have been reported on them.

Until such time as the above research is complete, it is recommended that production of draft AFB should not be considered, and that bottled draft AFB (where conditions of storage are not controllable) should not be not packaged. This would include the bottling of AFB after filtration. 


\section{CONCLUSIONS}

1. P. acidilactici NCIB \#6990 demonstrated significant heat resistance in $5 \%$ $A B$ and the results are similar to those reported by Tsang and Ingledew (1982). This Pediococcus strain was the most resistant microbe tested in $\mathrm{AB}$ of the four microbes examined in this project, and also the most heat resistant in the chosen $\mathrm{AFB}$.

2. E. coli $0157: \mathrm{H7}$ and S. typhimurium were 17 and 3 times more heat resistant at $60^{\circ} \mathrm{C}$ in $\mathrm{AFB}$ than in $\mathrm{AB}$ respectively. The pasteurization temperature normally used by brewers is $60^{\circ} \mathrm{C}$. L. delbrueckii and $P$. acidilactici showed an increased resistance to heat $\left(60^{\circ} \mathrm{C}\right)$ of 4 to 7 fold in AFB compared to AB.

3. Because of their very low $D_{60}$ values, pathogens do not represent a risk in pasteurized AFB. However, the industry is cautioned about bottled draft AFB prepared using filtration instead of pasteurization. AFB products with much less than $0.5 \%$ alcohol may be even more of concern with respect to survival and growth of pathogens. 
4. The possibility of the presence of pathogenic microbes in AFB may significantly alter the quality control programs, operational and legal costs of the brewery, and governmental surveillance of this industry may be required if any sort of outbreak affecting human health takes place.

5. Different brands of AFB can have very different chemical composition which will directly affect stability of any bacterial contaminants found. Production of beers at $\mathrm{pH}$ values of 4.5 to 5.2 must be avoided.

6. Heat resistance of AFB spoilage organisms needs to be determined in order to determine appropriate pasteurization parameters for these products. Until this results in significant data, the $D_{60}$ value for Pediococcus in AFB should be used as the most resistant microbe. More work is required on the chemical analyses of $A F B$ and the ability of pathogens to grow and to survive processing technology.

7- $\quad$ None of the pathogens grew in AB. However, E. coli 0157:H7, S. typhimurium, Shighella flexneri, Pseudomonas aeruginosa, Klebsiella pneumoniae, and Yersinia enterocolitica showed, to different degrees, an ability to multiply in AFB. Draft AFB should not be manufactured in industry. 


\section{BIBLIOGRAPHY}

Adams, M.R., O'Brien, P.J. and Taylor, G.T. 1989. Effect of the ethanol content of beer on the heat resistance of spoilage Lactobacillus. J. Appl. Bacteriol. 66:491-495.

Anonymous. 1975. Center for Disease Control. Salmonella typhimurium outbreak traced to a commercial apple cider - New Jersey. Morbid Mortal Weekly Rep. 24:87-88.

Anonymous. 1978. Subcommittee report on instrumentation. Amer. Soc. Brew. Chem. J. 36:118.

Anonymous. 1992. Analytical Methods. Determination of FAN. Wort-12, and Hydrogen ion concentration. Beer-9. Amer. Soc. Brew. Chem., St. Paul, MN.

Attenborough, W.M. 1985. Processing systems for the production of reduced alcohol and near beers. Proc. First Conv. Inst. Brew. (Central and Southern African Section) pp. 295-312.

Attenborough, W.M. 1988. Evaluation of processes for the production of lowand non-alcohol beer. Ferment. 1:40-44.

Ault, R.G. 1965. Spoilage bacteria in brewing - a review. J. Inst. Brew. 71:376391.

Ault, R.G., and Newton, R. 1971. Brewing hygiene and biological stability of beers. In: Modern Brewery Technology. Edited by: P.K. Findlay. Macmillan Press, London. pp. 198-218.

Back, W. 1981. The indication and identification of Gram-negative bacteria harmful to beer. Brauwiss. 34:197-294.

Baumgartner, J.G. and Herson, A.C. 1956. Canned Foods: An Introduction to Their Microbiology. 4th ed. J. and A. Churchill Ltd., London. 
Berger, H.F. 1982. Theoretische grundlagen der dünnschichtverdampfung zur alkoholreduktion von bier am beispiel centri-therm. Monatsschrift für Brauerei. 35:98-101.

Baselt, F.C., Dayharsh, C.A., and Del Vecchio, H.W. 1954. Thermal death time studies on beer spoilage organisms. III. Proc. Amer. Soc. Brew. Chem. 141-146.

Besser, R., Lett, S., Weber, T., Barret, T., Doyle, M., and Griffin, P. 1992. Outbreak of hemolytic uremic syndrome (HUS) and Escherichia coli 0157:H7 (EC157) infections associated with apple cider. Program Abstr. 32nd Intersci. Conf. Antimicrob. Agents Chemother. Abstr. 99, p. 127.

Beuchat, L.R. 1978. Injury and repair of Gram-negative bacteria with special consideration of the involvement of the cytoplasmic membrane. Adv. Appl. Microbiol. 23:219-243.

Brenner, H.W. and Hsu, W.P. 1971. A study of wild yeast and lactic acid bacteria in the brewery. MBAA Tech. Quart. 8:45-51.

Brenner, M. W. 1980. Beer for the future. MBAA Tech. Quart. 17:185-195.

Campbell, I. 1987. Wild yeasts in brewing and distilling. In: Brewing Microbiology. Edited by: F.G. Priest and I. Campbell. Elsevier Applied Science, New York. pp. 187-205.

Chandrasekhar, J. 1994. Production of low-alcohol beer and alcohol-free beer using a combination of high temperature mashing and cold contact fermentation. Ferment. 7:241-244.

Chelak, B.J. and Ingledew, W.M. 1987. Anaerobic Gram-negative bacteria in brewing - a review. Amer. Soc. Brew. Chem. J. 45:123-127.

Coleman, M. 1976. General Developments in Pasteurization. Brew. Guard. 105:51, 53, 57.

Dadds, M.J.S. and Martin, P.A. 1973. The genus Zymomonas - a review. J. Inst. Brew. 79:386-391.

Dallyn, H. and Falloon, W.C. 1976. The heat resistance of yeasts and the pasteurization of beer. The Brewer. 62:354-356.

Dayharsh, C.A. and Del Vecchio, H.W. 1952. Thermal death time studies on beer spoilage organisms. II. Proc. Amer. Soc. Brew. Chem. 45-50. 
De Clerck, J. and Konovaloff, C. 1946. Etude sur la fabrication de la bière à faible teneur en alcool. Bulletin de l'Association des Anciens Etudiants en Brasserie de l'Université de Louvain. 42:101-116, 149-189.

Del Vecchio, H.W., Dayharsh, C.A., and Baselt, F.C. 1951. Thermal death time studies on beer spoilage organisms. Proc. Amer. Soc. Brew. Chem. 45-50.

Doyle, M.P. 1991. Escherichia coli 0157:H7 and its significance in foods. Int. J. Food Microbiol. 12:289-302.

Epstein, S.S. and Dee Snell, F. 1940. Thermal death time of microorganisms encountered in the brewing industry. J. Inst. Brew. 46:175-178.

Etuk, B.R. and Murray, K.R. 1990. Potential to use liquid membranes for alcohol reduced beer production. Proc. Biochem. 25:25-32.

Foster, J. and Hall, H.K. 1991. Inducible $\mathrm{pH}$ homeostasis and the acid tolerance response of Salmonella typhimurium. J. Bacteriol. 172:771-778.

Foster, J. 1992. Beyond $\mathrm{pH}$ homeostasis: The acid tolerance response of salmonellae. Amer. Soc. Microbiol. News 58:266-270.

Frazier, W.C. and Westhoff, D.C. 1978. Preservation by use of high temperatures. In: Food Microbiology. McGraw-Hill Book Co. pp. 101129.

Fricker, R. 1984. The flash pasteurization of beer. J. Inst. Brew. 90:146-152.

Gilliland, R.B. 1980. Microbial enemies in brewing. Proc. 14th Conv. Inst. Brew. (Australia and New Zealand section) pp. 135-141.

Glass, K.A., Loeffelholz, J.M., Ford, J.P., and Doyle, M.P. 1992. Fate of Escherichia coli $0157: \mathrm{H} 7$ as affected by $\mathrm{pH}$ or sodium chloride and in fermented, dry sausage. Appl. Environ. Microbiol. 58:2513-2516.

Gorden, J. and Small, P.L.C. 1993. Acid resistance in enteric bacteria. Infect. Immun. 61:364-367.

Haehn, H. 1938. Das ludwigsbier. Wochenschrift für Brauerei. 55:334-336.

Hansen, N.H. and Rieman, H. 1963. Factors affecting the heat resistance of nonsporing organisms. J. Appl. Bact. 26:314-333. 
Ingledew, W.M. 1975. Utilization of wort carbohydrates and nitrogen by Saccharomyces carlsbergensis MBAA Tech. Quart. 12:146-150.

Ingledew, W.M. 1979. Effect of bacterial contaminants on beer - a review. Amer. Soc. Brew. Chem. J. 37:145-150.

Ingledew, W.M. and Hysert, J.H. 1994. Brewing Technology. Encyclopedia of Agricultural Science. 1:315-326.

Ingram, M. 1969. Sporeformers as food spoilage organisms. In: The Bacterial Spore. Edited by G.W. Gould and A. Hurst. Academic Press, New York. pp. 549-609.

Jäger, P. 1983. Technologische massnahmen im hinblinck auf die bildung einiger aroma und geschmackstoffe zur herstellung von alkoholreduzierten bieren bzw. 37:100-106, 130-133.

Kieninger, H., Narziss, L., N., Heil, G. 1975. The production of low-alcohol beer using reverse osmosis. International symposium: Séparation par membranes, échanges d'ions et cryo-concentration dans l'industrie alimentaire. APRLA. Paris. pp. A5-1 - A5-22.

Kilgour, W.J. and Smith, P. 1985. The determination of pasteurization regimes for alcoholic and alcohol-free beer. Proc. Eur. Brew. Conv. (Helsinki). pp. 435-443.

Kissel, T. and Dakin, P.E. 1956. Pediococcus: Cultural method for their detection and a report of their growth characteristics. Tech. Proc. 69th Ann. Conv. MBAA. pp. 44-53.

Kleyn, J. and Hough, J. 1971. The microbiology of brewing. Ann. Rev. Microbiol. 25:583-608.

Krüger, E., Olivier-Daumen, B., Sommer, G., Metscher, M., and Berger, H. 1986. Die herstellung alkoholreduzierter biere. Monatsschrift für Brauerei. 39:132-142.

Laufer, S. 1937. Flash pasteurization with "astra" short period plate heater. Proc. Amer. Soc. Brew. Chem. 30-37.

Laufer, S. and Brenner, M.W. 1940. Thermal death time of brewery microorganisms in relation to beer pasteurization. I. Progress report. Proc. Amer. Soc. Brew. Chem. pp. 30-37. 
Lee, S.Y., Mabee, M.S., Jangaard, N.O., and Horiuchi, E.K. 1980. Pectinatus, a new genus of bacteria capable of growth in hopped beer. J. Inst. Brew. 86:28-30.

Leyer, G.J. and Johnson, E.A. 1993. Acid adaptation induces cross-protection against environmental stresses in Salmonella typhimurium. Appl. Environ. Microbiol. 59:1842-1847.

Lund, A. 1946. Thermal death point of microorganisms in beer. J. Inst. Brew. 52:307-311.

Magnus, C.A., Ingledew, W.M. and McCurdy, A.R. 1986. Thermal resistance of streptococci isolated from pasteurized ham. Can. Inst. Food Sci. Tech. J. 19: 62-67.

Mändl, B. 1977. Herstellung alkoholarmer/alkoholfrier biere mit hefen ohne maltosegärung. Brauwelt. 117:732-737.

Matches, J.R. and Liston, J. 1968. Low temperature growth of Salmonella. J. Food Sci. 33:641-645.

McNeil, K.E. and Garrick, C.C. 1984. Influence of product composition on pasteuriation efficiency. Proc. 18th Conv. Inst. Brew. (Australia and New Zealand section). 244-251.

Menegazzi, G.S. and Ingledew, W.M. 1980. Heat processing of spent brewers' yeast. J. Food Sci. 45:182-186.

Miller, L.G. and Kaspar, C.W. 1994. Escherichia coli 0157:H7 acid tolerance and survival in apple cider. J. Food Protection. 57:460-464.

Moll, M. 1991. Alcohol-free beers. In: Beers and Coolers. Edited by: M. Moll and J.-J. De Blauwe, Lavoisier, France. pp. 415-424.

Molzahn, S.W., Hockney, R.C., and Kelsey, P. 1983. Factors influencing the flash pasteurization of beer. Proc. Eur. Brew. Conv. (London). 255262.

Muller, R. 1990. The production of low-alcohol and alcohol-free beers by limited fermentations. Ferment. 3:224-230.

Niefind, H.J. and Smith, F.J. 1981. Neues verfahren alkoholreduzierung von bier durch selektive diffusion an membranen. Proc. Eur. Brew. Conv. (Copenhagen) 599-606. 
O'Connor-Cox, E.S.C., Yiu, P.M., and Ingledew, W.M. 1991. Pasteurization: Thermal death of microbes in brewing. MBAA Tech. Quart. 28:67-77.

O'Connor-Cox, E.S.C., Yui, P.M., and Ingledew, W.M. 1991. Pasteurization: Industrial practice and evaluation. MBAA Tech. Quart. 28:99-107.

Olivier-Daumen, B. 1982. Praktische erfahrungen mit dem centri-therm zur alkoholfreduktion von biere. Monatsschrift für Brauerei. 35:101-106.

Patino, H., Lewis, M.J., and Heil, J.R. 1985. Design of pasteurization processes for packaged beer. Brew. Dig. 60:28-31.

Potter, N.N. 1978. Food Science. 3rd edition. AVI Publ. Co. Inc. Westport Connecticut. pp. 780.

Rainbow, C. 1971. Spoilage organisms in breweries. Proc. Biochem. 6:1517,31 .

Regan, J. 1990. Production of alcohol-free and low-alcohol beers by vacuum distillation and dialysis. Ferment. 3:235-237.

Reichart, O. 1979. A new experimental method for the determination of the heat destruction parameters of microorganisms. Acta Alimentaria. 8:131-155.

Richards, M. and Corbey, D.A. 1974. Isolation of Zymomonas mobilis from primed beer. J. Inst. Brew. 80:241-244.

Röcken, W. 1985. Actual view-points on the theme "pasteurization". Biological fundamentals. Brauwelt Internat. 1:95-98.

Runkel, U.D. 1975. Sterile filtration versus flash pasteurization. MBAA Tech. Quart. 12:28-30.

Russell, A.D. 1971. The destruction of bacterial spores. In: Inhibition and Destruction of the Microbial Cell. Edited by: W.B. Hugo. Academic Press, New York. pp. 451-612.

Schleifer, K.H., Leuteritz, M., Weiss, N., Ludwig, W., Kirchhof, G., and SeidlerRufer, H. 1990. Taxonomic study of anaerobic, Gram-negative, rod shaped bacteria from breweries; emended description of Pectinatus cerevisiiphilus and description of Pectinatus frisingensis sp. nov., Selenomonas lacticifex sp. nov., Zymophilus raffinosivorans gen. nov., sp. nov., and Zymophilus paucivorans sp. nov. Internat. J. Syst. Bacteriol. 40:19-27 
Schmidt, C.F. 1954. Thermal resistance of microorganisms. In: Antiseptics, Disinfectants, Fungicides and Chemical and Physical Sterilization. Edited by: G.F. Reddish. Lea and Febiger. Philadelphia.

Scruggs, C.E. and Baselt, F.C. 1955. Pasteurization of packaged beer. A survey of industry practises 1952-1955. Wallerstein Lab. Commun. 18:159-169.

Shimwell, J.L. 1935. The cultural characteristics of Saccharobacillus pastorianus. J. Inst. Brew. 41:481-487.

Shimwell, J.L. 1936. Study of the comun rod bacteria of brewers' yeast. J. Inst. Brew. 42:119-129.

Shimwell, J.L. 1937. Study of a new type of beer desease bacterium producing alcoholic fermentation of glucose. J. Inst. Brew. 43:507-509.

Shimwell, J.L. 1949. Brewing bacteriology VI. The lactic acid bacteria (Family Lactobacteriaceae). Wallerstein Lab. Commun. 12:71-88.

Simpson, W.J. 1993. Studies on the heat sensitivity of lactic acid bacteria to hop bitter acids. J. Inst. Brew. 99:405-411.

Splittstoesser, D.F., Lienk, L.L., Wilkison, M., and Stamer, J.R. 1975. Influence of wine composition on the heat resistance of potential spoilage organisms. Appl. Microbiol. 30:369-373.

Stein, W. 1993. Dealcoholization of beer. MBAA Tech. Quart. 30:54-57.

Steiner, K. 1987. Alkoholfreies bier. Lebensmittel-Technologie. 20:44-45.

Stumbo, C.R. 1973. Thermobacteriology in Food Processing. 2nd edition Academic Press, N.Y.

Stumbo, C.R. 1976. Elements of heat and gaseous sterilization. In: Industrial Microbiology. Edited by: B.M. Miller and W. Litsky. McGraw-Hill Book Co. pp. $412-450$.

Thomas, K.C., Hynes, S.H., Jones, A.M., and Ingledew, W.M. 1993. Production of fuel alcohol from wheat by VHG technology. Effect of sugar concentration and fermentation temperature. Appl. Biochem. Biotech. 43:211-226.

Torreggiana, D. and Toledo, R.T. 1986. Influence of sugars on heat inactivation, injury and repair of Saccharomyces cerevisiae. J. Food Sci. 51:211-215. 
Tsang, E.W.T. 1981. Studies on heat resistance of wild yeasts and bacteria in beer. M. Sc. Thesis, University of Saskatchewan, Saskatoon, SK.

Tsang, E.W.T. and Ingledew, W.M. 1982. Studies on heat resistance of wild yeasts and bacteria in beer. Amer. Soc. Brew. Chem. J. 40:1-8.

van Vuuren, H.J.J. 1987. Gram-negative spoilage bacteria. In: Brewing Microbiology. Edited by: F.G. Priest and I. Campbell, Elsevier Appl. Science. N.Y. pp. 154-185.

Weiss, N.H., Seidal, W., and Back, W. 1979. Isolation and systematic identification of Gram negative bacteria which are harmful to beer. Brauwiss. 32:189-194.

Wellhoner, J.H. 1965. Gedanken zur herstellung von alkoholarmen lagerbier. Brauwelt. 105:645-646.

Wiles, A.E. 1954. The wild yeast problem as a facet of brewing technology. Wallerstein Lab. Commun. 17:259-281.

Zhao, T., Doyle, M.T., and Besser, R.E. 1993. Fate of enterohemorrhagic Escherichia coli 0157:H7 in apple cider with and without preservatives. Appl. Environ. Microbiol. 59:2526-2530. 
7. APPENDIX 


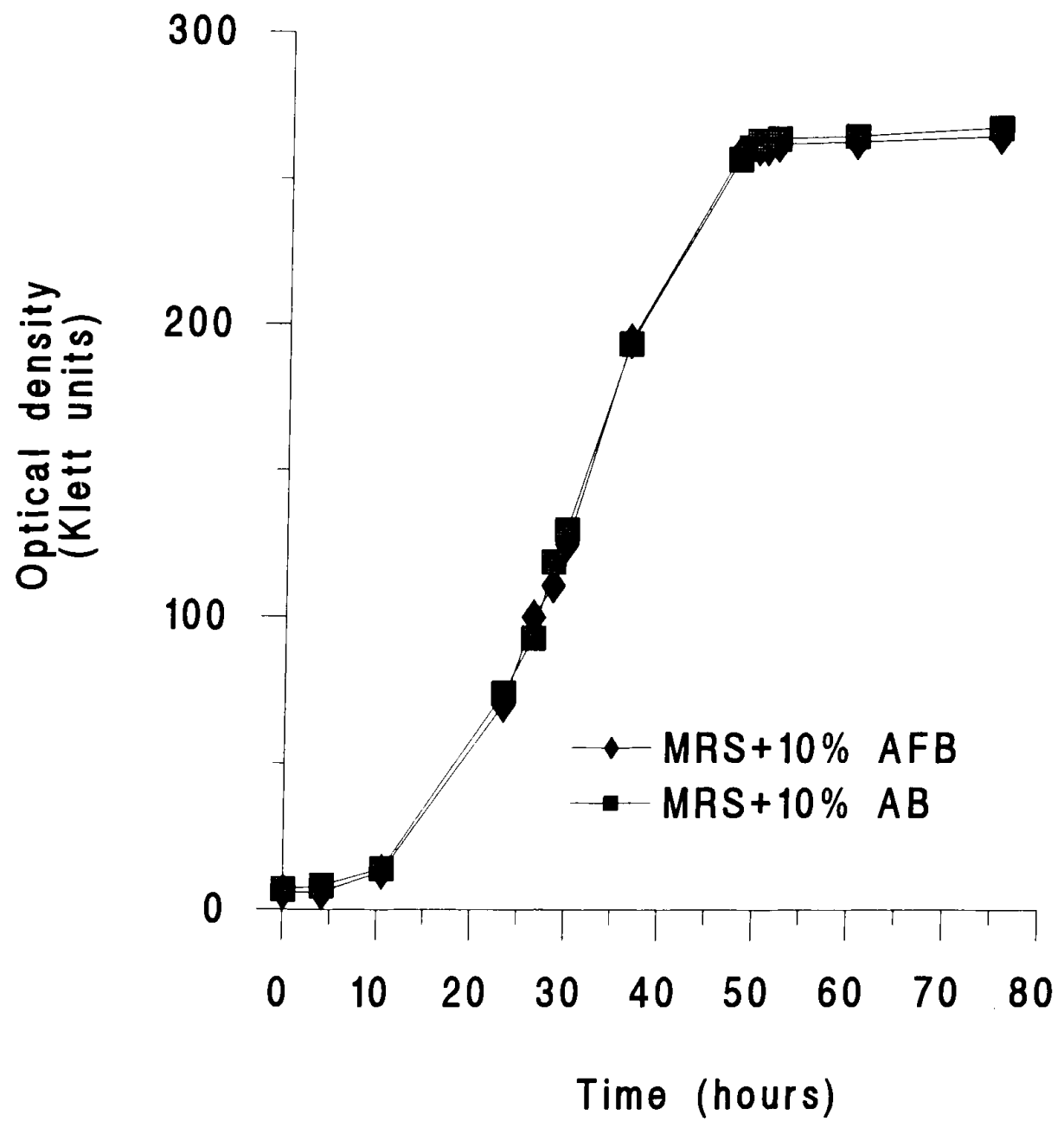

Fig 7.1: $\quad$ Growth curves of L. delbrueckii in MRS $+10 \% \mathrm{AB}$ and MRS $+10 \%$ $\mathrm{AFB}$ at $27^{\circ} \mathrm{C}$ in $\mathrm{CO}_{2}$ incubator. 


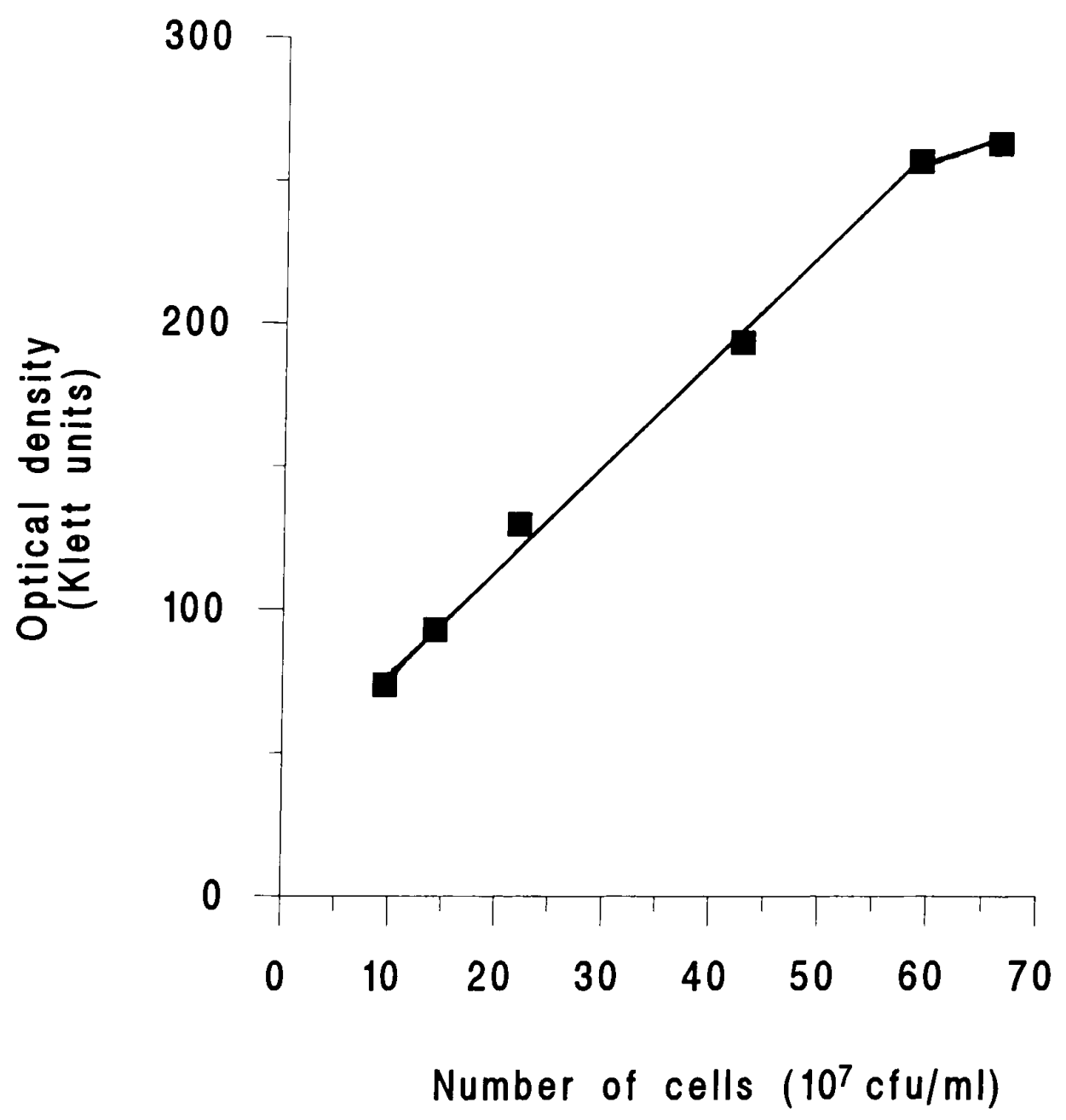

Fig 7.2: $\quad$ Viable counts of L. delbrueckii in MRS $+10 \% \mathrm{AB}$. 


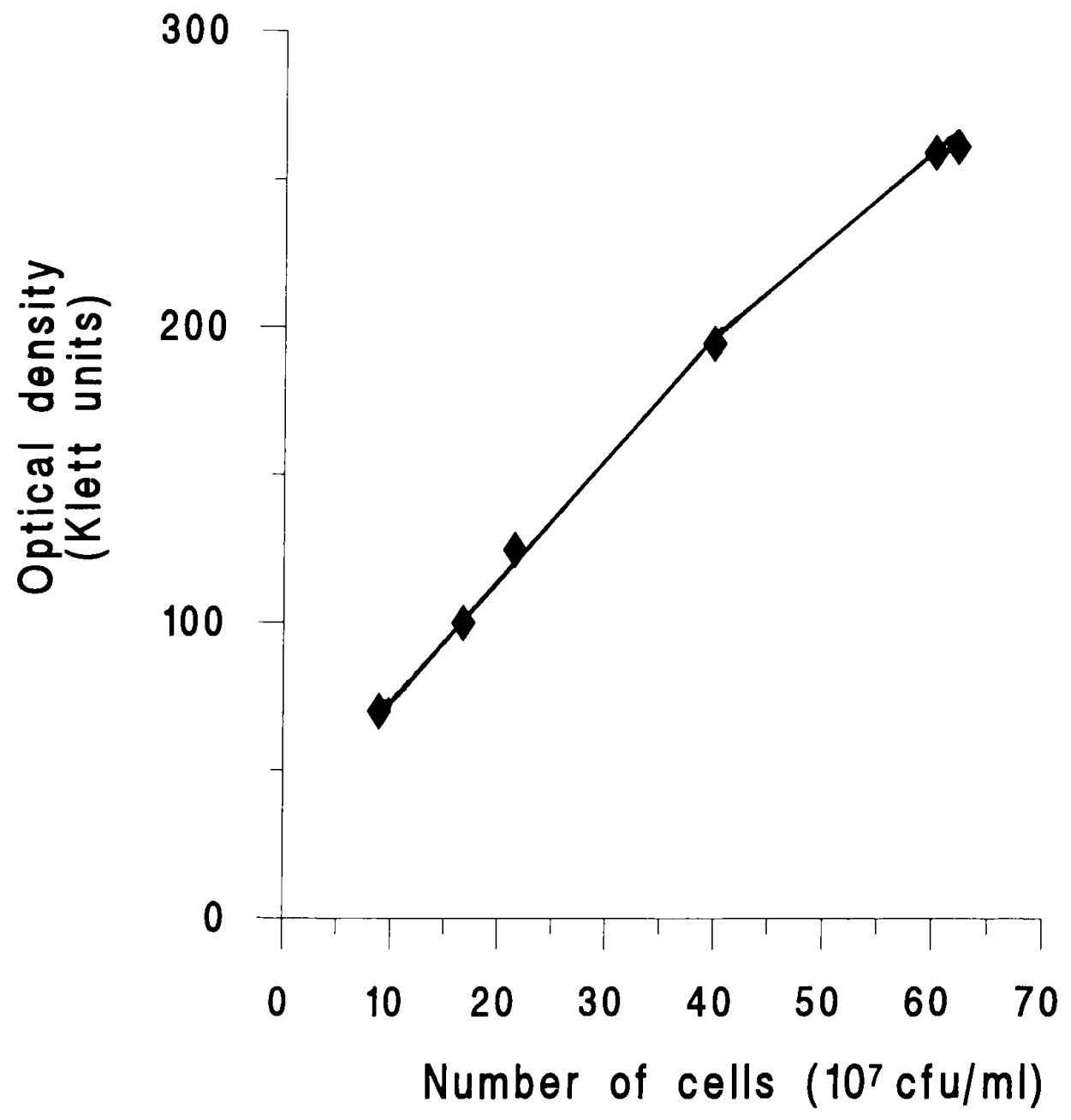

Fig 7.3: $\quad$ Viable counts of $L$. delbrueckii in MRS $+10 \%$ AFB. 


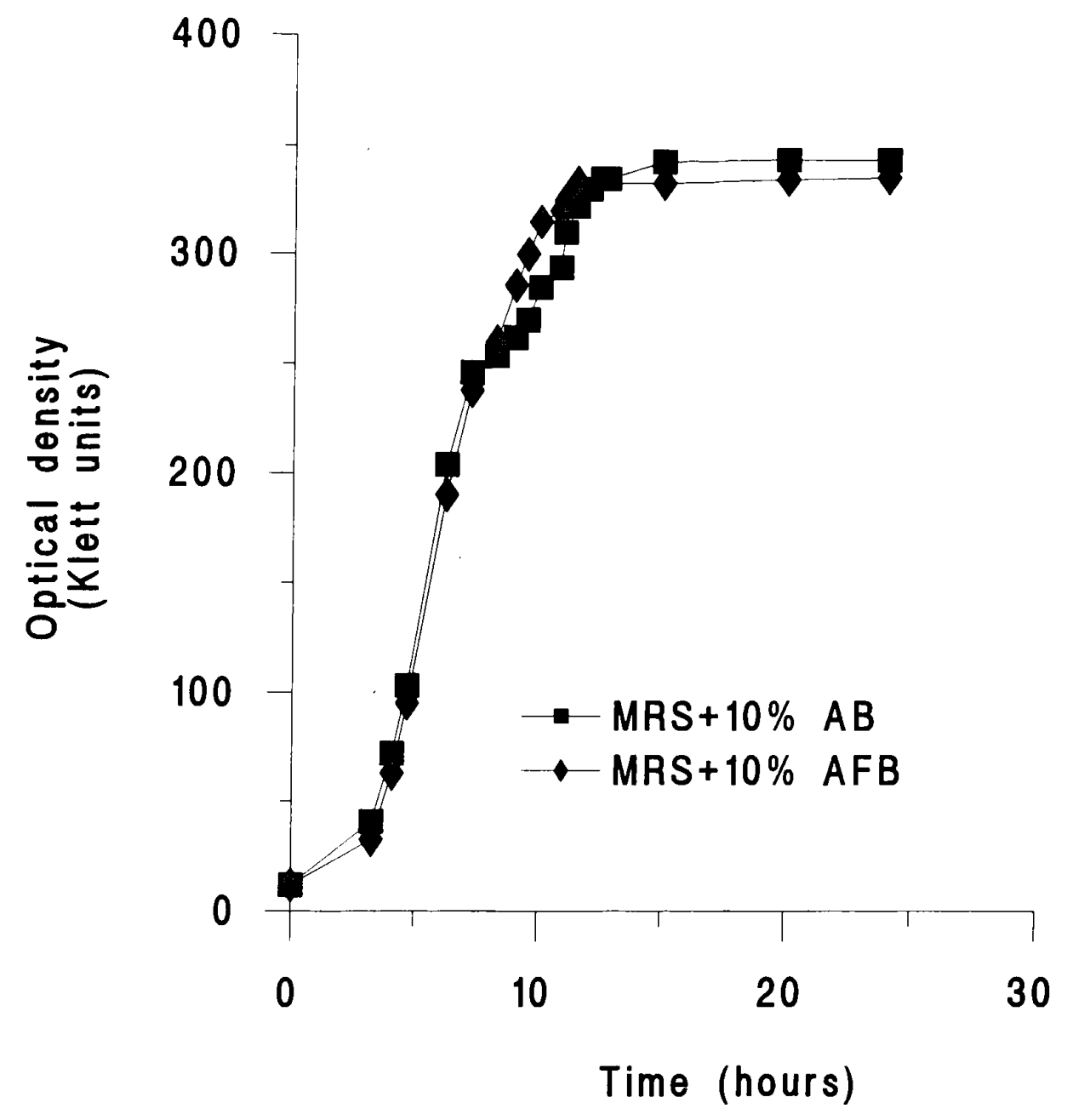

Fig 7.4: $\quad$ Growth curves of $P$. acidilactici NCIB \#6990 in MRS $+10 \% \mathrm{AB}$ and MRS $+10 \%$ AFB at $27^{\circ} \mathrm{C}$ in $\mathrm{CO}_{2}$ incubator. 


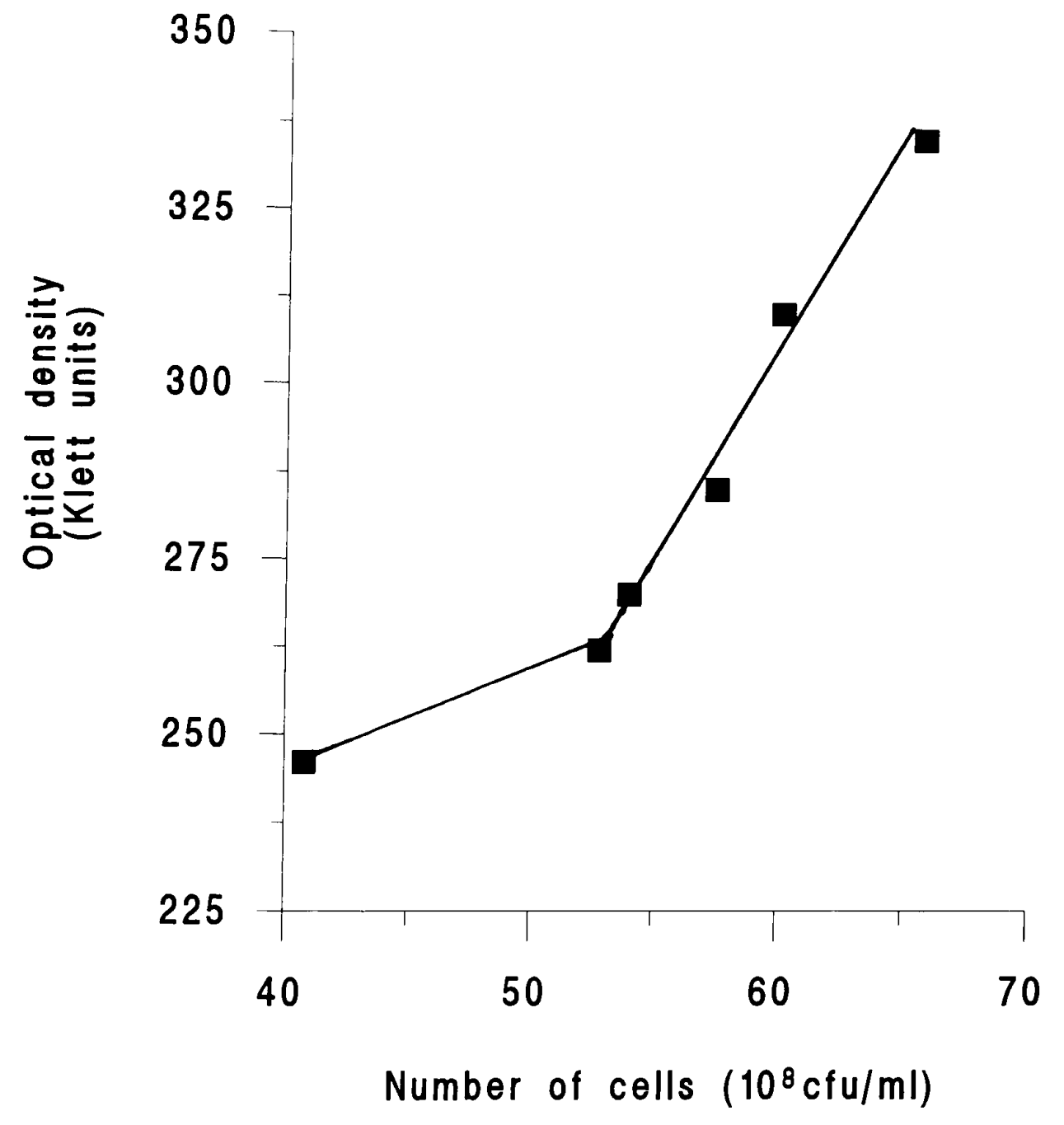

Fig 7.5: $\quad$ Viable counts of $P$. acidilactici NCIB \#6990 in MRS $+10 \%$ AB. 


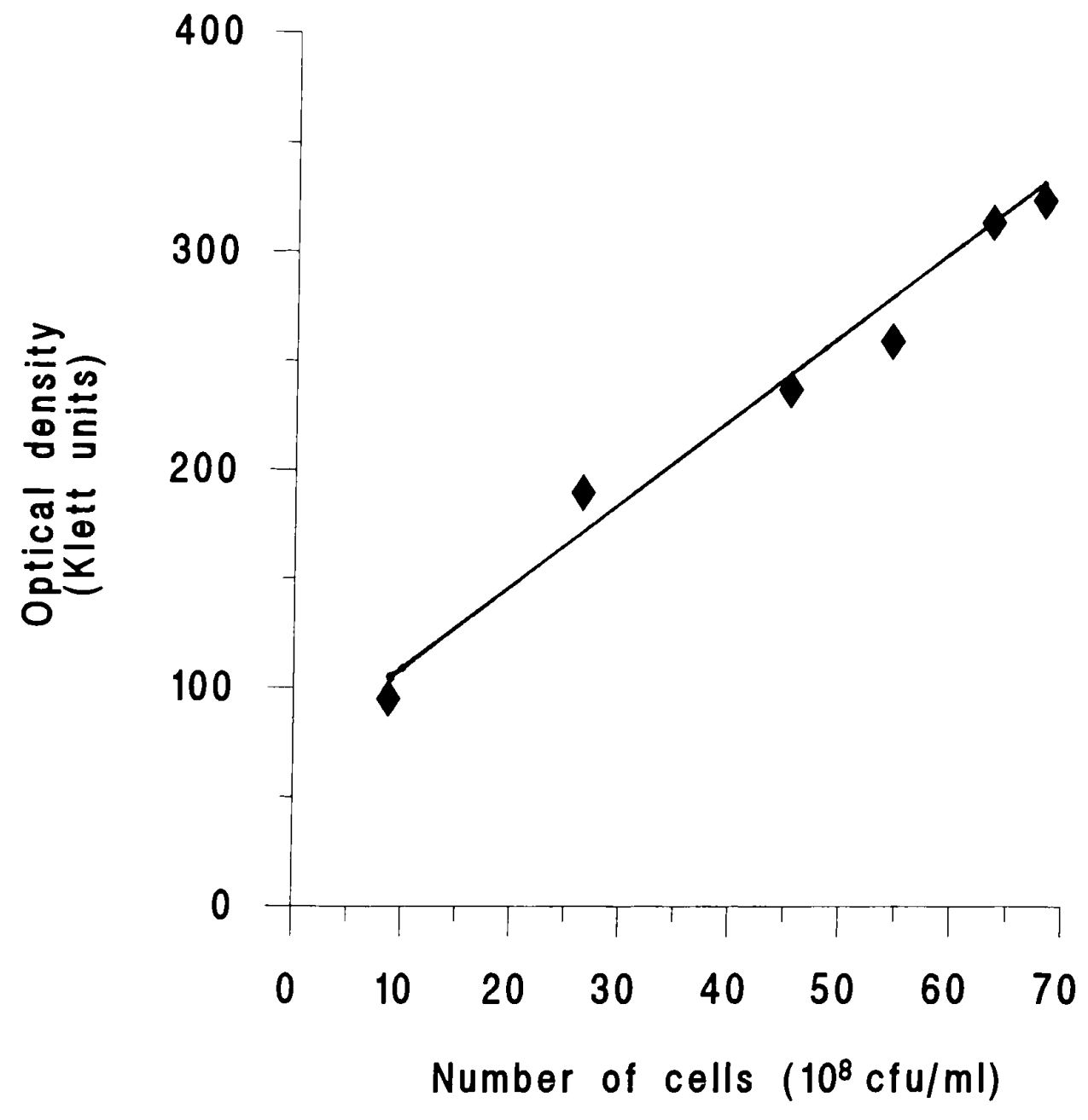

Fig 7.6: $\quad$ Viable counts of $P$. acidilactici NCIB \#6990 in MRS $+10 \%$ AFB. 


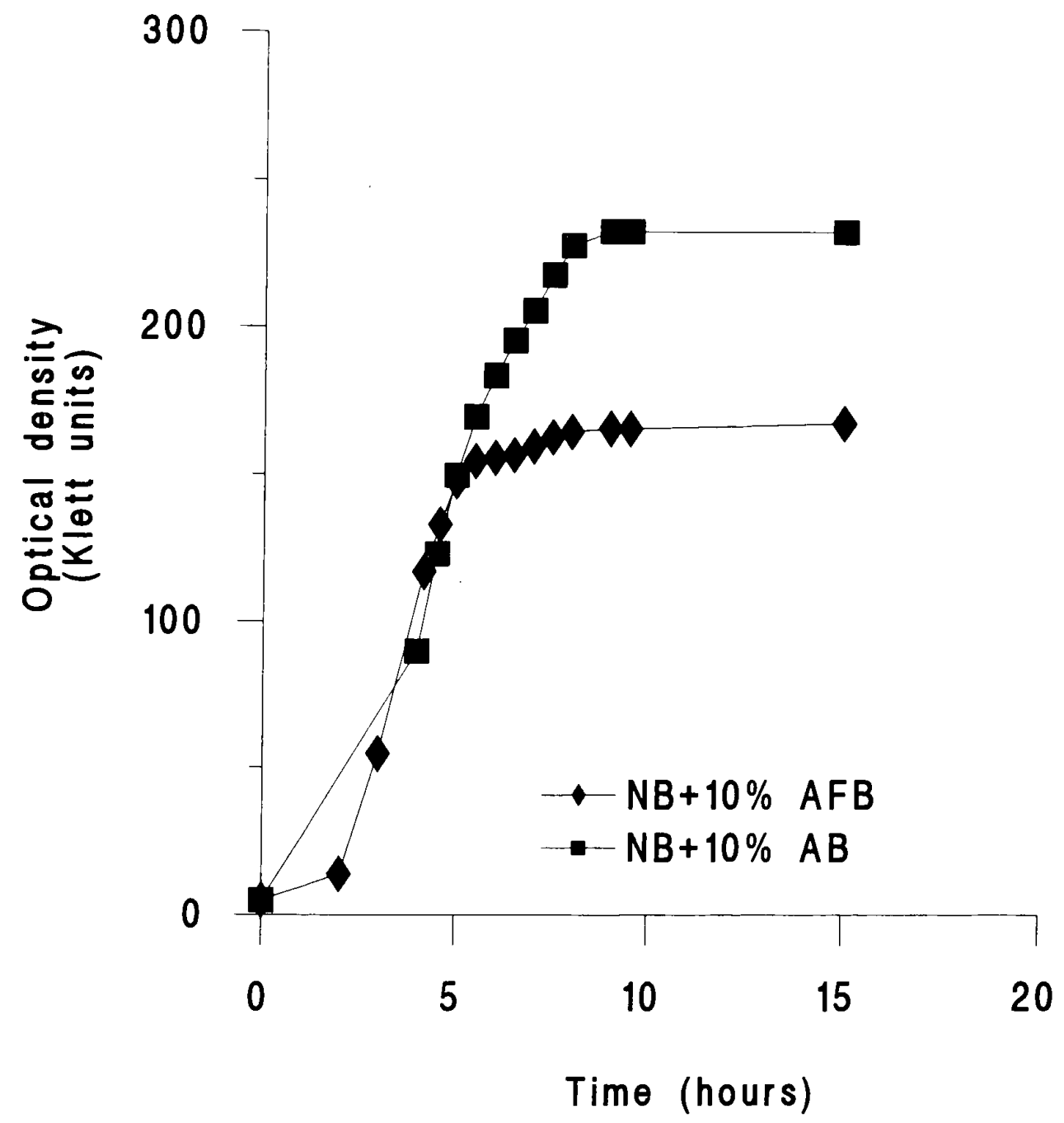

Fig 7.7: $\quad$ Growth curves of E. coli 0157:H7 ATCC \#43889 in NB + 10\% AB and $\mathrm{NB}+10 \% \mathrm{AFB}$ at $30^{\circ} \mathrm{C}$. 


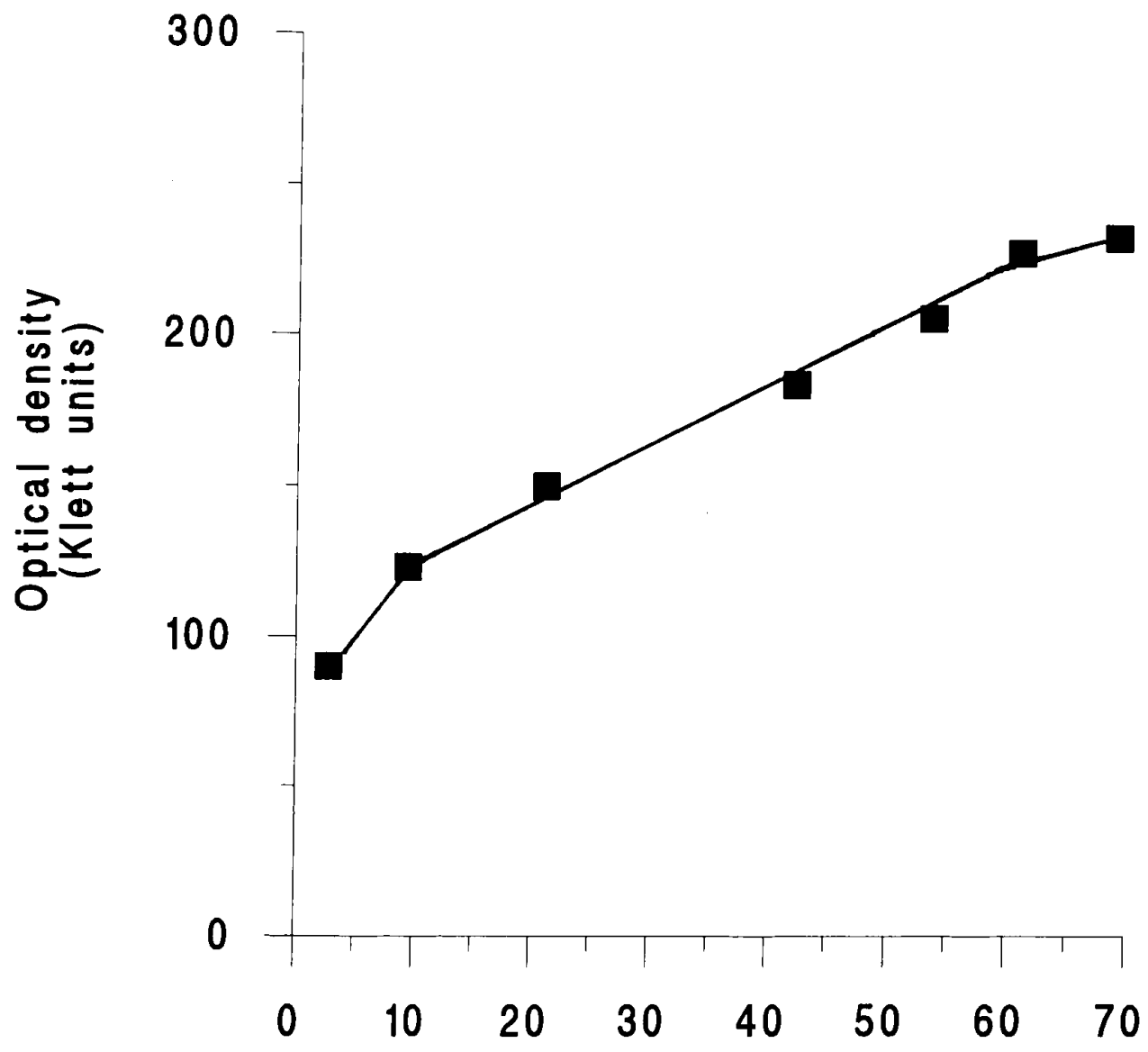

Number of cells $\left(10^{8} \mathrm{cfu} / \mathrm{ml}\right)$

Fig 7.8: Viable counts of E. coli $0157:$ H7 ATCC \#43889 in NB $+10 \%$ AB. 


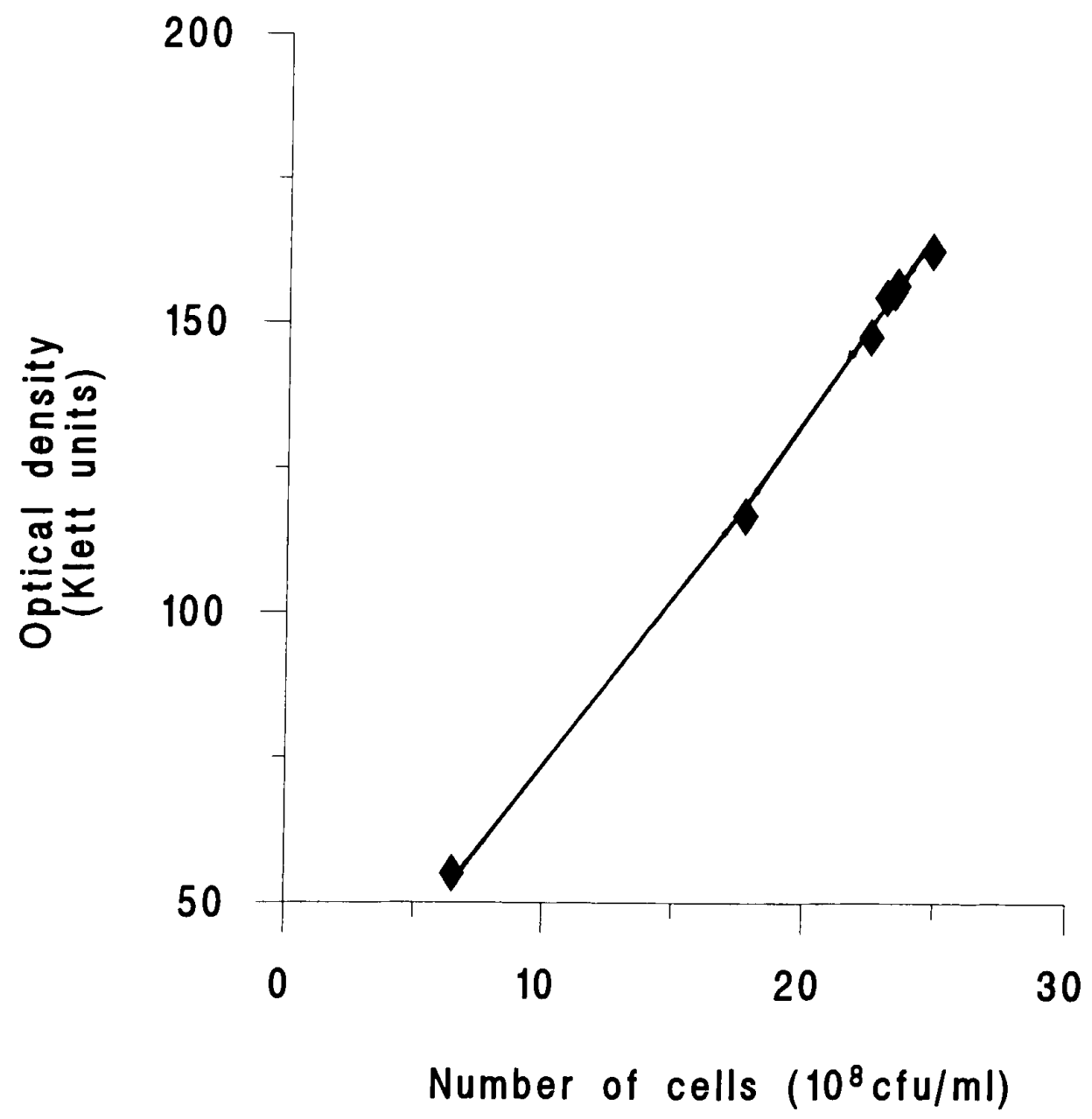

Fig 7.9: Viable counts of E. coli 0157 :H7 ATCC \#43889 in NB + 10\% AFB. 


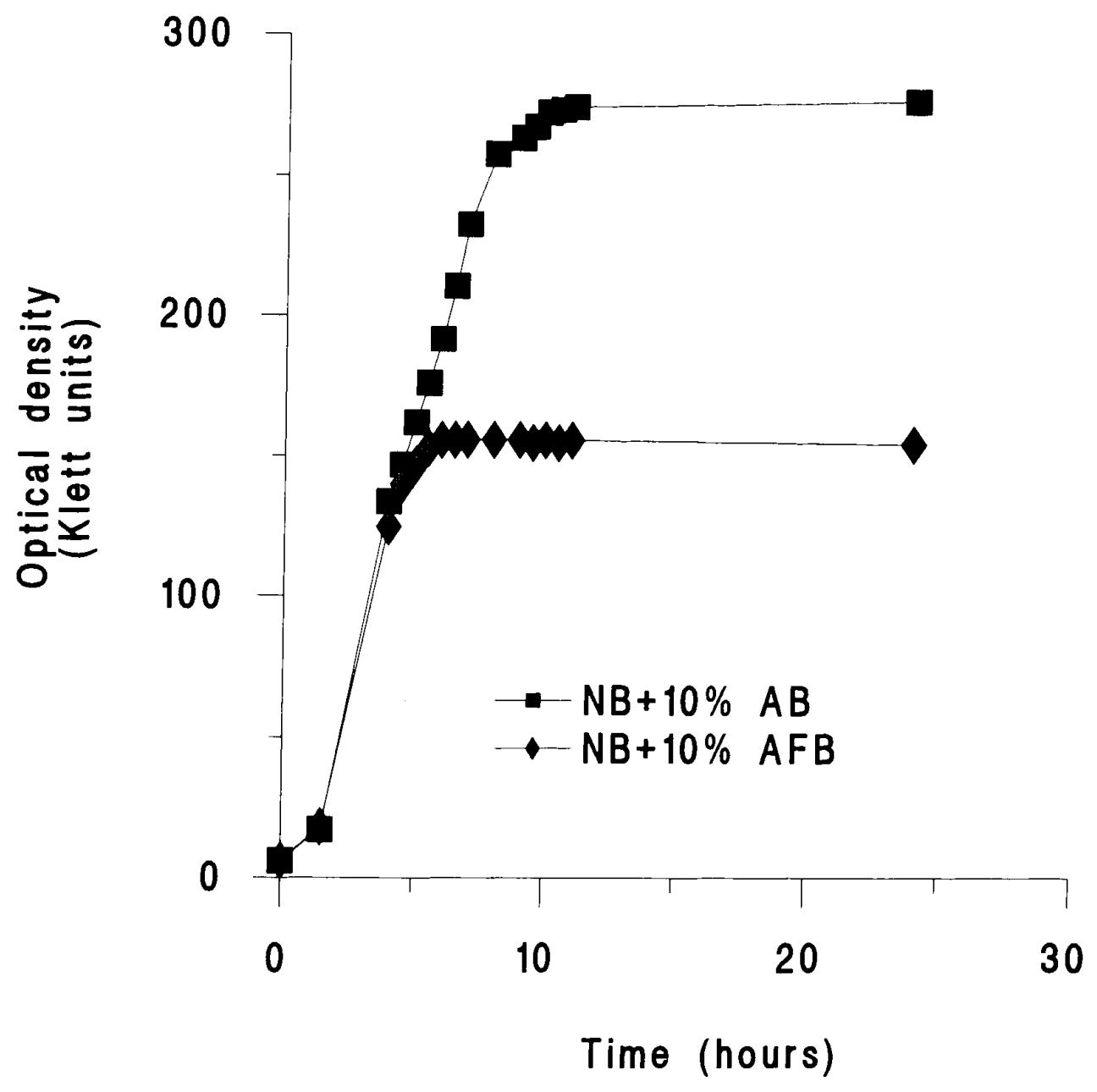

Fig 7.10: Growth curves of S. typhimurium ATCC \#14028 in NB $+10 \%$ AB and $\mathrm{NB}+10 \% \mathrm{AFB}$ at $30^{\circ} \mathrm{C}$. 


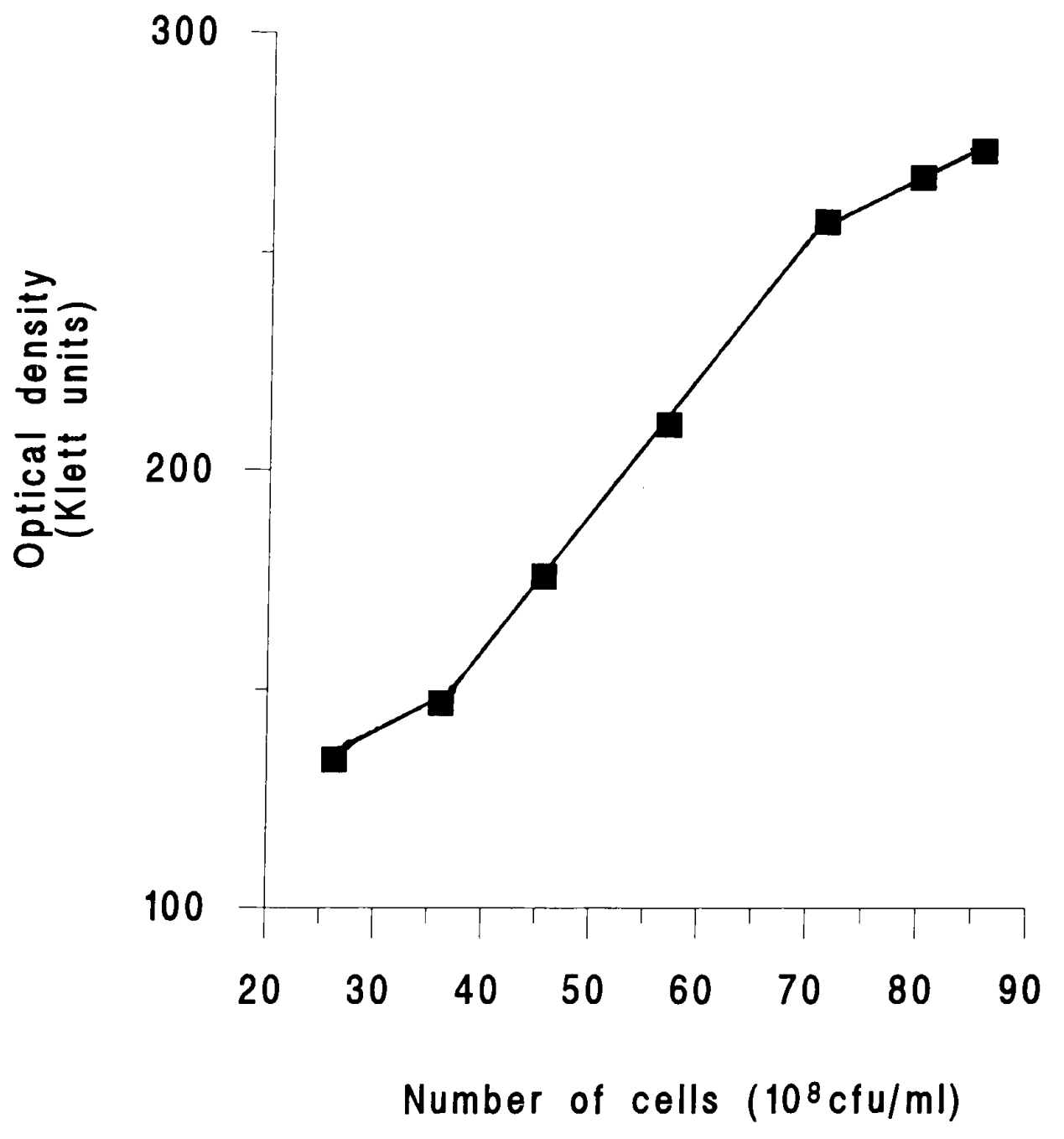

Fig 7.11: Viable counts of S. typhimurium ATCC \#14028 in NB + 10\% AB. 


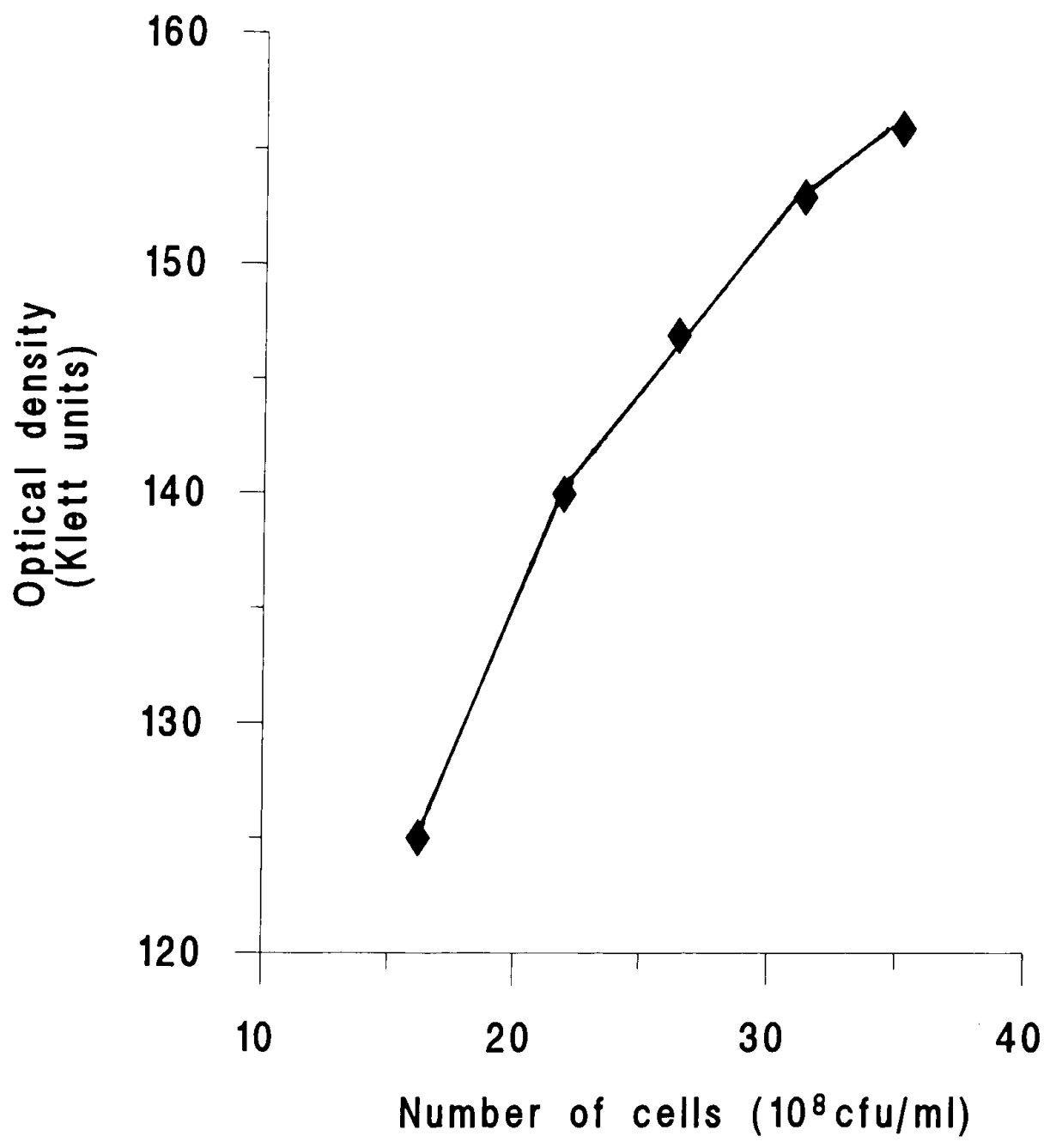

Fig 7.12: Viable counts of S. typhimurium ATCC \#14028 in NB + 10\% AFB. 


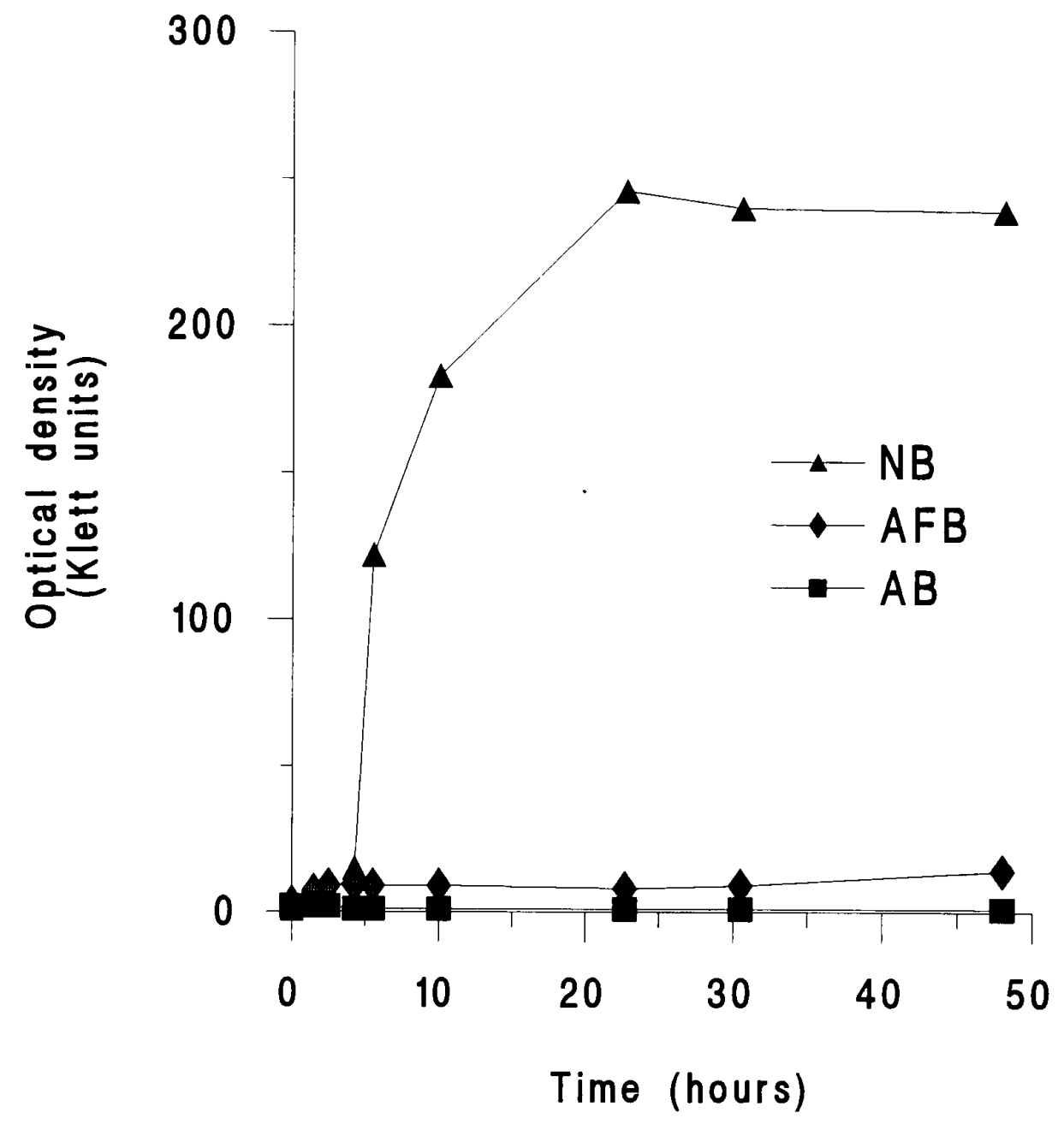

Fig 7.13: Growth curves of Aeromonas hydrophila ATCC \#7965 in NB, AFB and $\mathrm{AB}$, at $30^{\circ} \mathrm{C}$. 


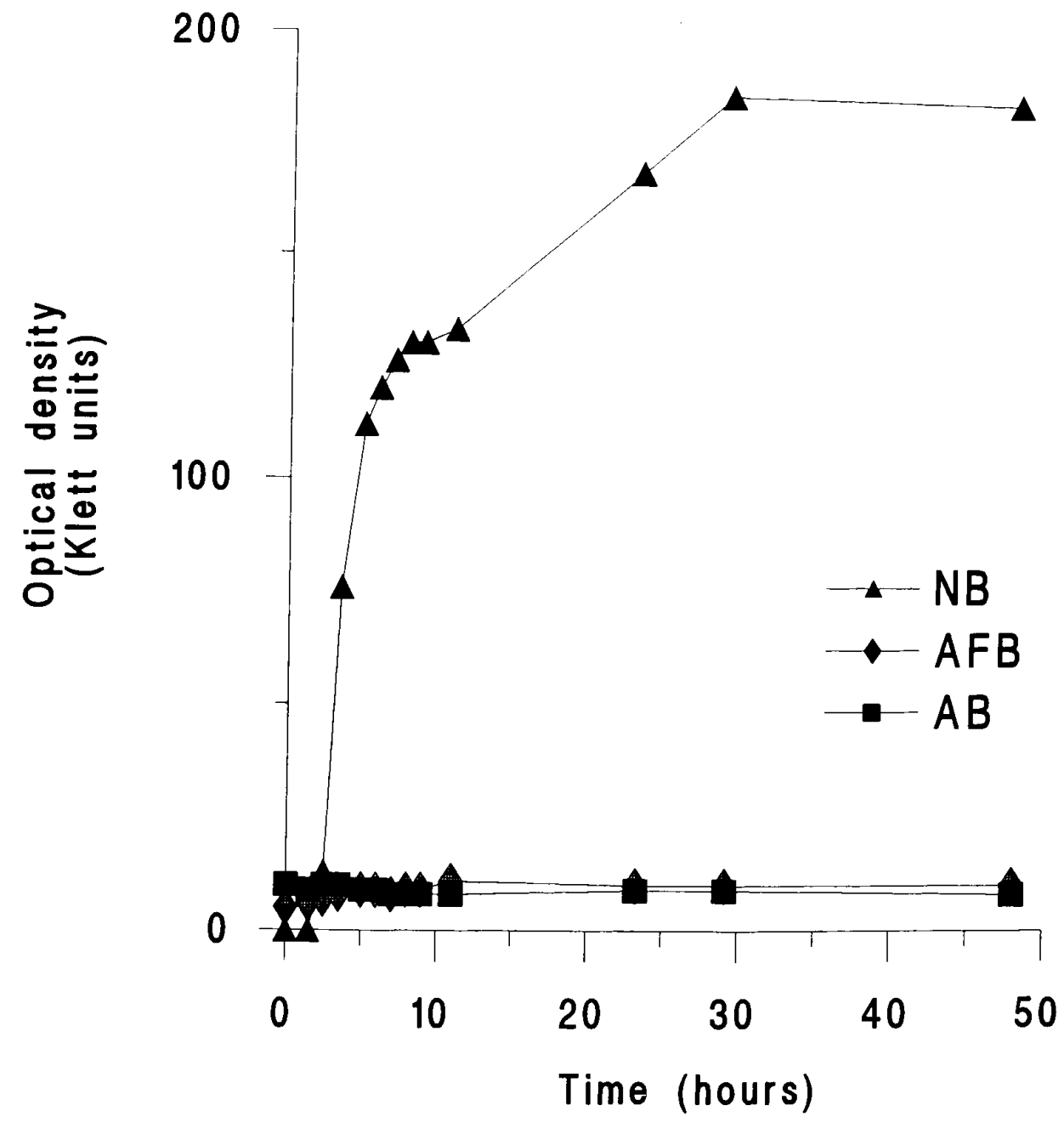

Fig 7.14: Growth curves of Bacillus cereus MBCL 27 in NB, AFB and AB, at $30^{\circ} \mathrm{C}$. 


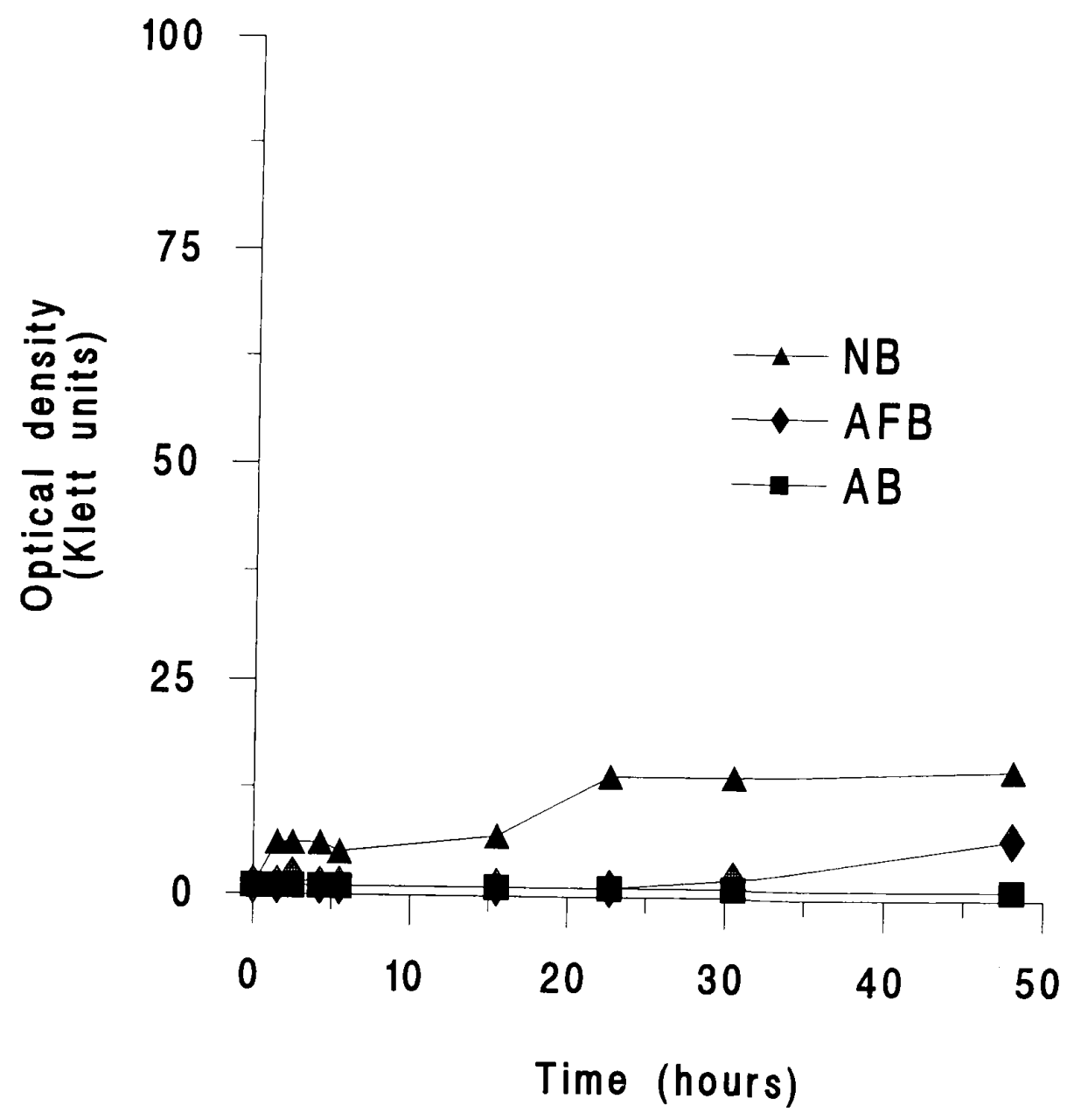

Fig 7.15: Growth curves of Enterococcus faecium ATCC \#19434 in NB, AFB and $\mathrm{AB}$, at $30^{\circ} \mathrm{C}$. 


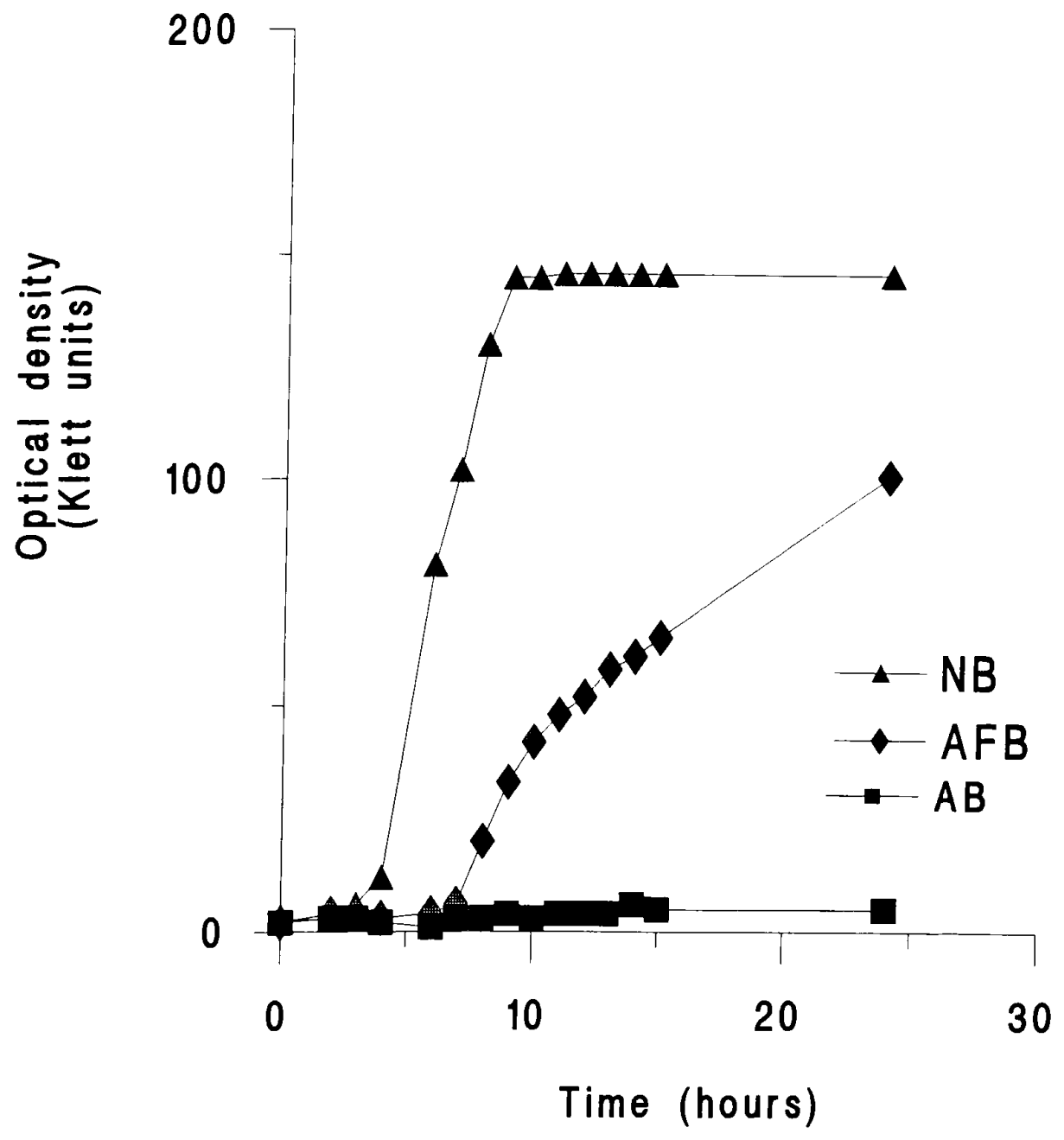

Fig 7.16: Growth curves of Escherichia coli 0157:H7 ATCC \#43889 in NB, $\mathrm{AFB}$ and $\mathrm{AB}$, at $30^{\circ} \mathrm{C}$. 


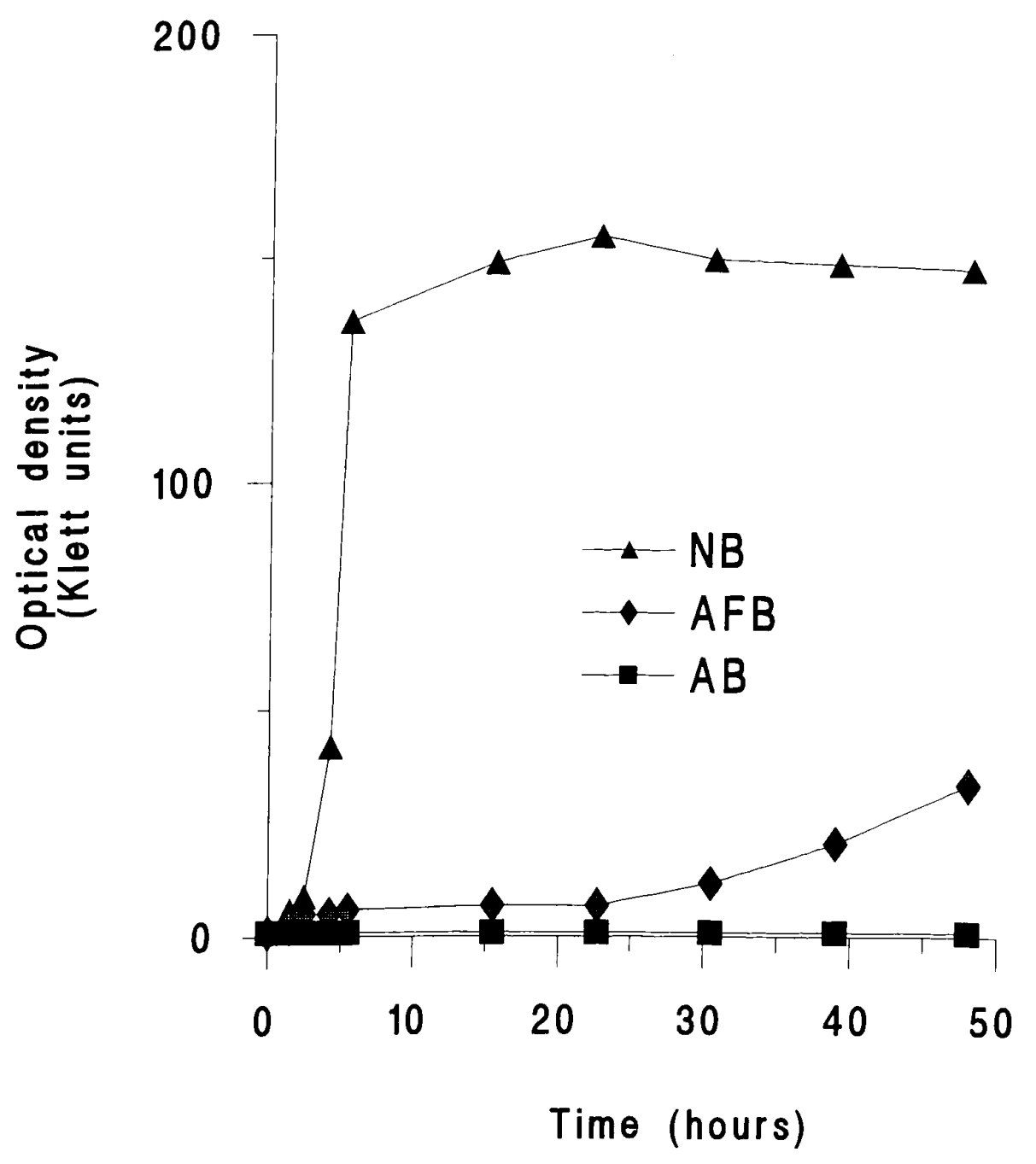

Fig 7.17: Growth curves of Klebsiella pneumoniae ATCC \#13883 in NB, AFB, and $\mathrm{AB}$, at $30^{\circ} \mathrm{C}$. 


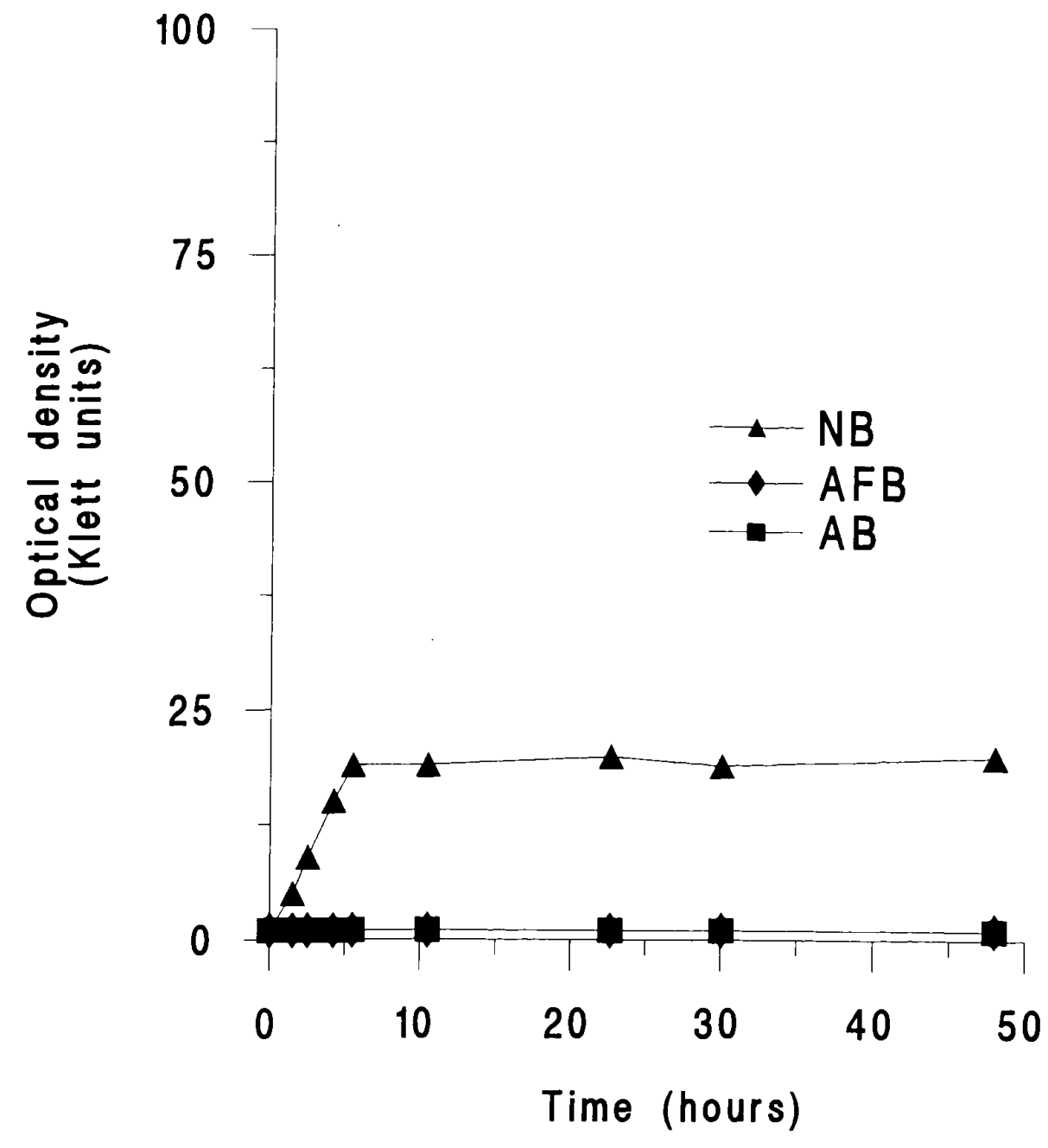

Fig 7.18: Growth curves of Listeria monocytogenes ATCC \#43256 in NB, AFB, and $A B$, at $30^{\circ} \mathrm{C}$. 


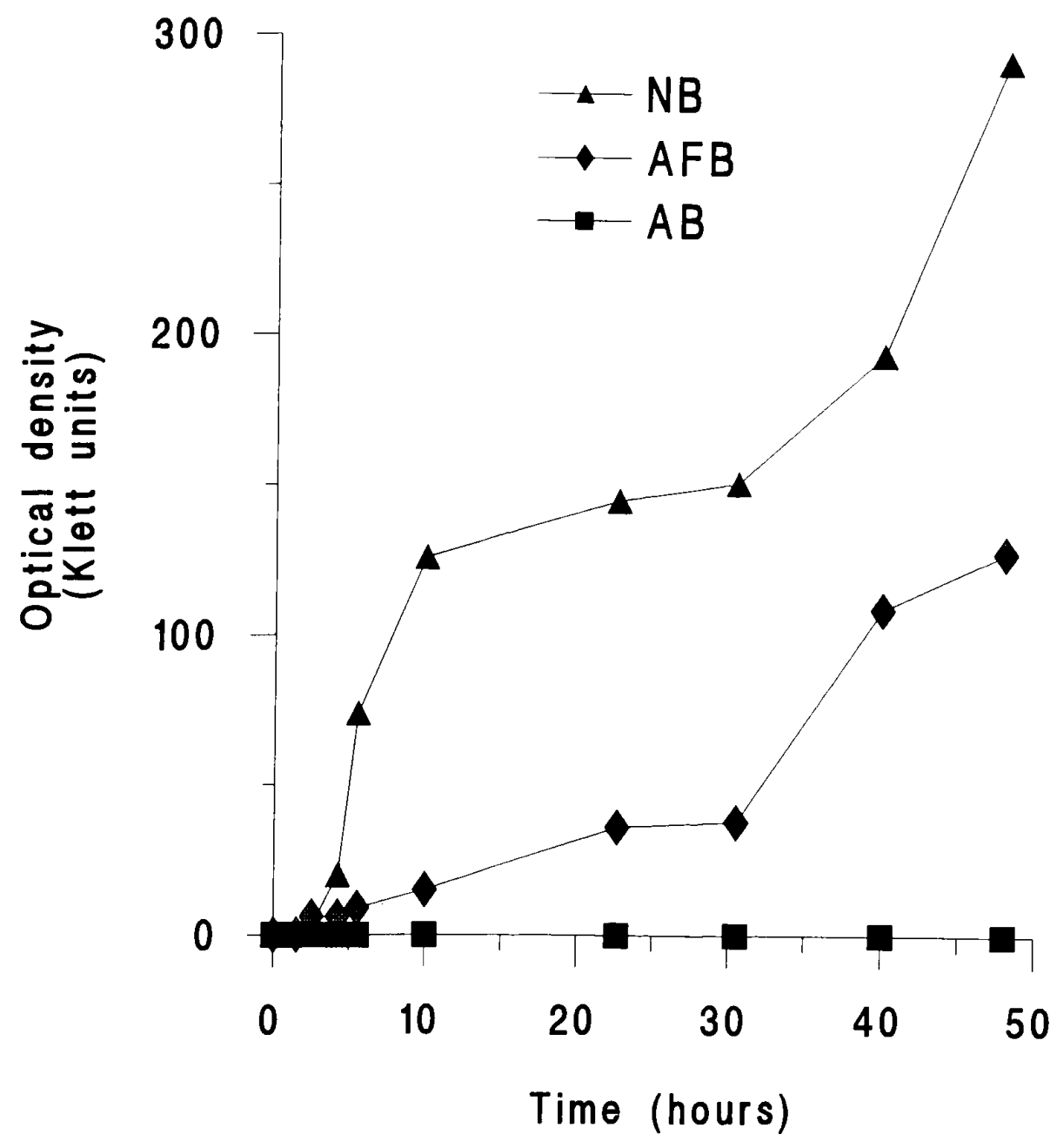

Fig 7.19: Growth curves of Pseudomonas aeruginosa ATCC \#27853 in NB, $\mathrm{AFB}$, and $\mathrm{AB}$, at $30^{\circ} \mathrm{C}$. 


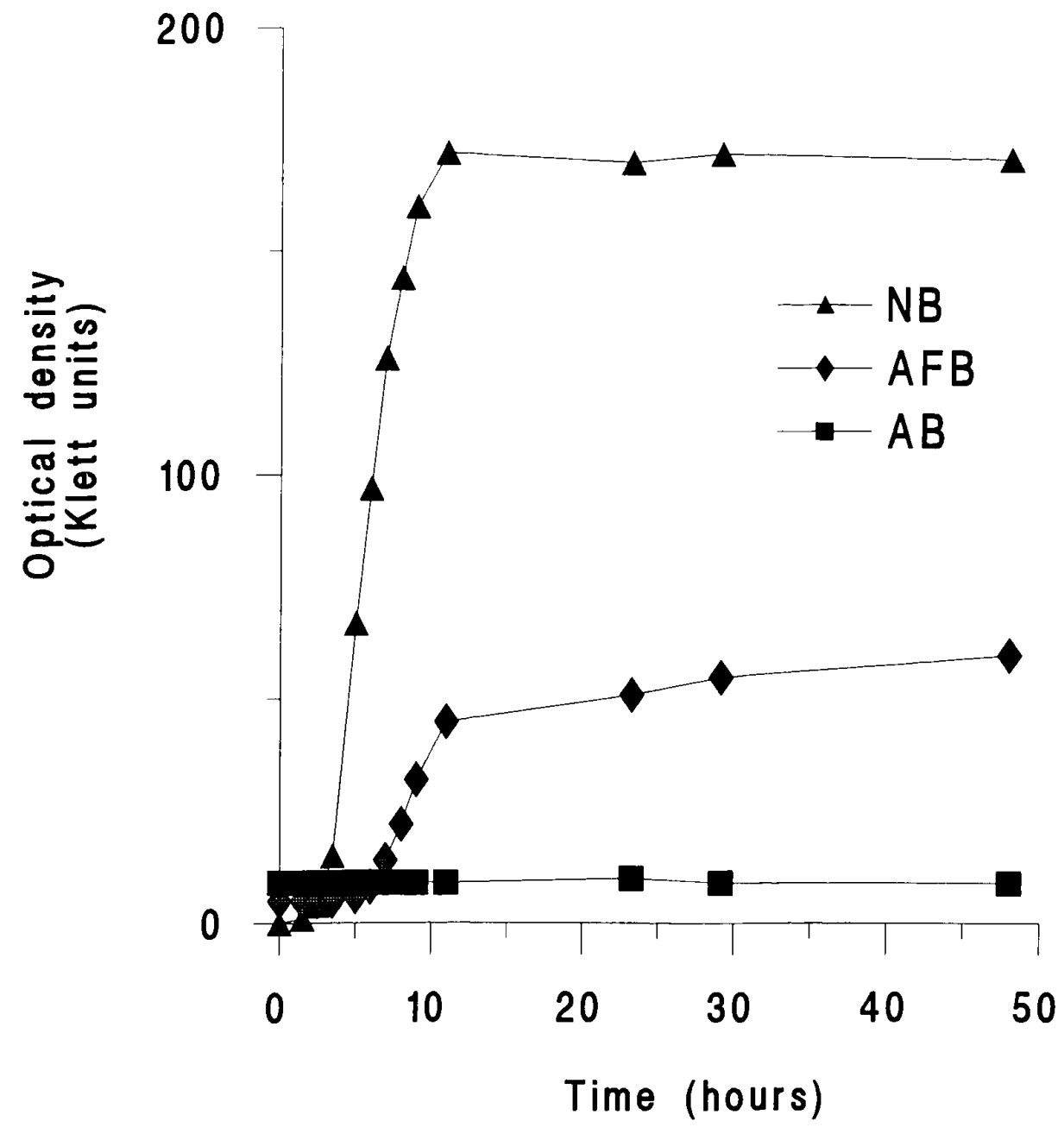

Fig 7.20: Growth curves of Salmonella typhimurium ATCC \#14028 in NB, $\mathrm{AFB}$, and $\mathrm{AB}$, at $30^{\circ} \mathrm{C}$. 


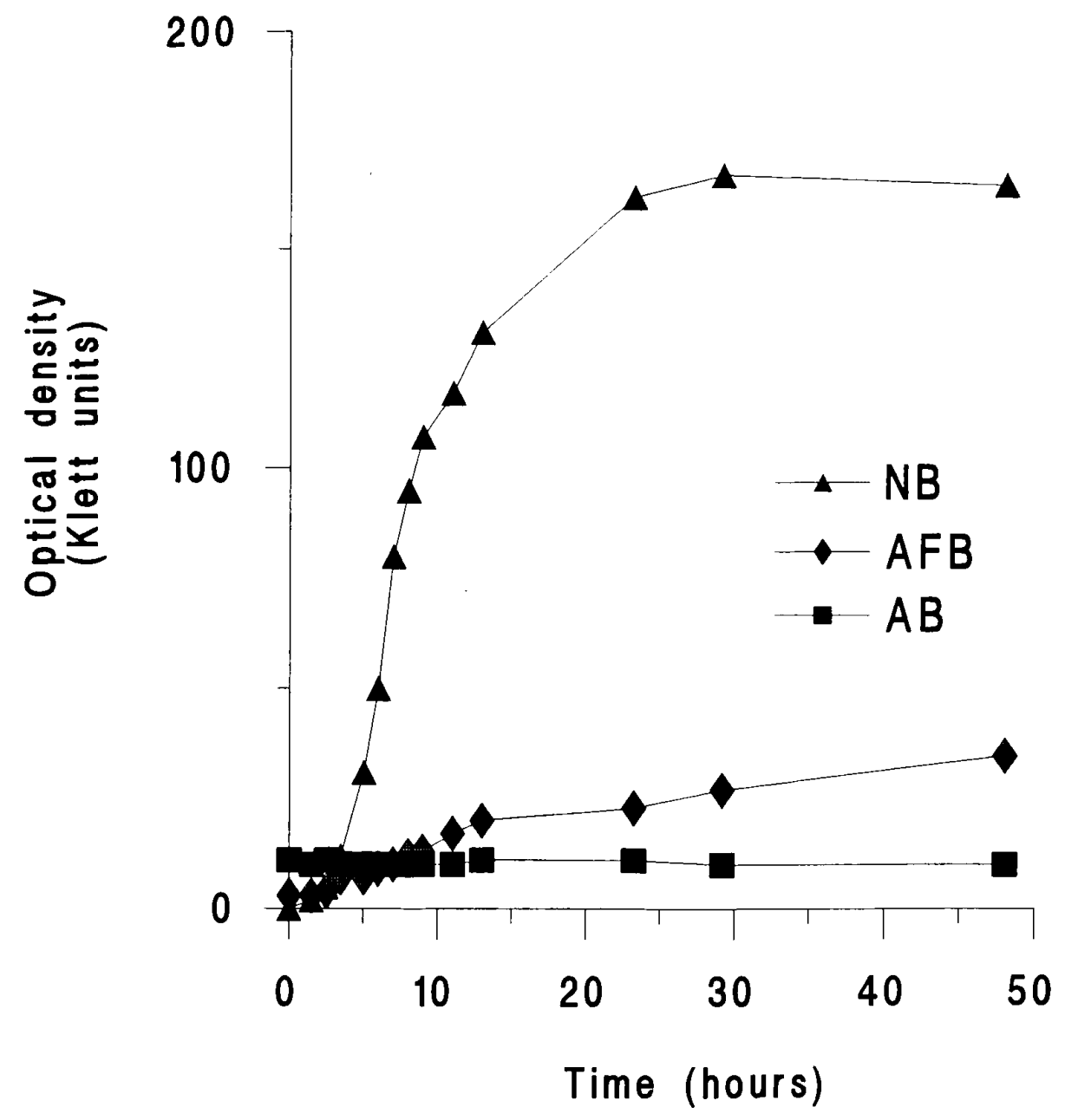

Fig 7.21: Growth curves of Shigella flexneri (Department of Microbiology, University of Saskatchewan) in NB, AFB, and $\mathrm{AB}$, at $30^{\circ} \mathrm{C}$. 


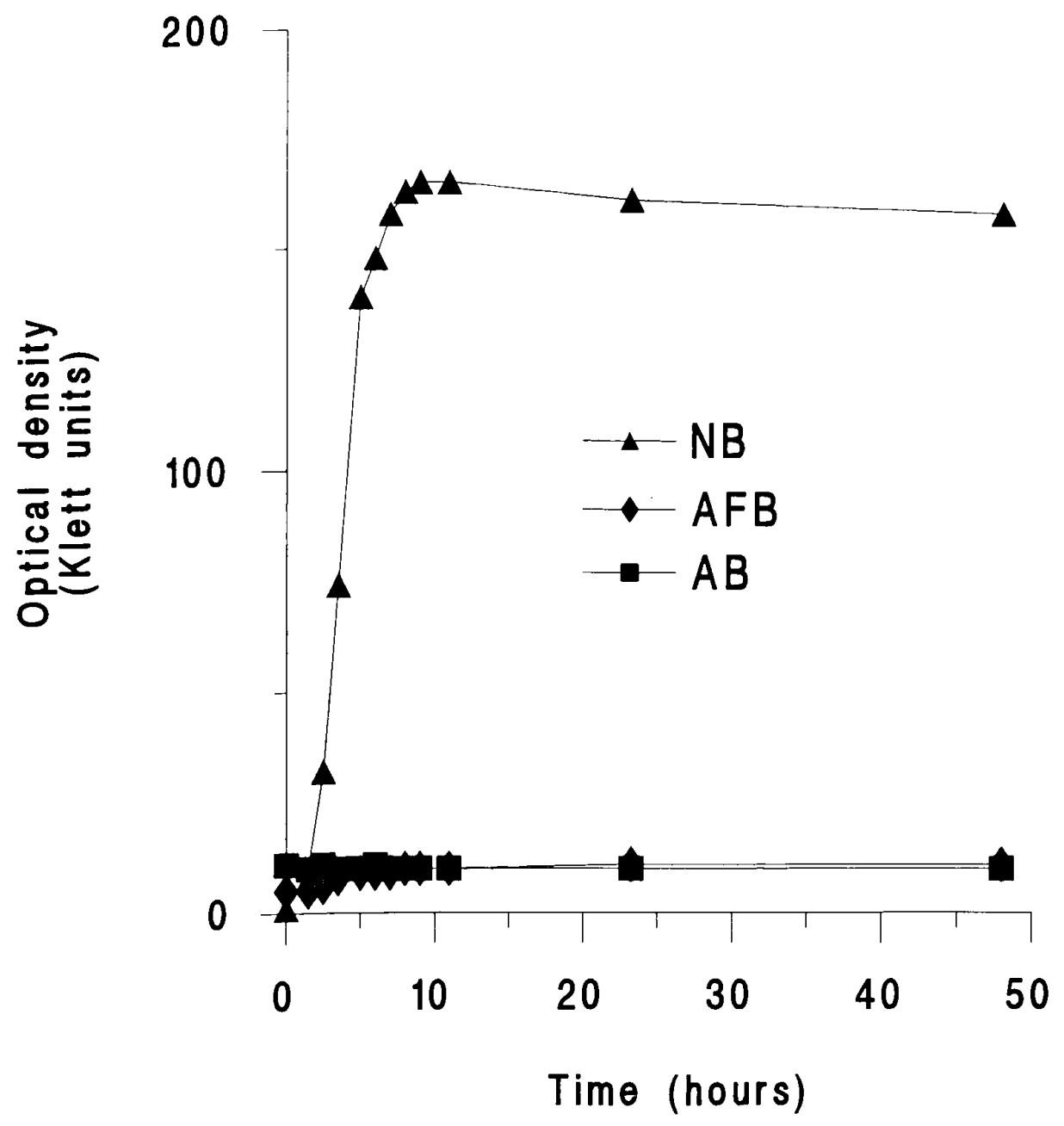

Fig 7.22: Growth curves of Staphylococcus aureus ATCC \#13565 in NB, AFB, and $\mathrm{AB}$, at $30^{\circ} \mathrm{C}$. 


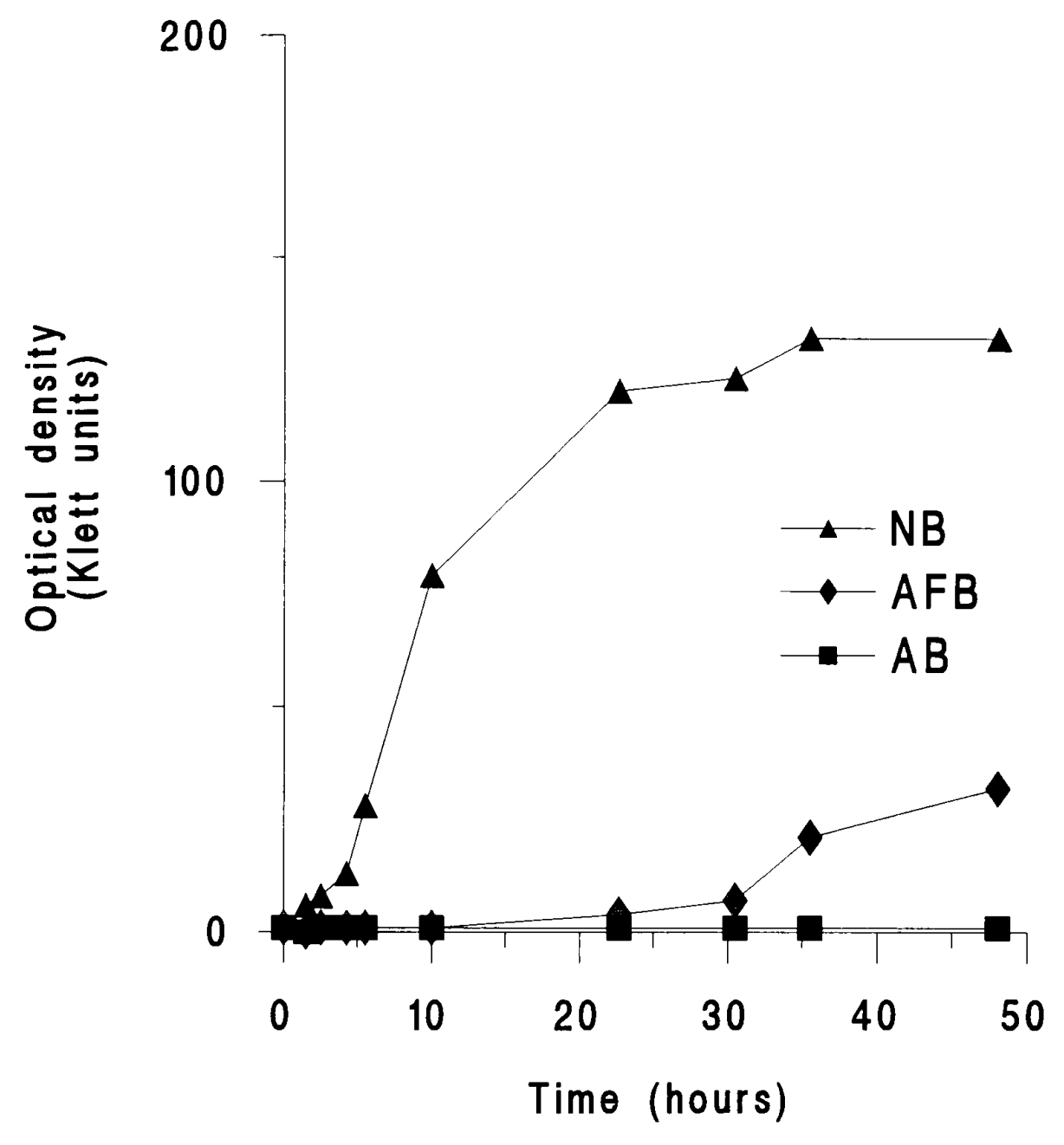

Fig 7.23: Growth curves of Yersinia enterocolitica ATCC \#35669 in NB, AFB, and $\mathrm{AB}$, at $30^{\circ} \mathrm{C}$. 


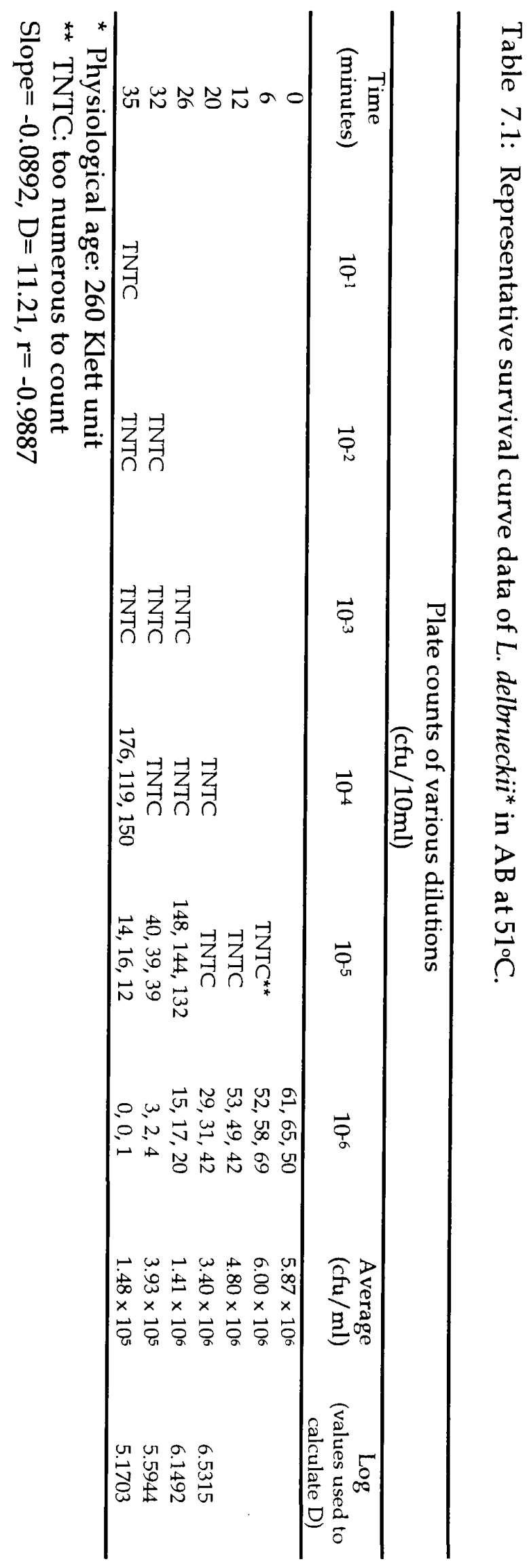




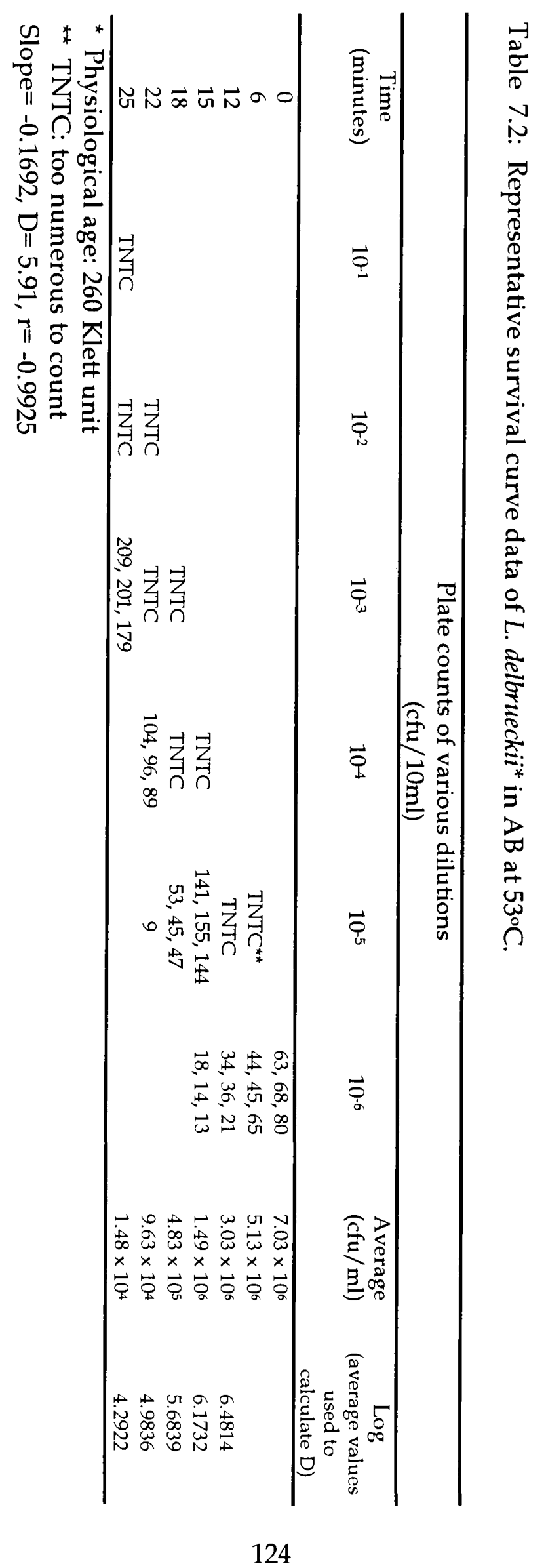




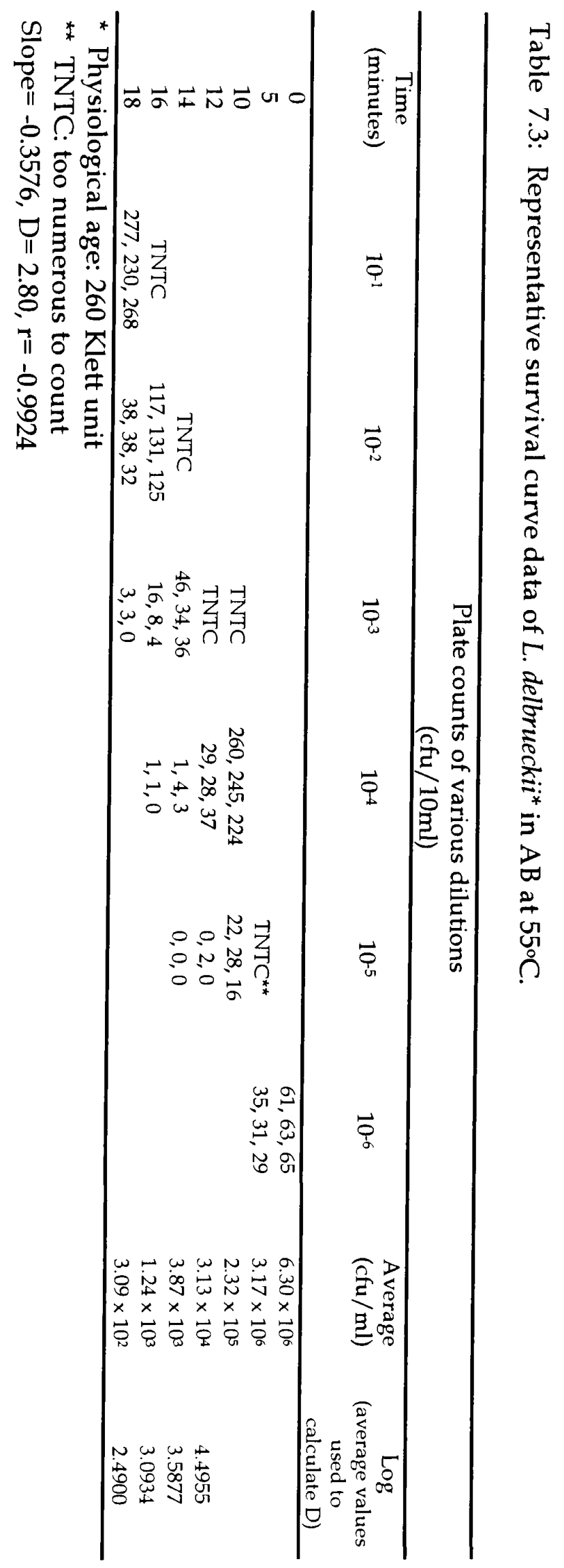




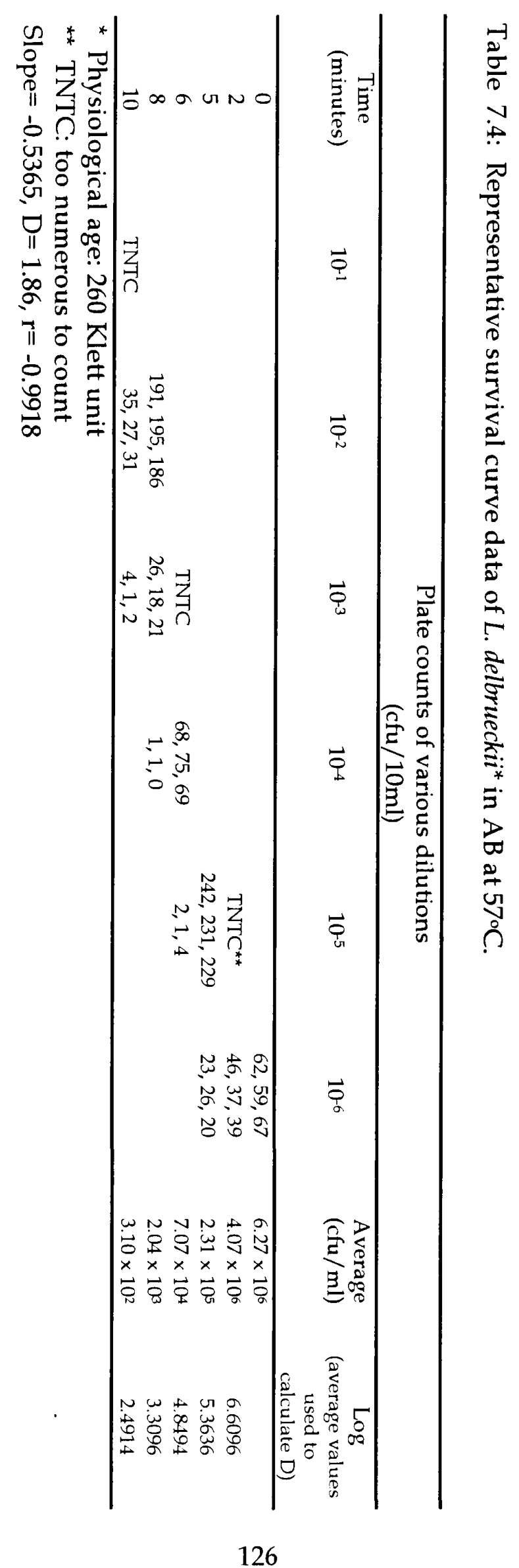




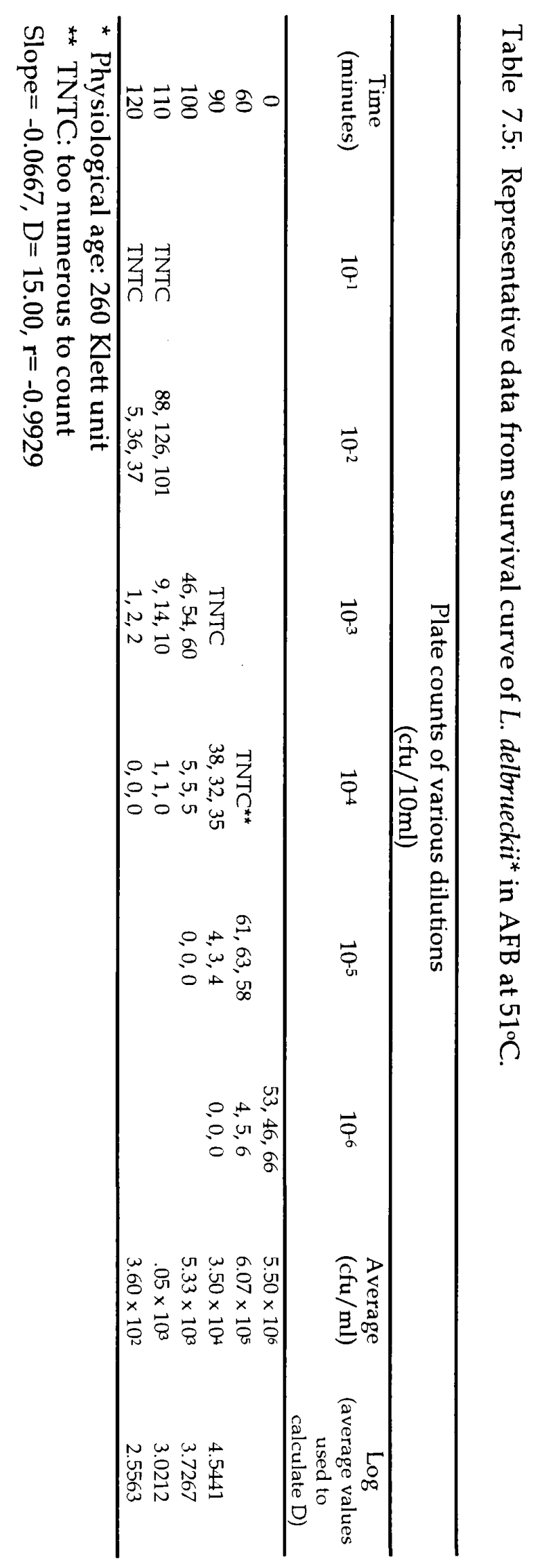




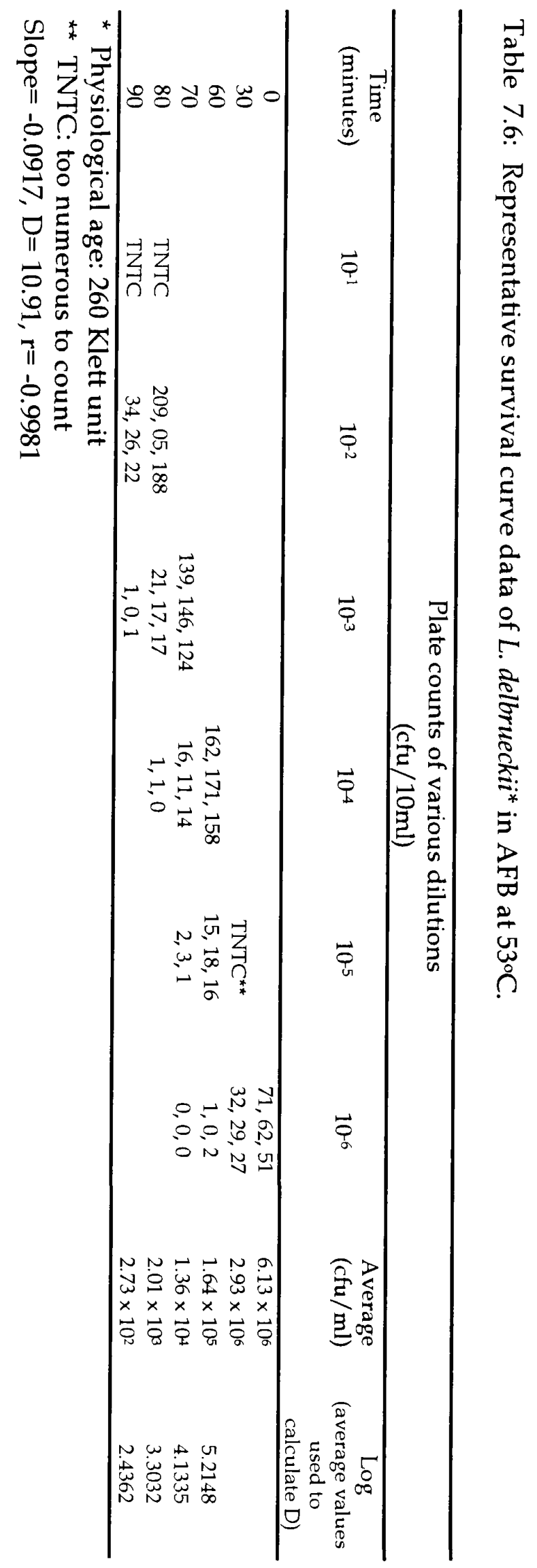




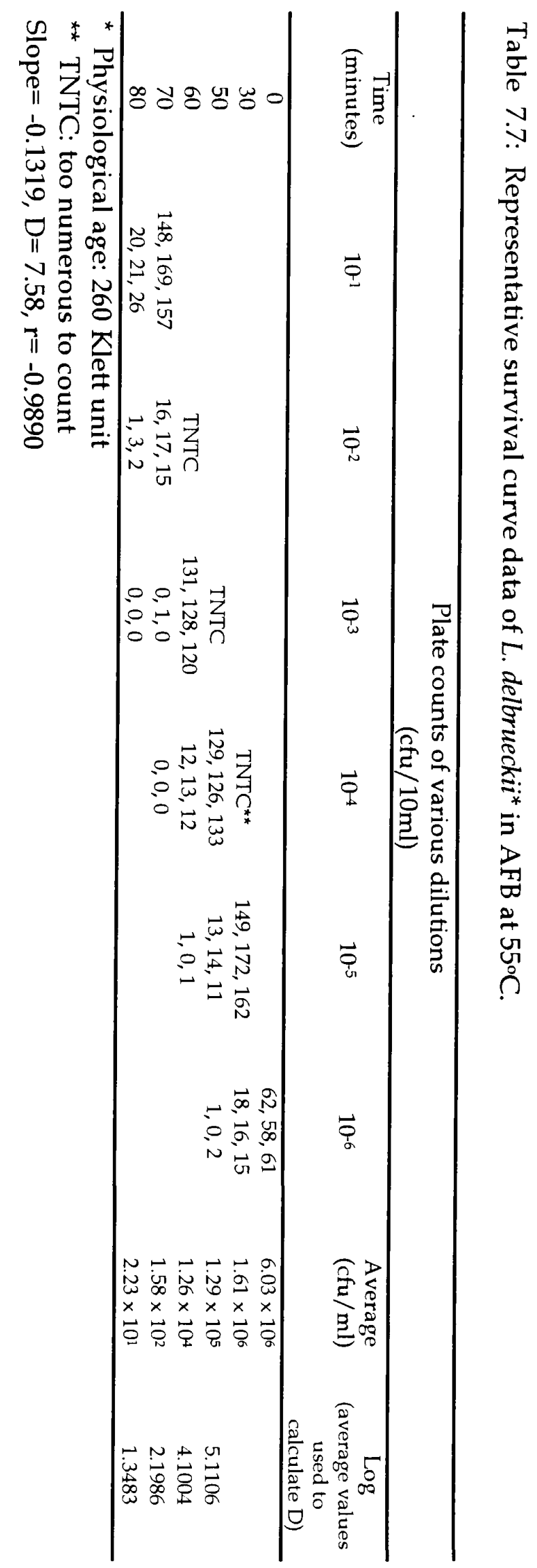




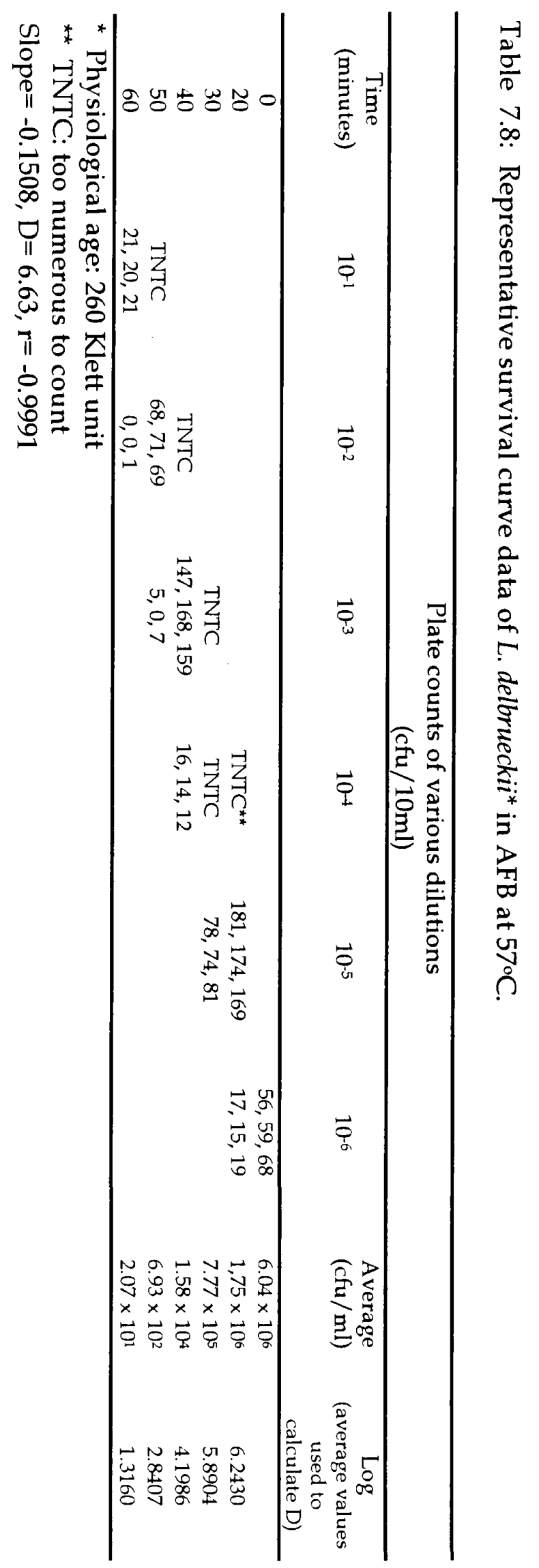




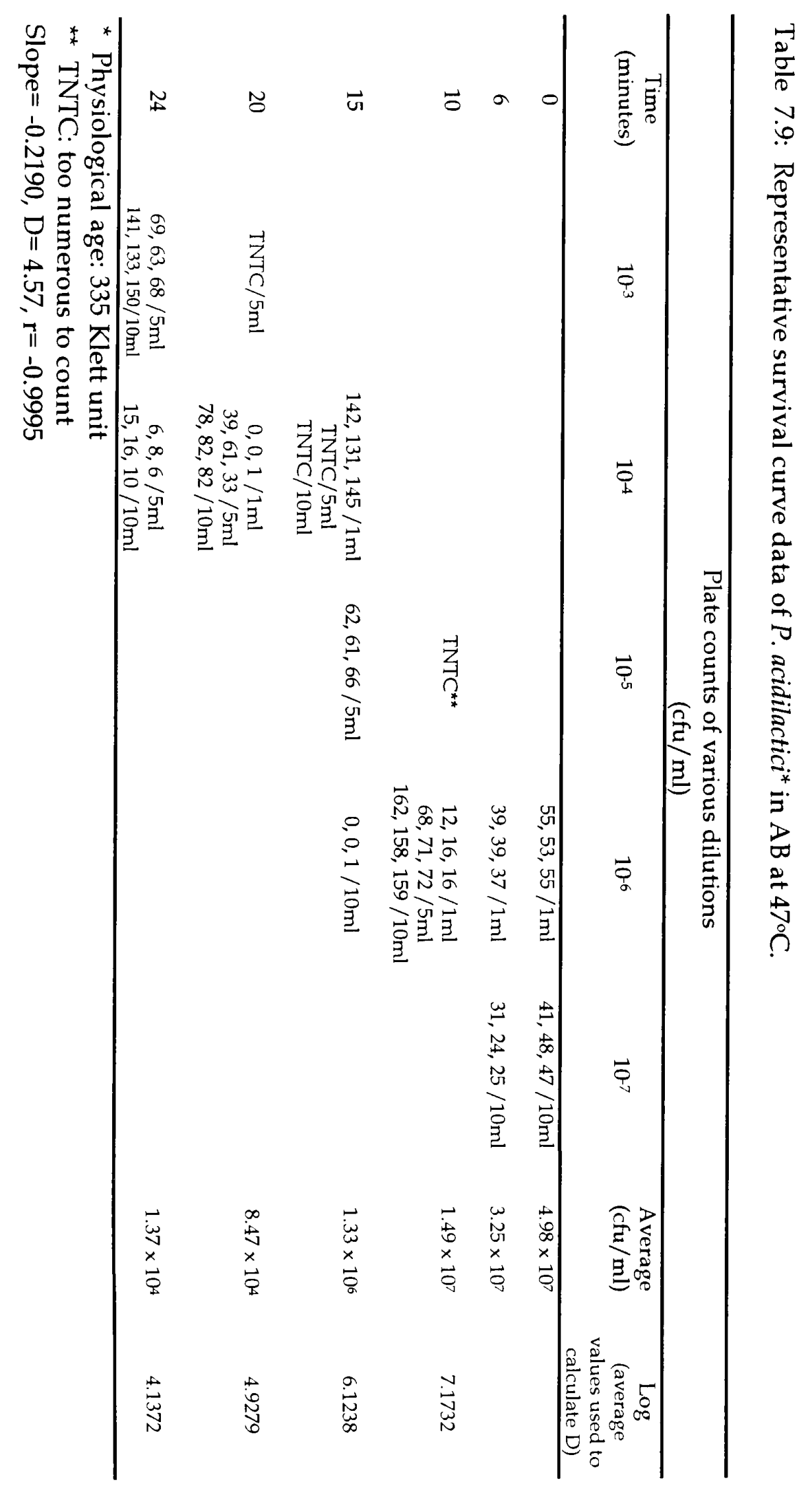




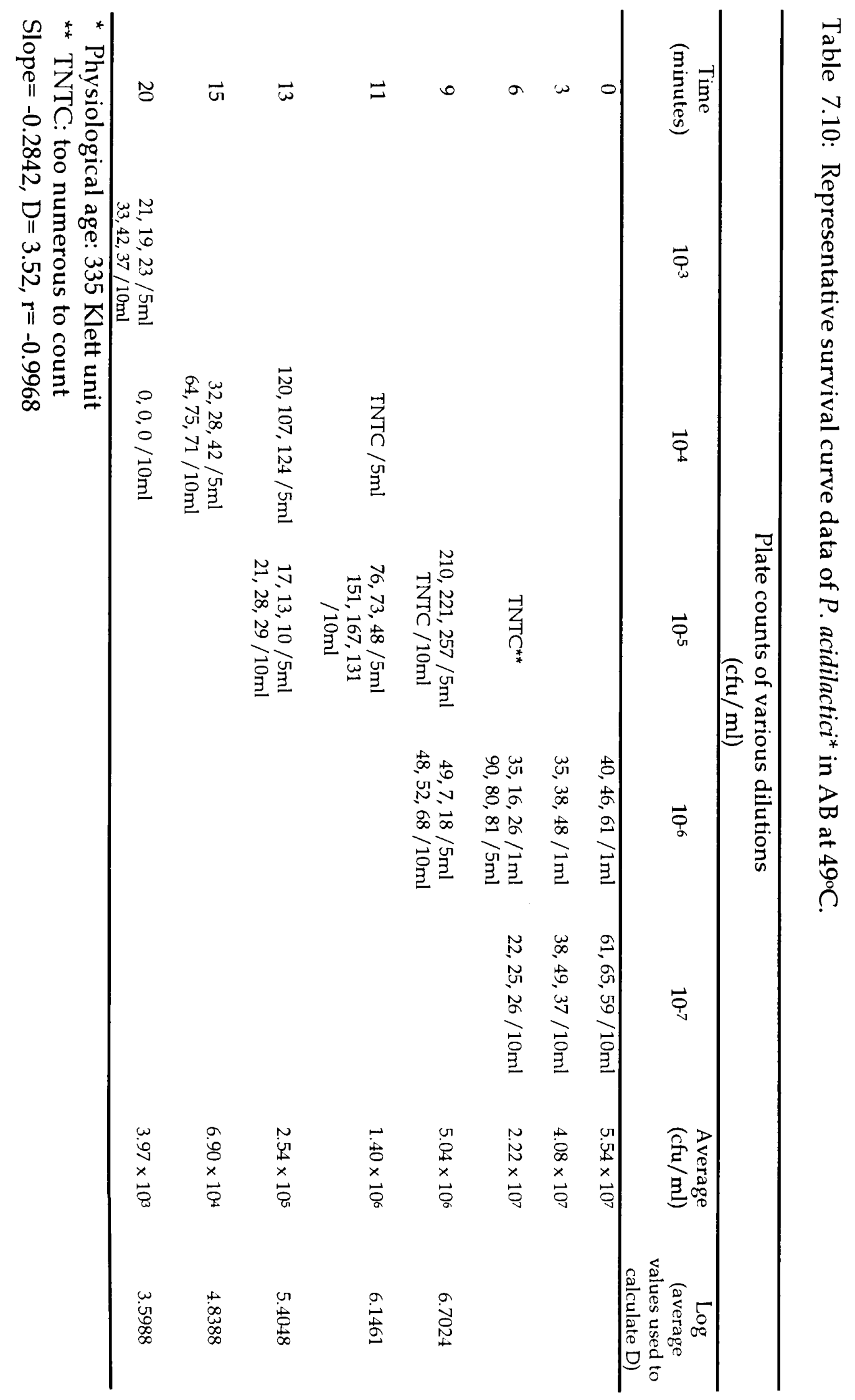




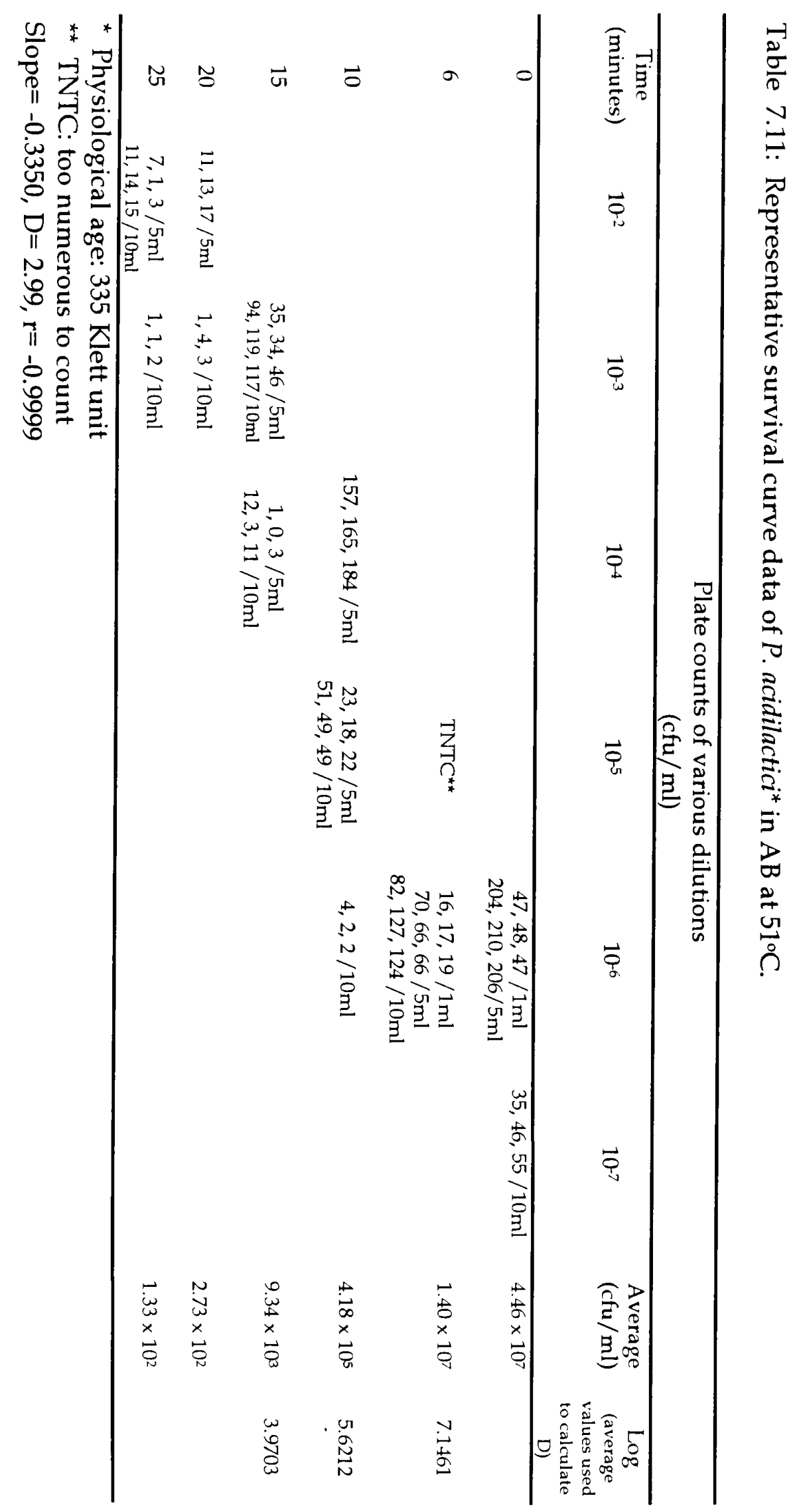




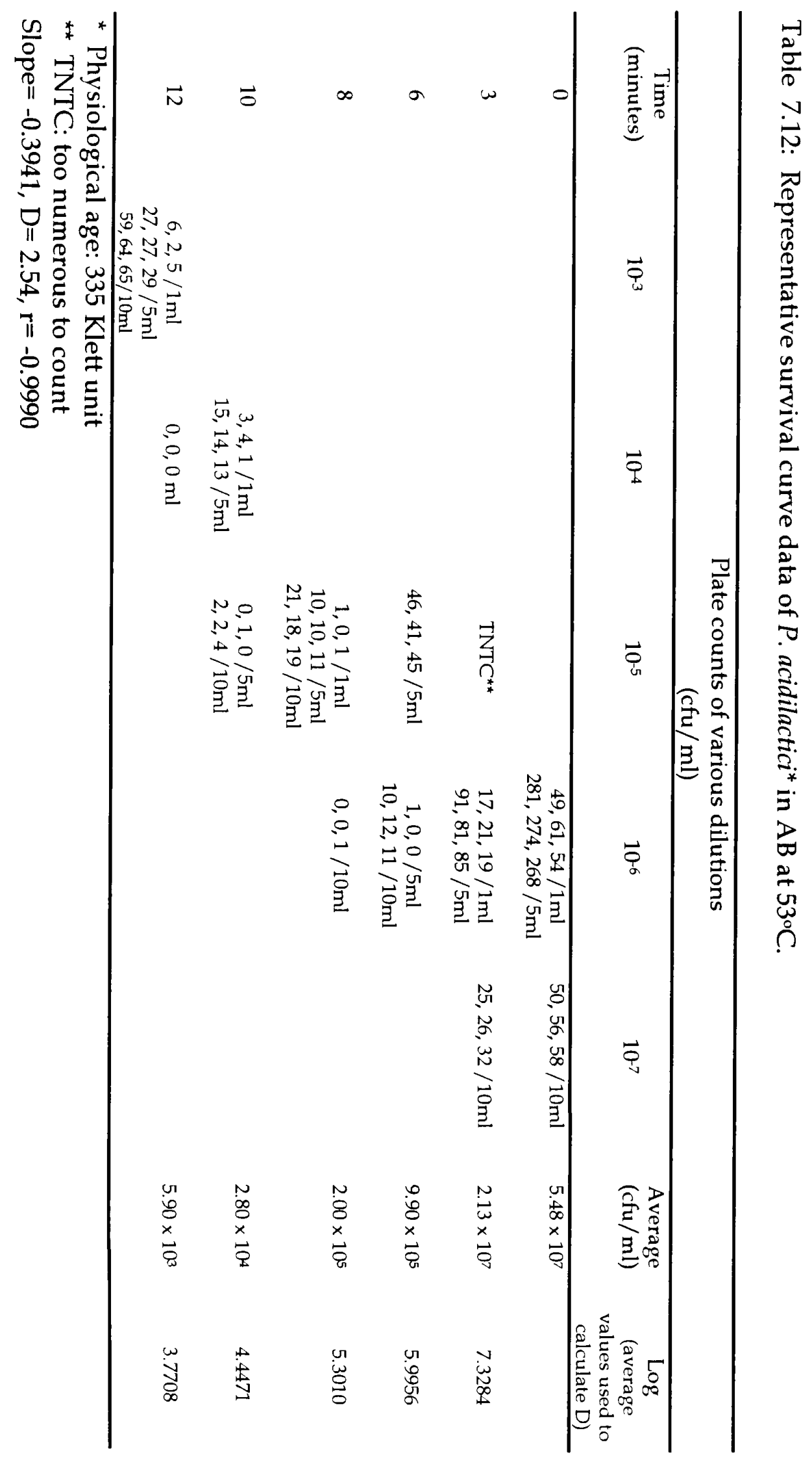




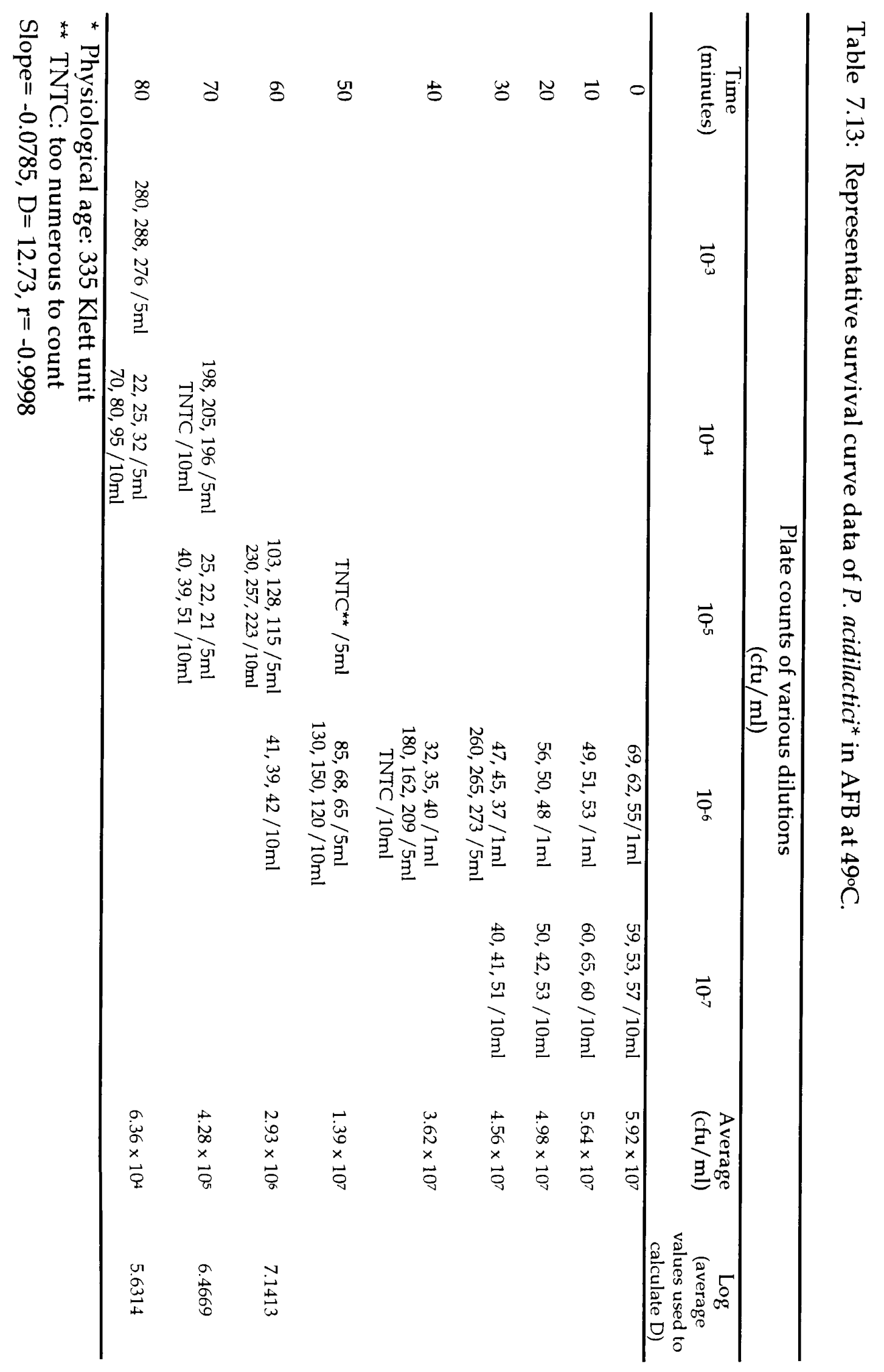




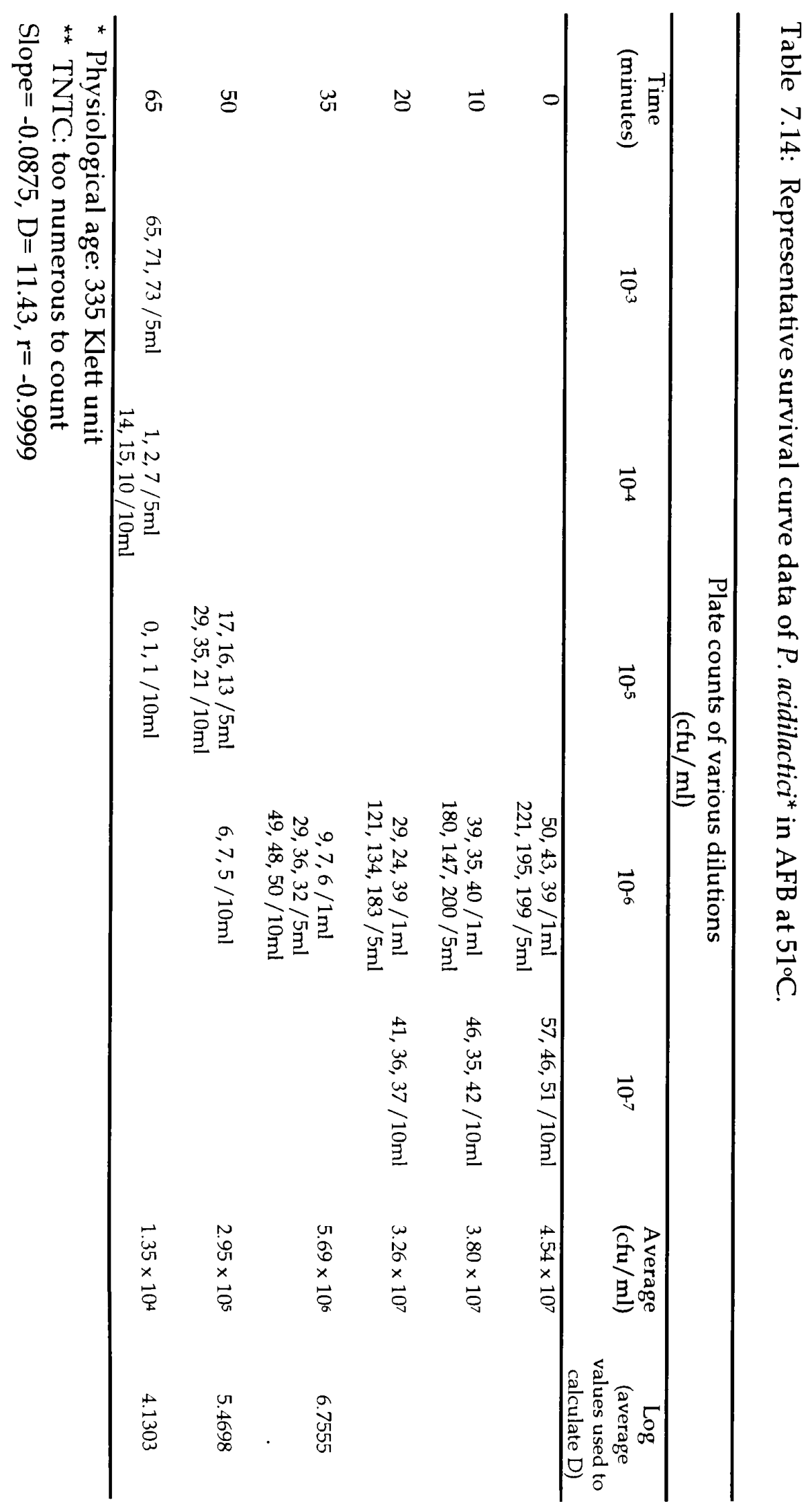




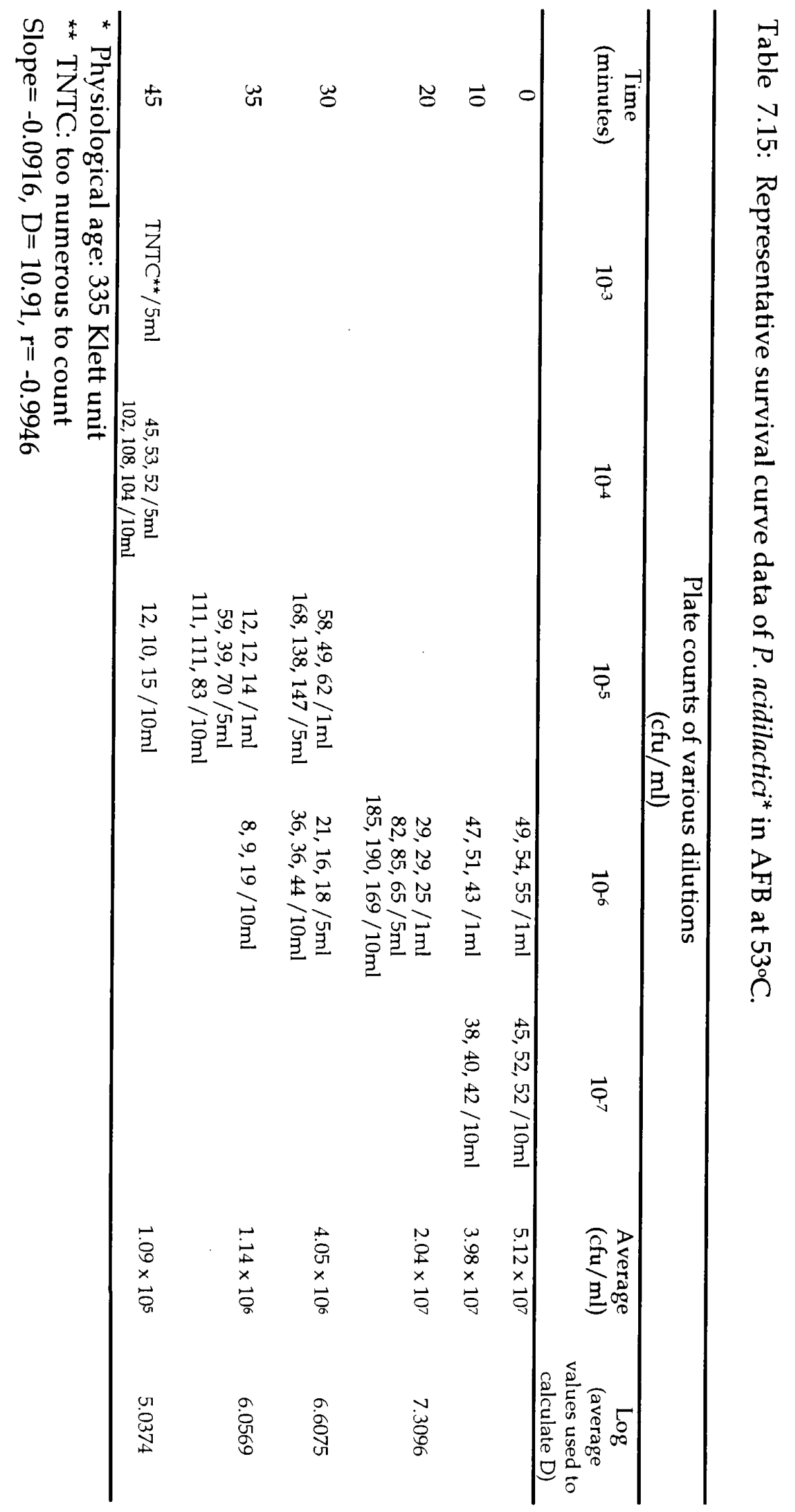




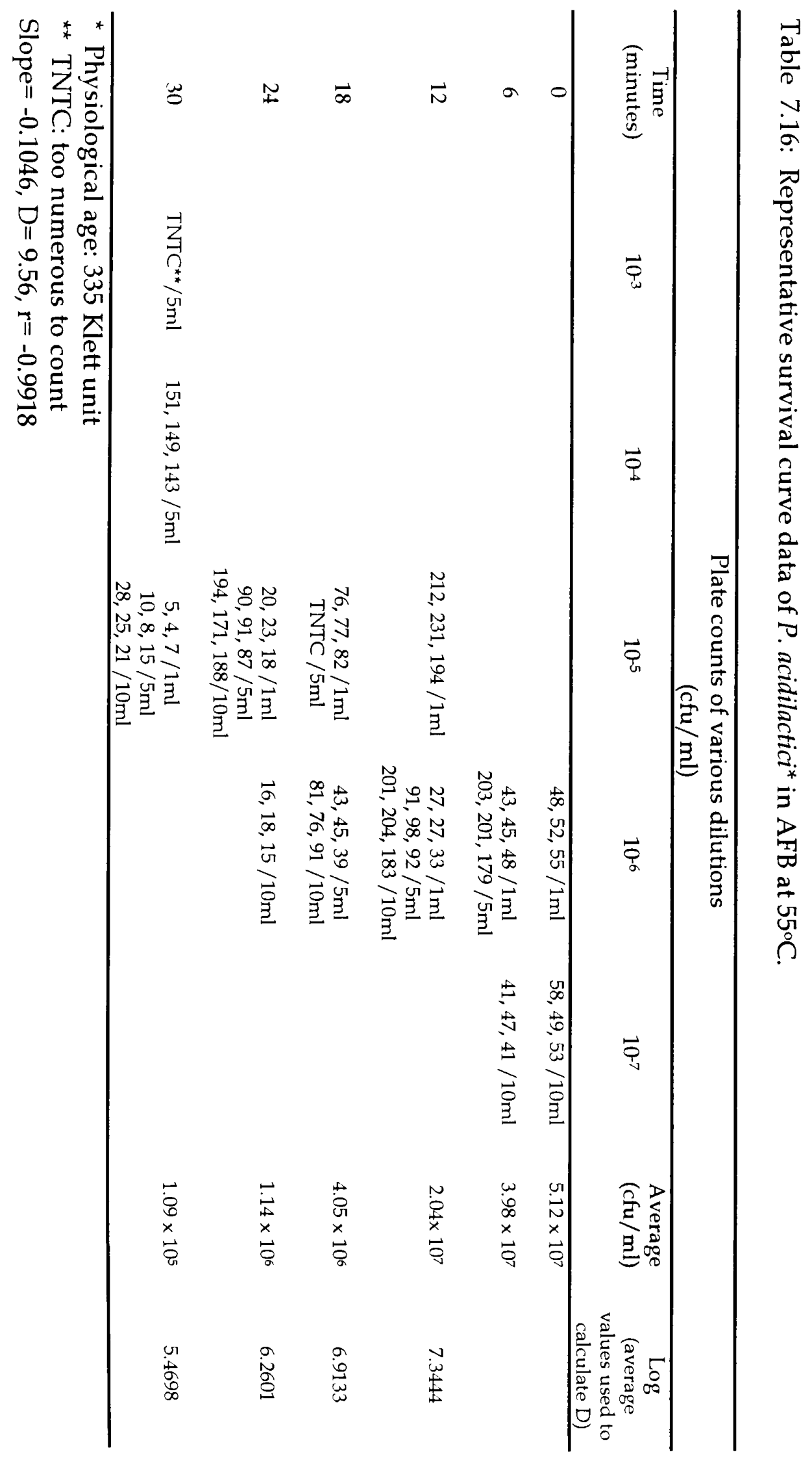




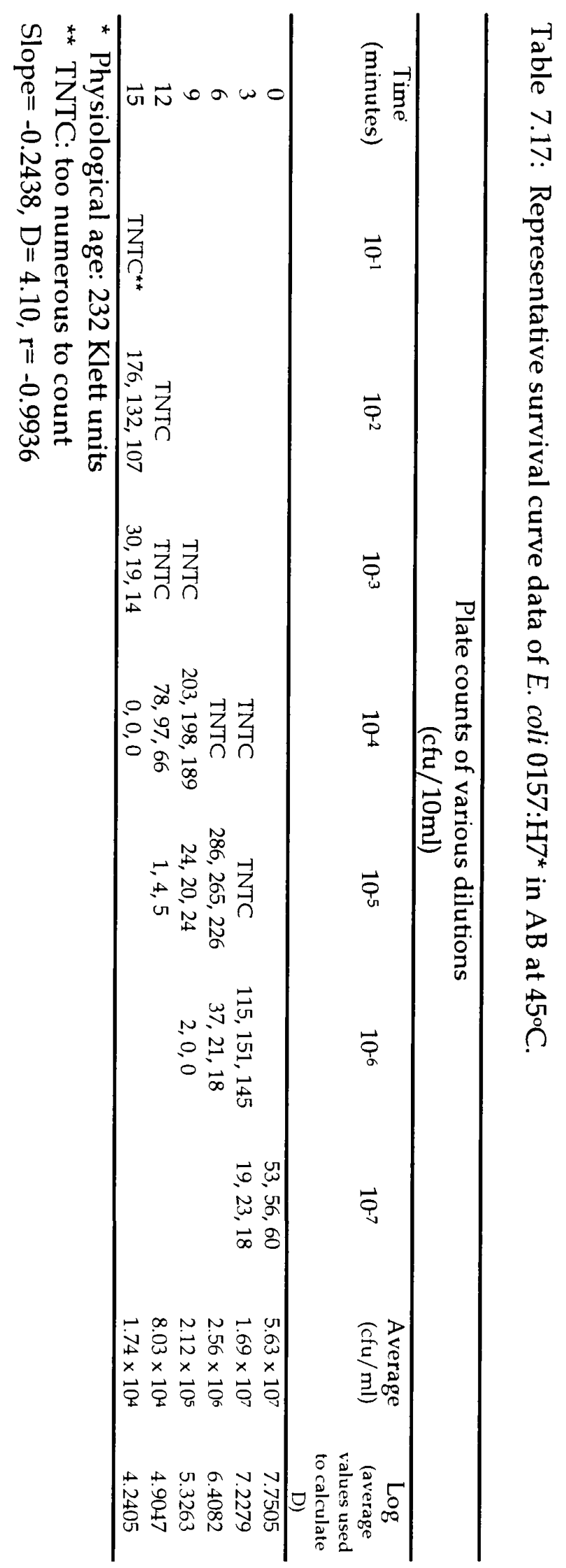




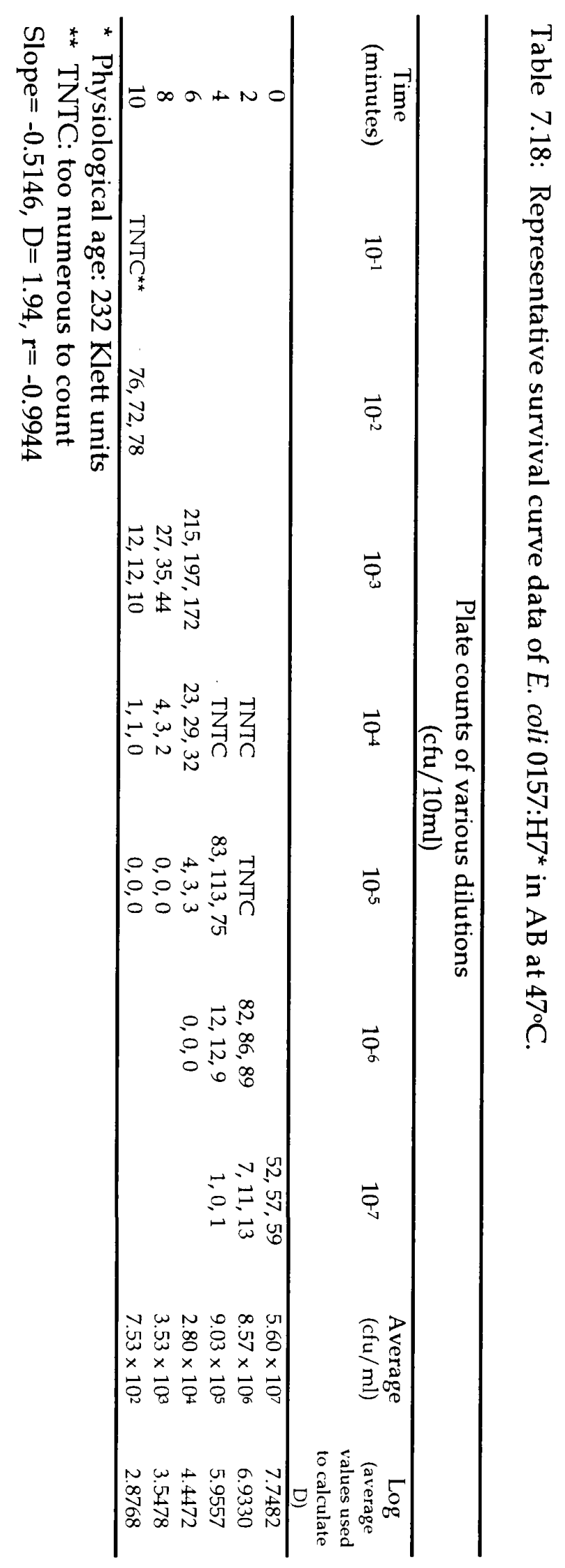




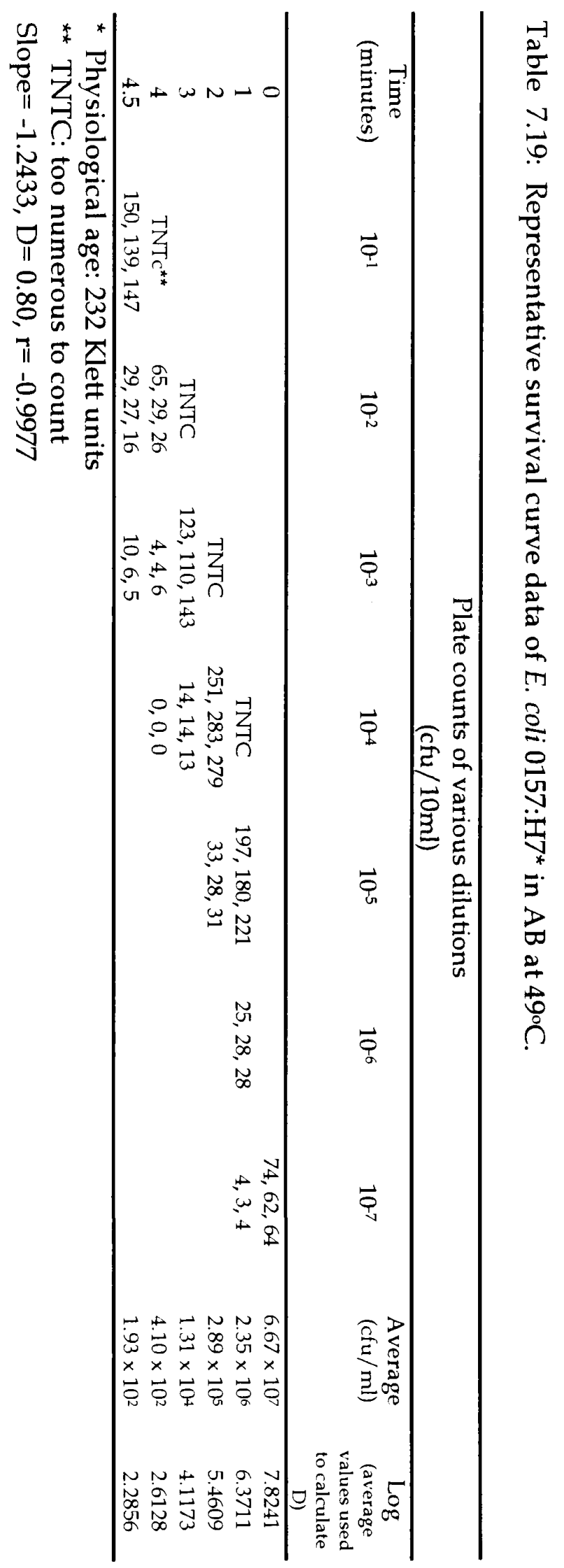




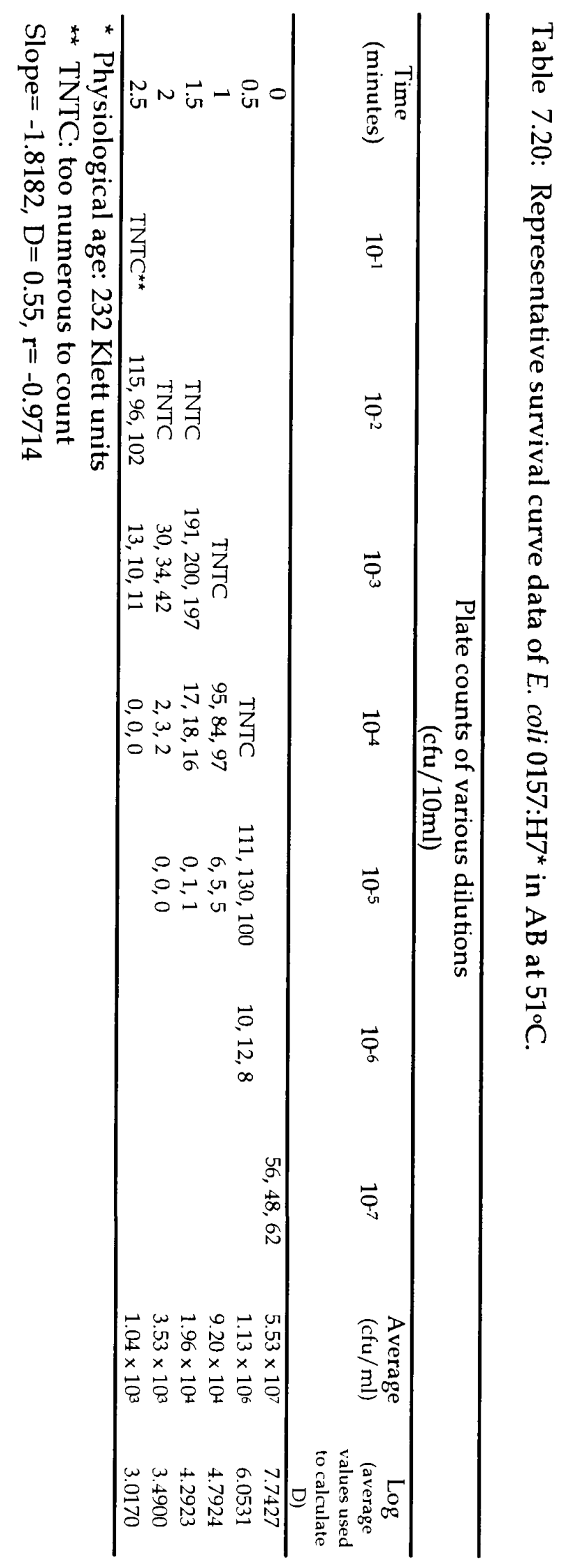




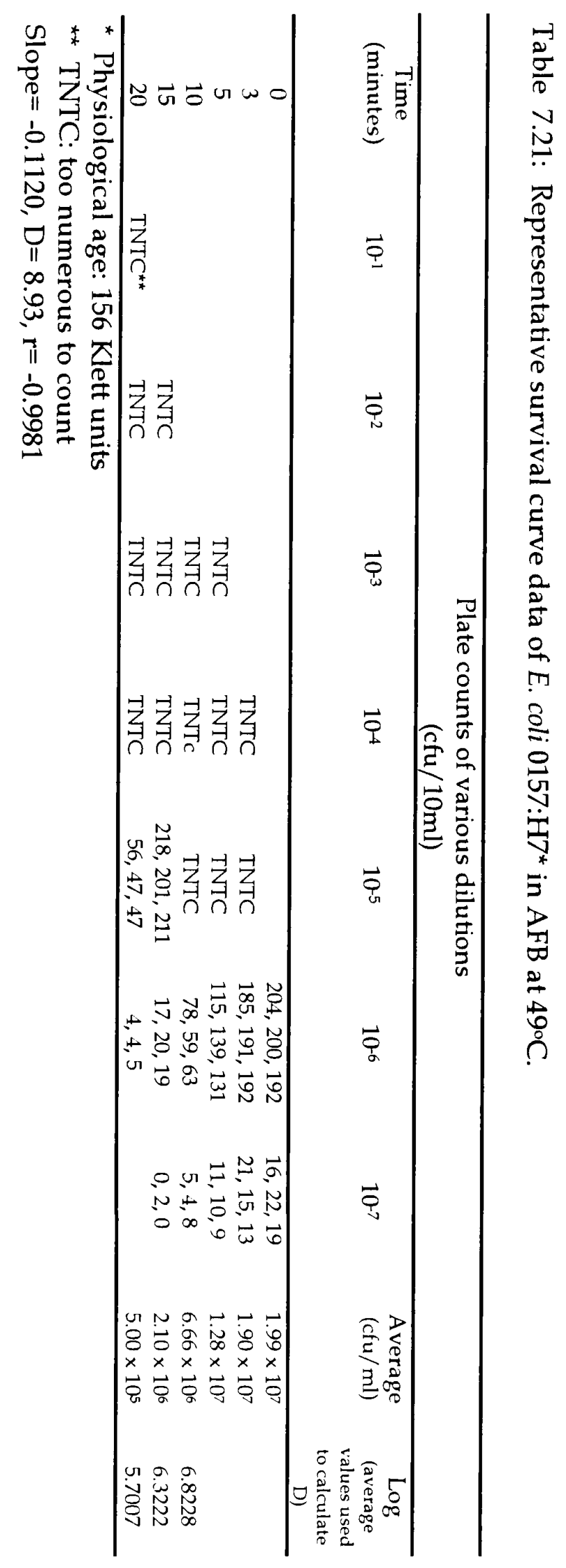




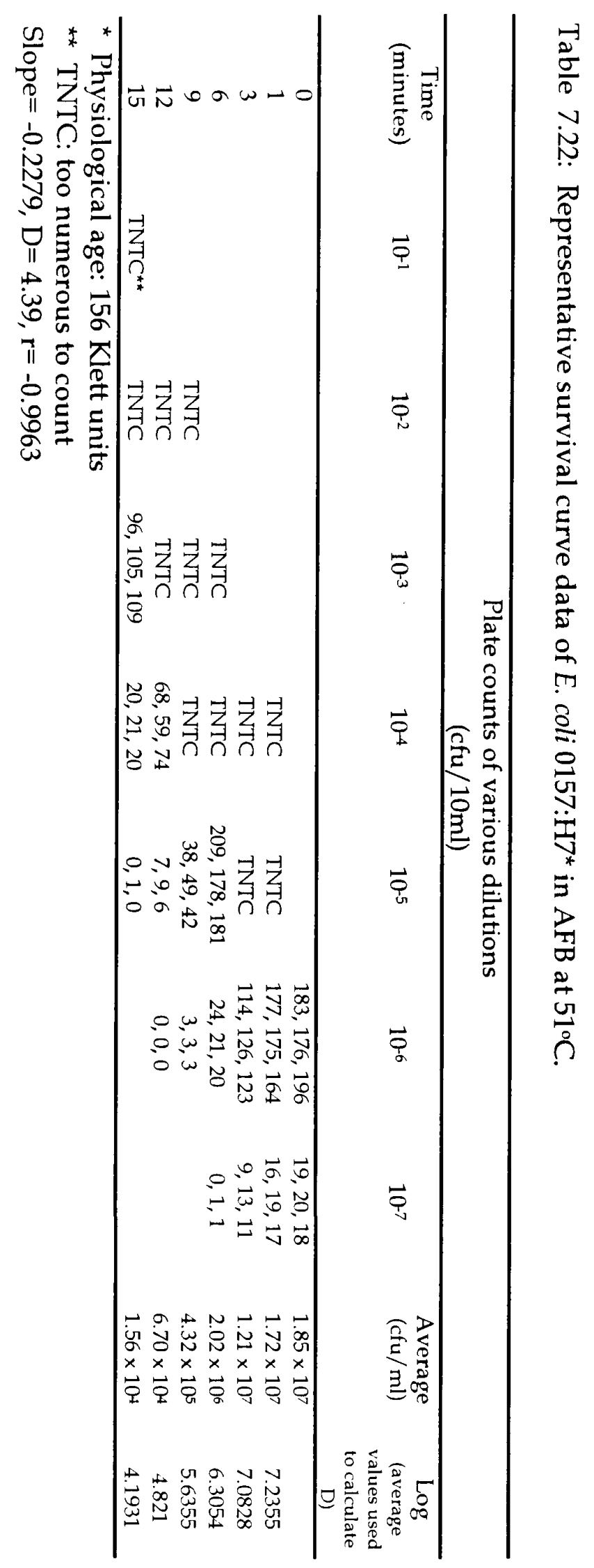




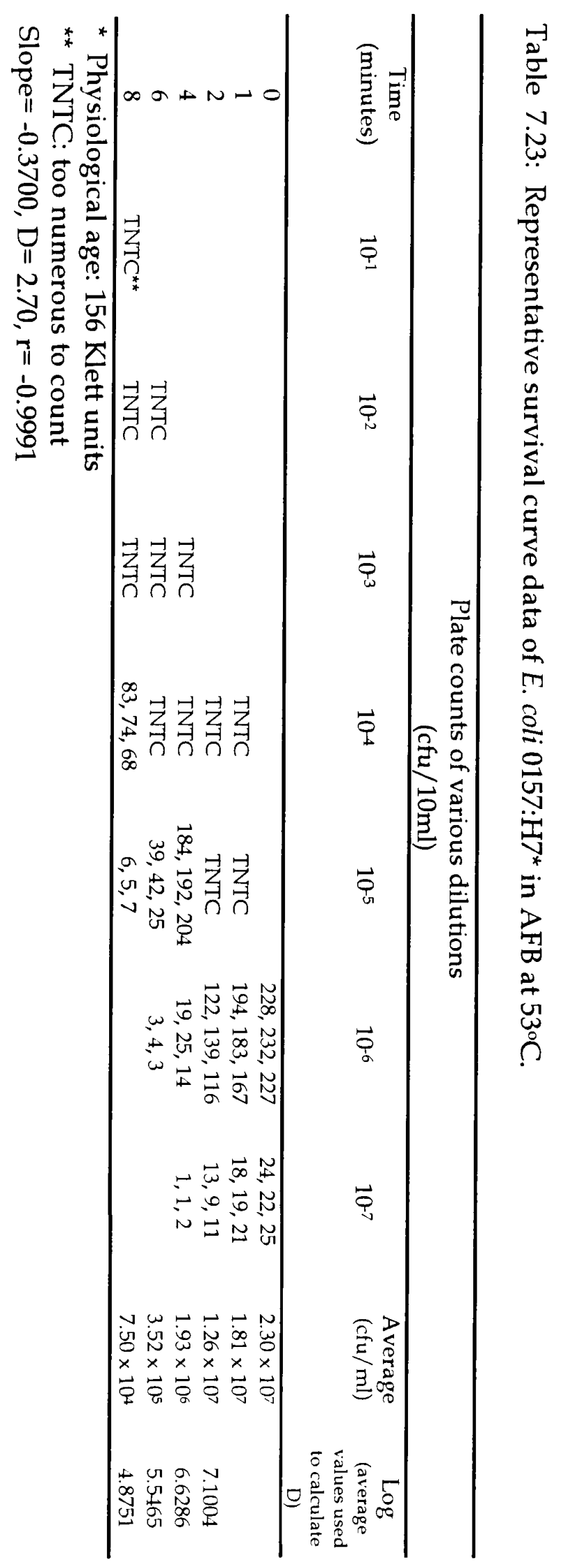




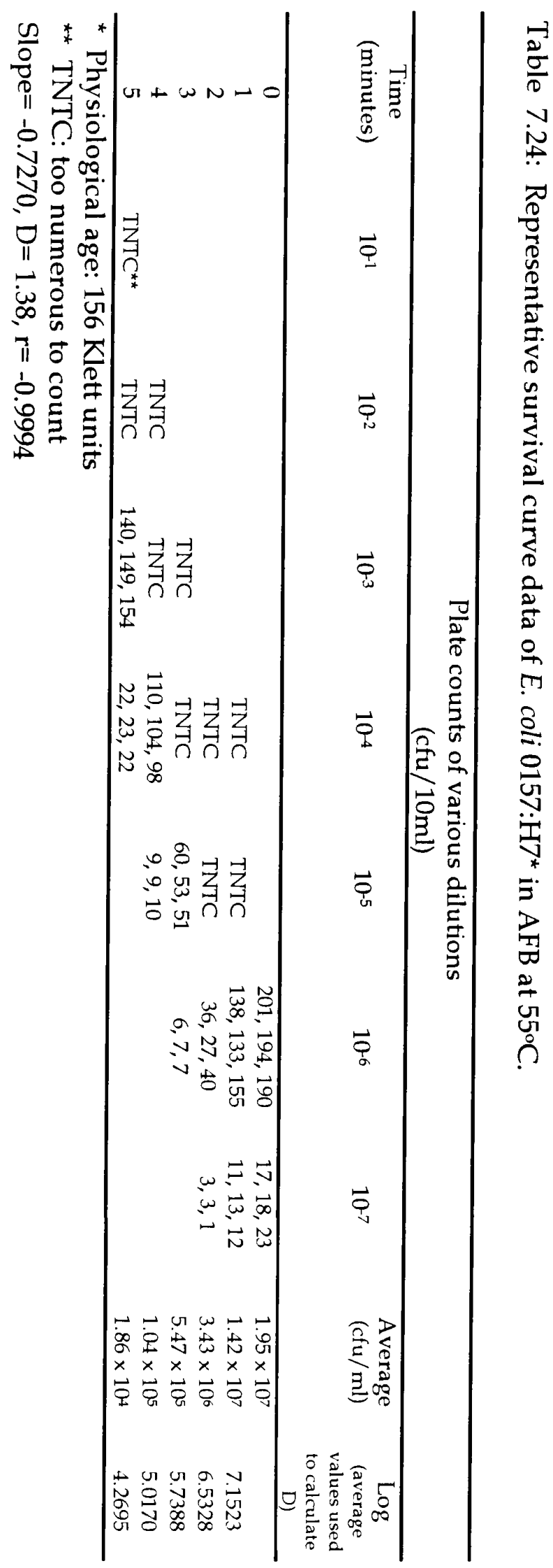




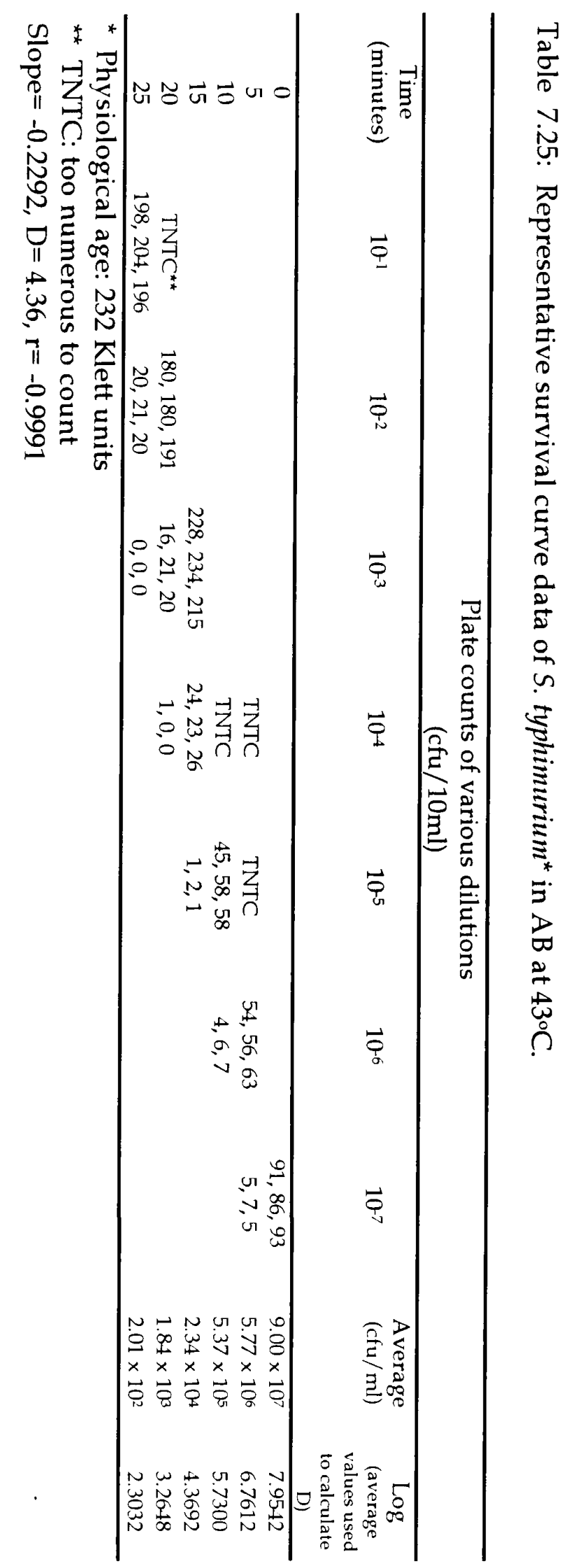




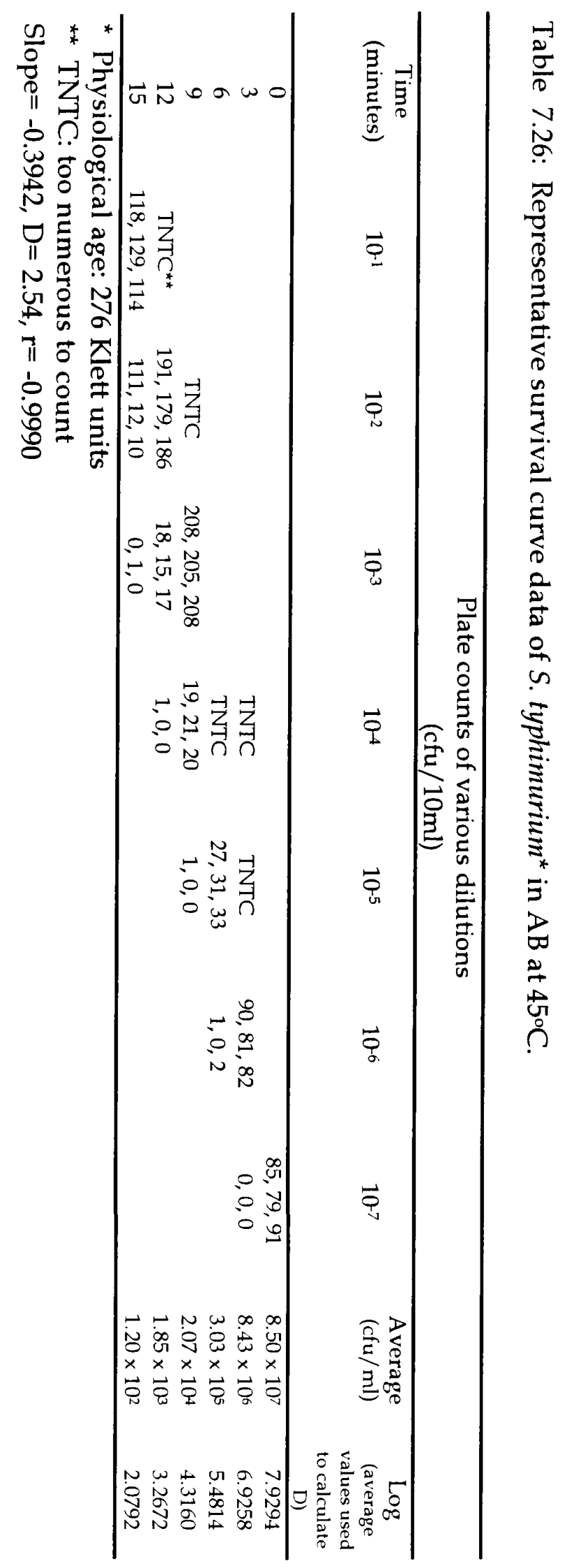




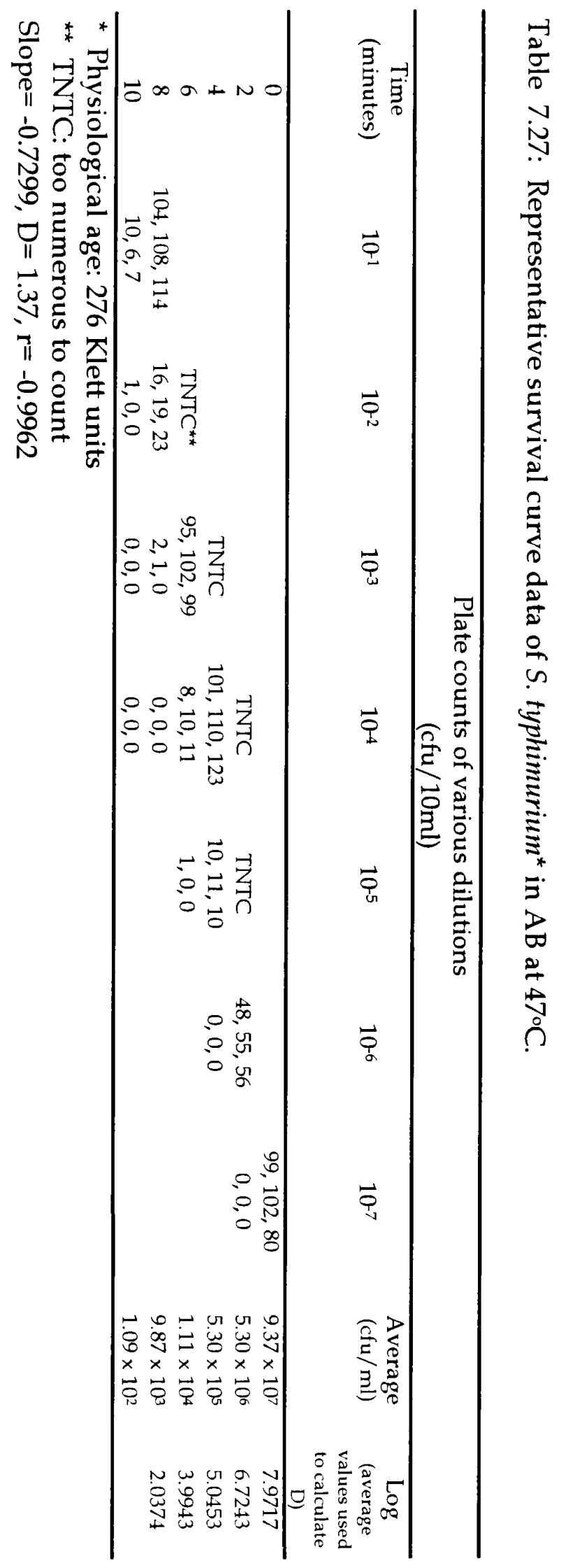




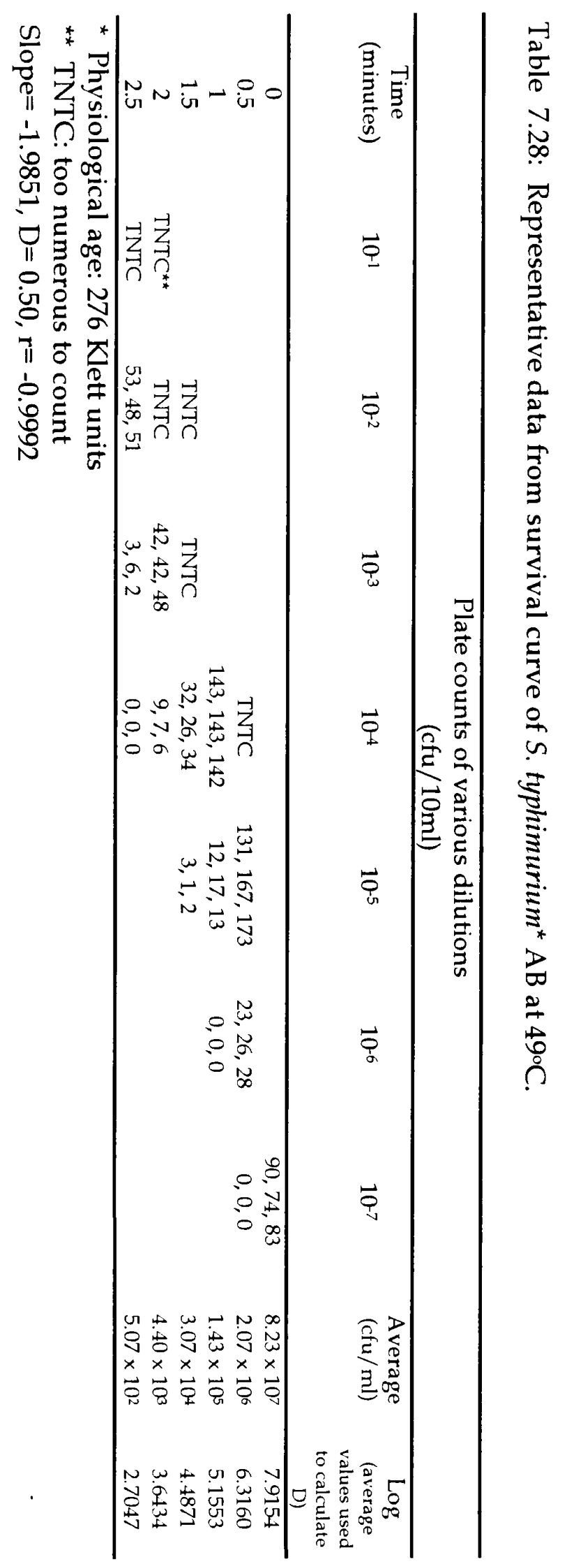




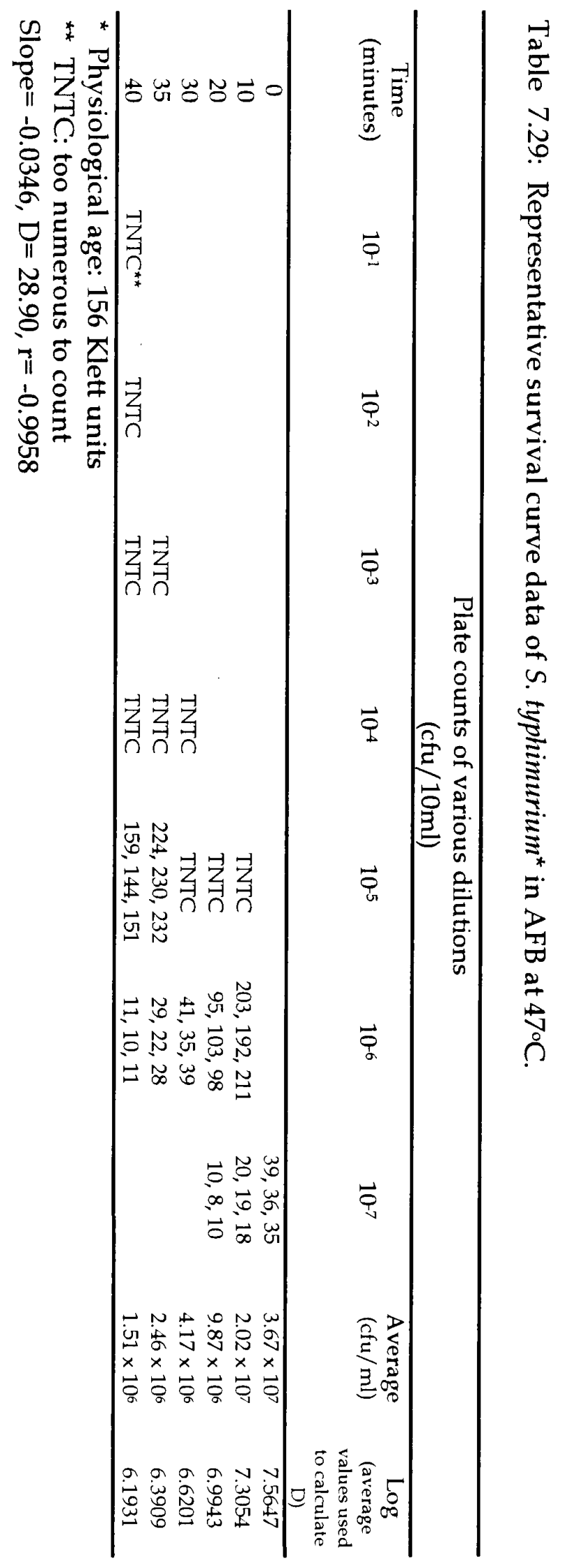




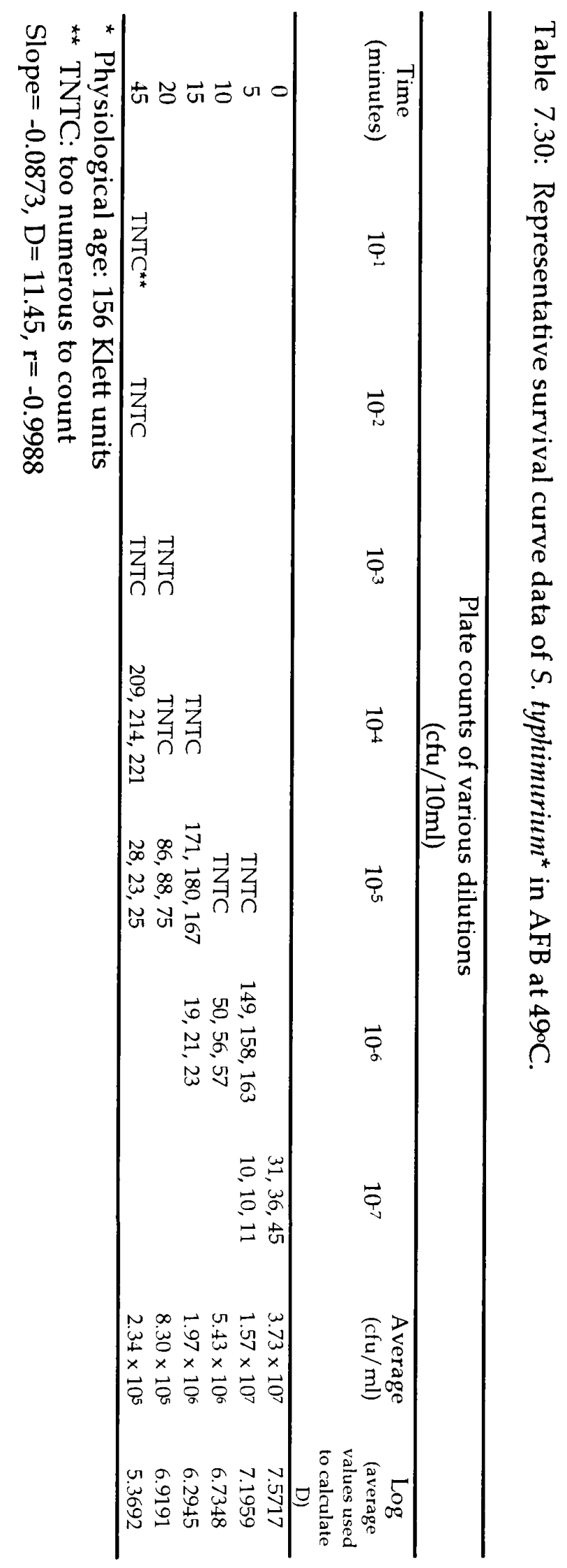




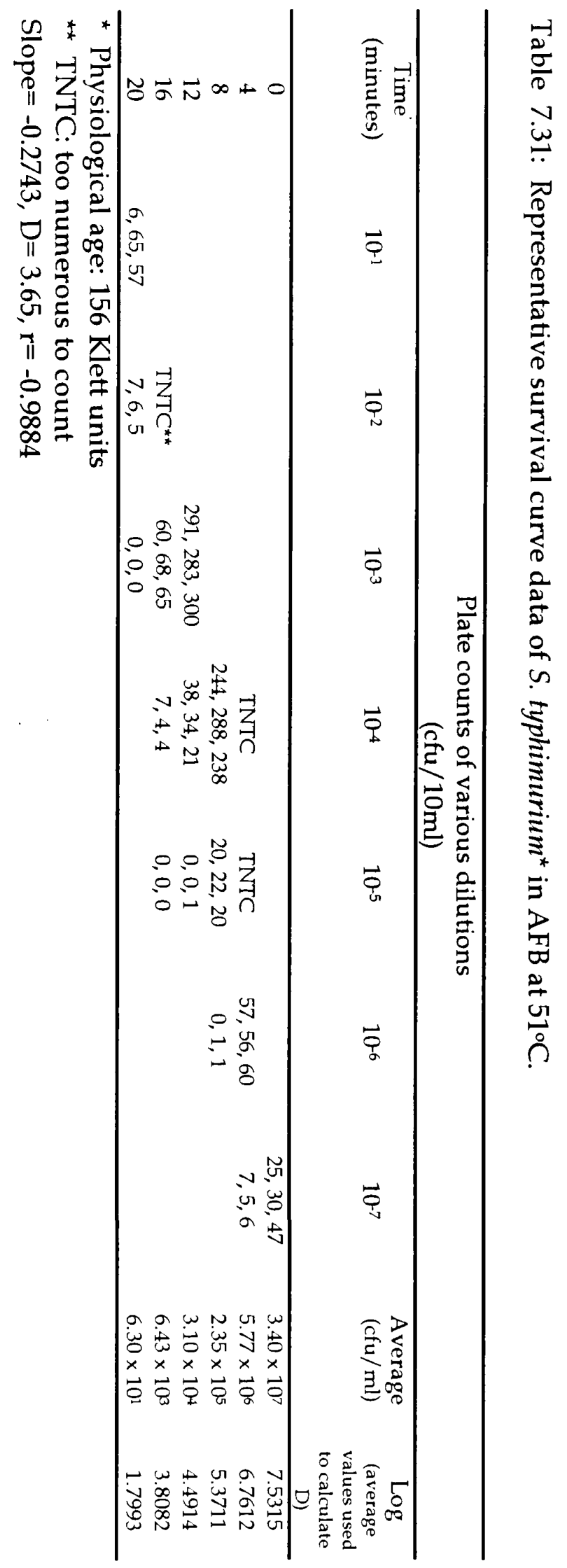




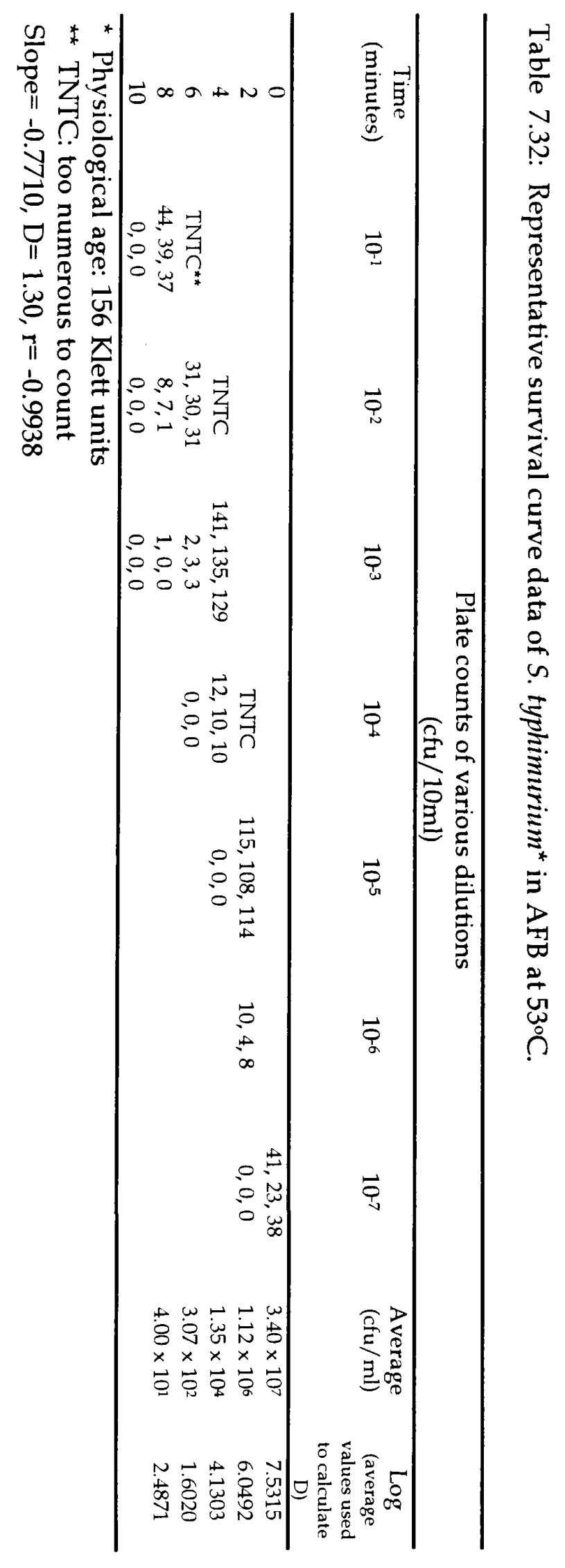

